\title{
WestVirginiaUniversity
}

THE RESEARCH REPOSITORY @ WVU

Graduate Theses, Dissertations, and Problem Reports

2011

\section{Investigation of Discharge Coefficients for Irregular Orifices}

\author{
P.J. Spaur \\ West Virginia University
}

Follow this and additional works at: https://researchrepository.wvu.edu/etd

\section{Recommended Citation}

Spaur, P.J., "Investigation of Discharge Coefficients for Irregular Orifices" (2011). Graduate Theses, Dissertations, and Problem Reports. 4796.

https://researchrepository.wvu.edu/etd/4796

This Thesis is protected by copyright and/or related rights. It has been brought to you by the The Research Repository @ WVU with permission from the rights-holder(s). You are free to use this Thesis in any way that is permitted by the copyright and related rights legislation that applies to your use. For other uses you must obtain permission from the rights-holder(s) directly, unless additional rights are indicated by a Creative Commons license in the record and/ or on the work itself. This Thesis has been accepted for inclusion in WVU Graduate Theses, Dissertations, and Problem Reports collection by an authorized administrator of The Research Repository @ WVU. For more information, please contact researchrepository@mail.wvu.edu. 
Investigation of Discharge Coefficients for Irregular Orifices

P.J. Spaur

Thesis submitted to the

College of Engineering and Mineral Resources

at West Virginia University

in partial fulfillment of the requirements

for the degree of

Master of Science

in

Mechanical Engineering

Wade W. Huebsch, Ph.D., Chair

Gregory Thompson, Ph.D.

Kenneth Means, Ph.D.

Donald D. Gray, Ph.D.

Department of Mechanical and Aerospace Engineering

Morgantown, West Virginia

2011

Keywords: discharge coefficient; orifice; tubes; irregular 


\title{
Abstract \\ Investigation of Discharge Coefficients for Irregular Orifices
}

\begin{abstract}
P.J. Spaur
Discharge coefficients for irregular orifices have not been extensively studied and there exists a need to investigate these discharge properties and compare them to uniform orifices. The definition of an irregular orifice is an orifice profile that has no uniform shape or dimension such as that found in circular and square geometries. An irregular orifice could be present in a fluid system as a result of a puncture, rupture or fault. This research was conducted alongside a project involving inflatable structures to seal off an underground large scale piping system running below a waterway. An accurate prediction of the resulting flow rate in the case of a rupture is critical to determine the amount of time available to activate a protection system. Therefore, the motivation of this study was the determination of discharge coefficients for irregular orifices.

The objective in this thesis was the study of irregular orifices both as thin wall as well as extruded three dimensional orifices to gain an understanding for engineering failures. A coobjective was the general study of tube-type orifices discharging into the open atmosphere since previous tube orifice literature has primarily focused on in-pipe flow situations as an orifice plate.
\end{abstract}

An apparatus was built to test these orifices in a controlled environment under a constant head. The weighed discharge measured over time was factored into the discharge coefficient calculation as mass flow rate. Irregular orifices and tubes were created in the WVU MAE rapid prototype ABS printer allowing precise control of orifice shapes and profiles.

Selections of irregular and tube orifices were evaluated in this study. Tube orifice results (exiting to the atmosphere) are in agreement with pipe flow studies for $l / d$ values ranging from 2.0 to 10.0. The discharge coefficient is drastically different in the $l / d$ range from 0.0 to 2.0 where the behavior mimics a thin plate circular orifice as $l / d$ approaches 2.0 with an average constant discharge coefficient of 0.63 in this region.

Irregular plate orifices resulted in a higher discharge coefficient across the orifice resulting in higher flow rates. This result can have significant impact on the calculations for a large scale piping breach. Extruding the irregular orifices to a tube orifice produced an interesting result; initially the extruded irregular orifice produces a maximum of $12.5 \%$ higher discharge coefficient, but after $l / d \sim 2$ the discharge coefficient behaves as a uniform tube orifice until convergence is achieved. 


\section{Dedication}

This thesis is dedicated to my mother, Janni Spaur, the most willed and strongest person I know, a true inspiration to not only me but everyone she meets. 


\section{Acknowledgments}

I would like to thank my committee members, Dr. Kenneth Means and Dr. Donald Gray for their help through the course of this project. I would like to give a special thanks to Dr. Greg Thompson for his continuous help and support throughout this project; thank you for your late hours making countless orifices. I would also like to thank my advisor Dr. Wade Huebsch for his guidance, support and confidence throughout my graduate studies.

The experimental tests performed for this thesis would have not been possible without the help from my good friends Josh Sill, Christopher Griffin and Jared Grim. Thanks for all of your help and guidance. Also, thanks to Byron Rapp for being a mentor and for your continuous hard work with the test apparatus.

I would like to most importantly thank my wonderful family for instilling the drive and determination to achieve everything I do. None of this would be possible without their love and support. A special acknowledgement goes out to my mother Janni Spaur, your determination and positive spirit with your battle has inspired me to never back down and always be optimistic. 


\section{Table of Contents}

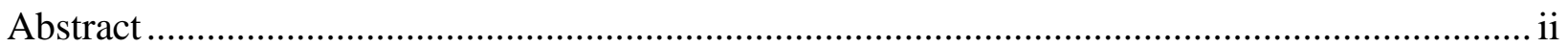

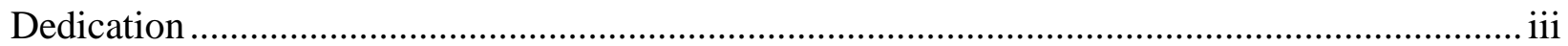

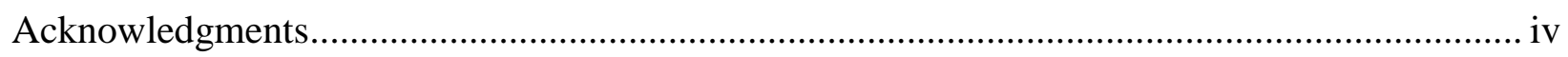

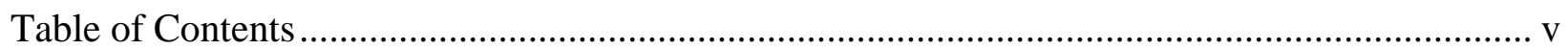

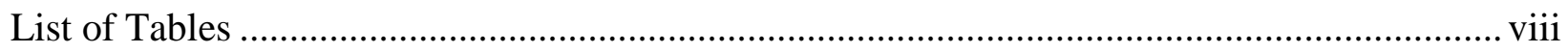

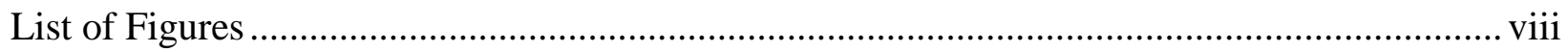

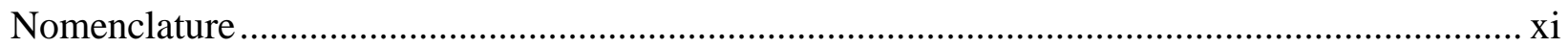

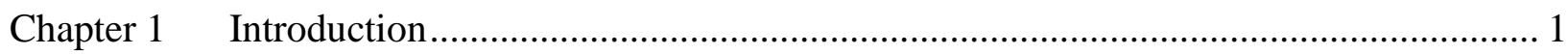

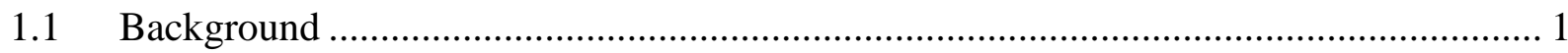

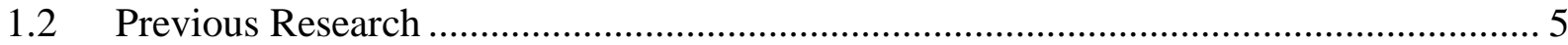

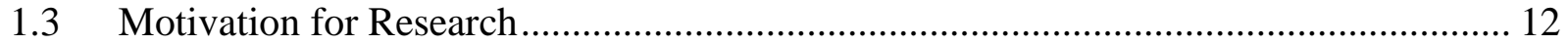

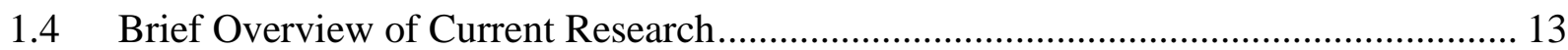

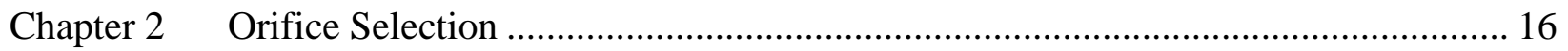

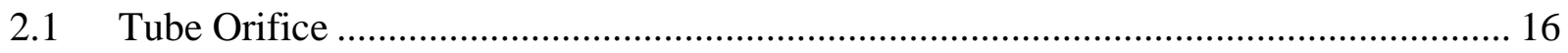

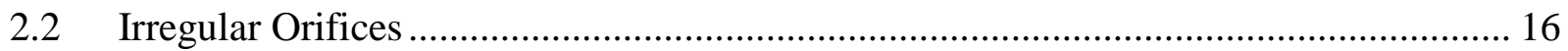

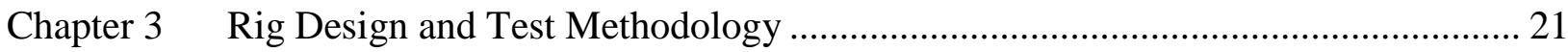

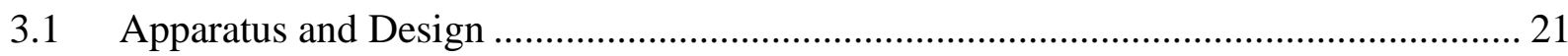

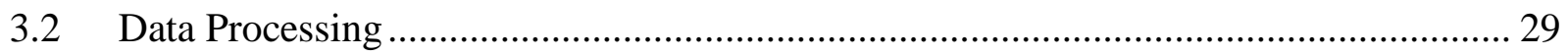

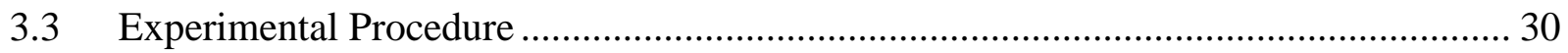


Chapter 4 Propagation of Uncertainty Analysis .

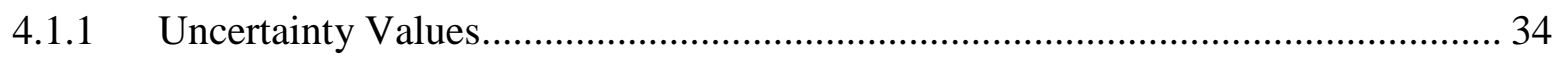

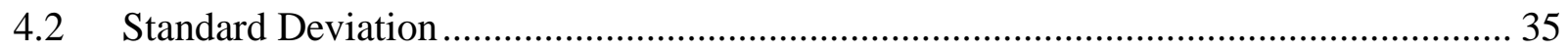

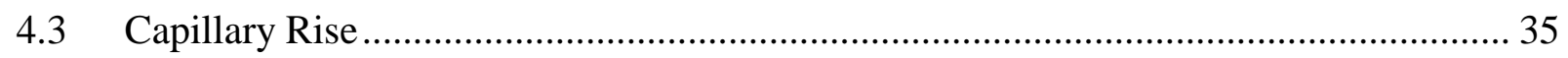

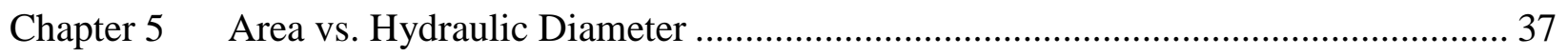

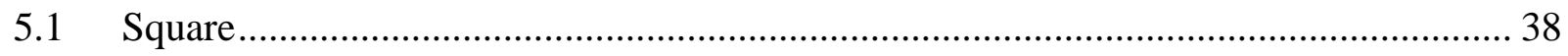

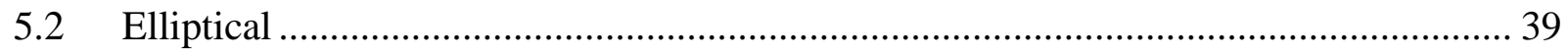

$5.3 \quad$ Uniform and Irregular Jagged Orifices ................................................................... 40

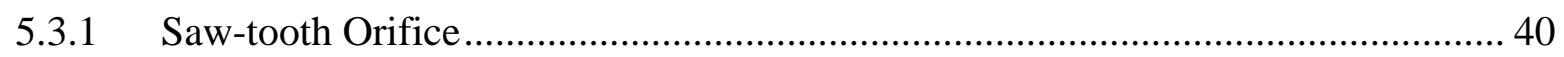

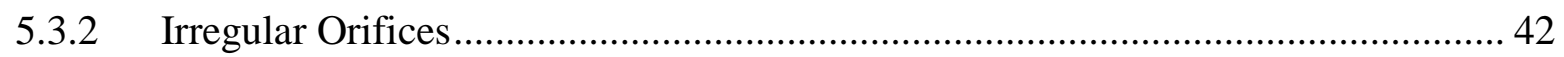

5.4 Reynolds Number................................................................................................. 44

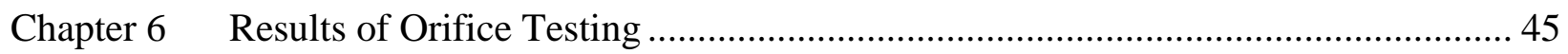

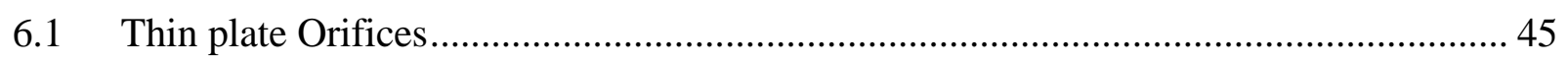

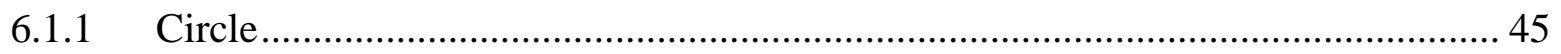

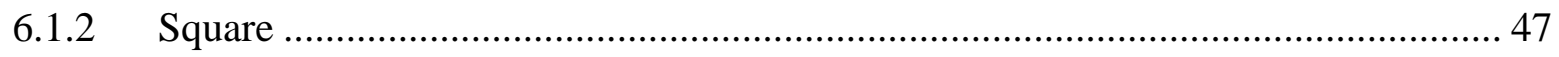

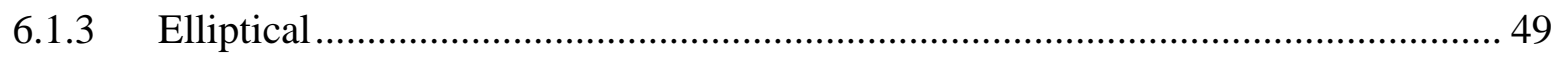

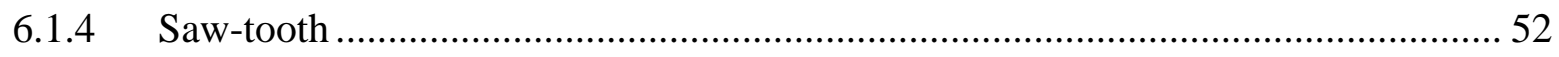

6.1.5 Irregular Jagged Thin Plate ............................................................................ 54

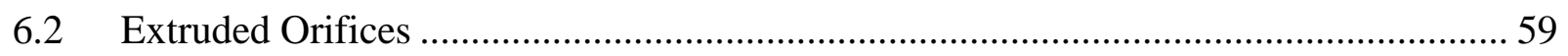

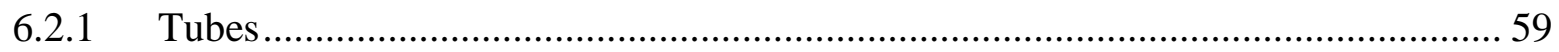




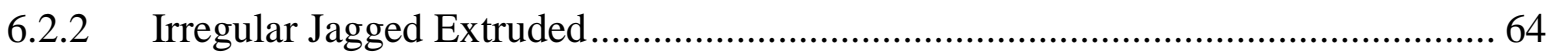

Chapter 7 Conclusions of Study and Recommendations for Future Work ............................. 68

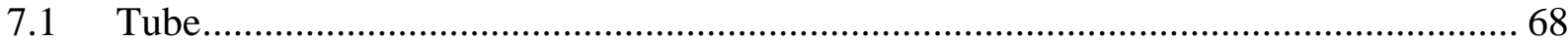

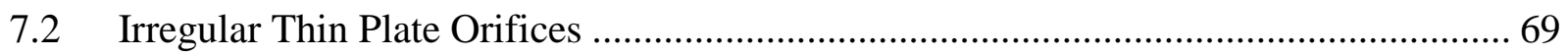

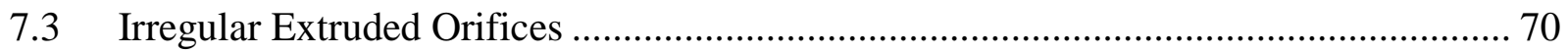

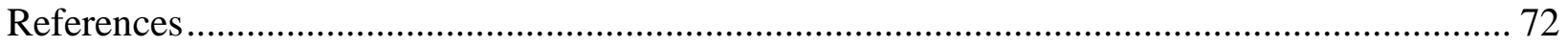

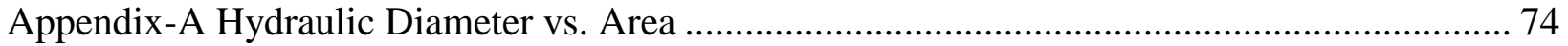

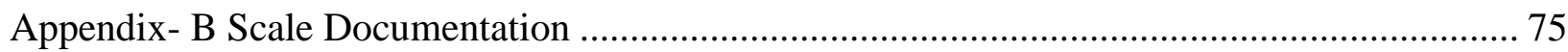

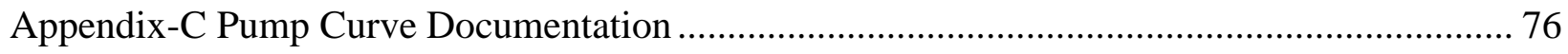




\section{List of Tables}

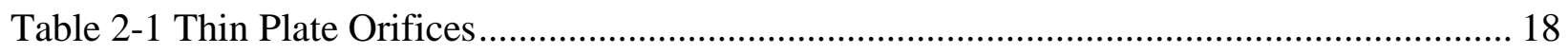

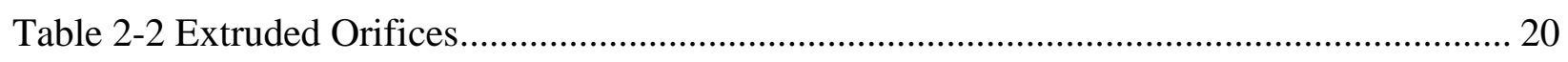

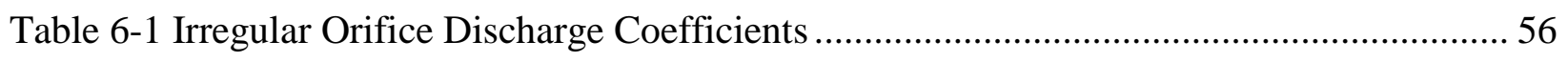

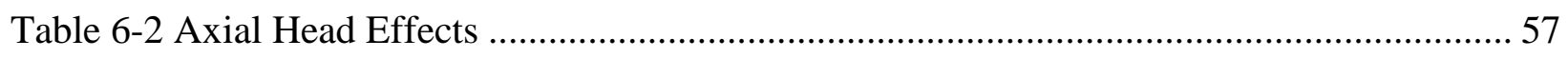

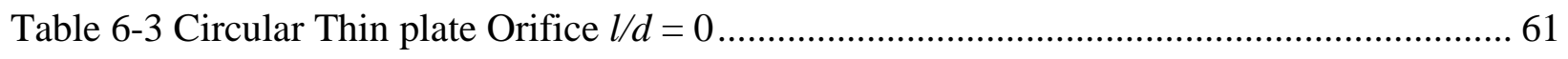

\section{List of Figures}

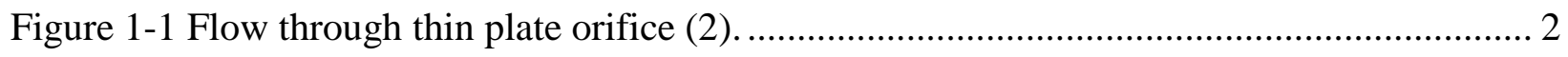

Figure 1-2 Tube Orifice Discharge Reference (4) ………………….................................... 5

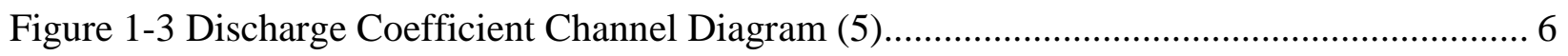

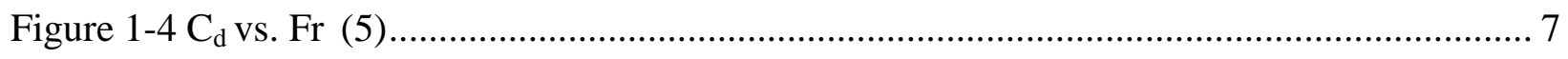

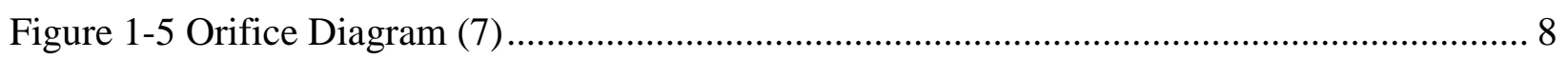

Figure 1-6 Discharge Coefficient as a Function of Reynolds Number (6) ................................... 8

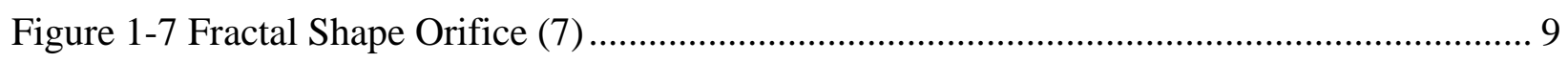

Figure 1-8 a.) Thin plate Circular Orifice; b.) Tube Orifice …….............................................. 10

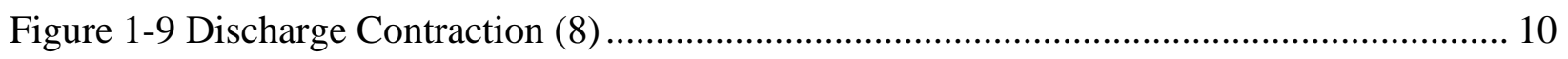

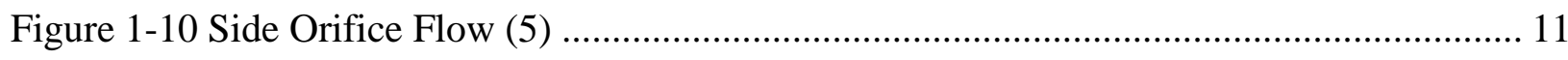

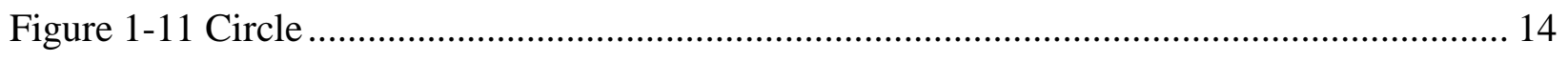

Figure 1-12 Tube

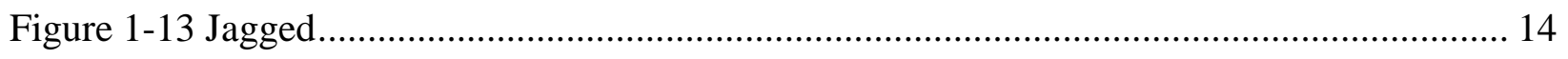

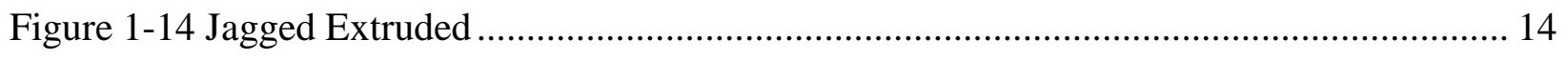

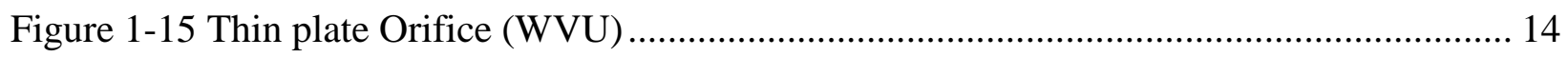




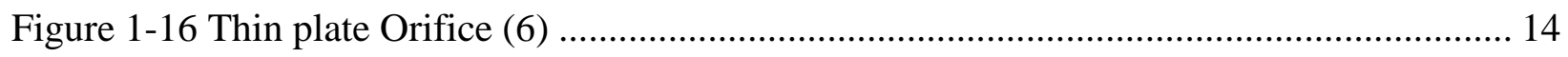

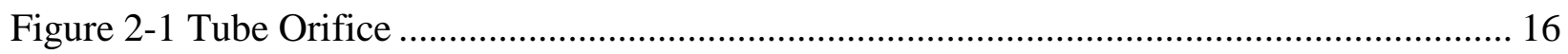

Figure 2-2 Irregular Orifices 1.) 33 degrees. 2.) 60.5 degrees. 3.) 42.5 degrees. 4 .) 74 degrees. 17

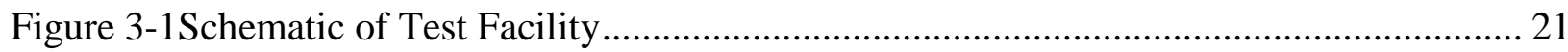

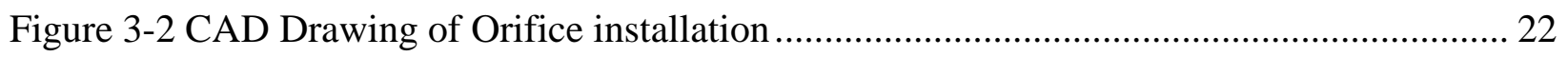

Figure 3-3 CAD Drawing of Orifice and Test Bed................................................................. 22

Figure 3-4 CAD Drawing of Test Bed installation in Test Tank ................................................. 23

Figure 3-5 CAD Drawing of Test Bed in Test Tank ............................................................. 23

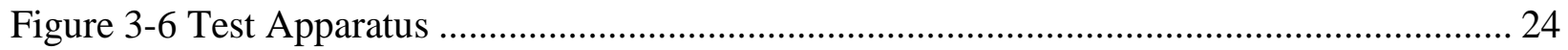

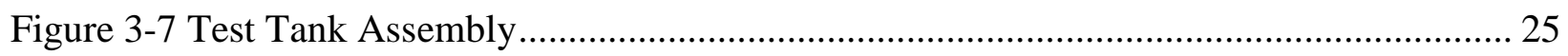

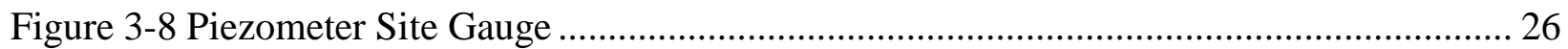

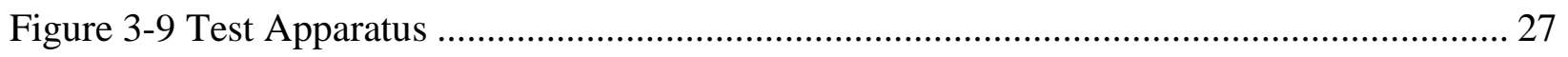

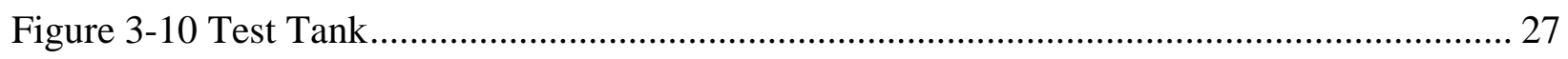

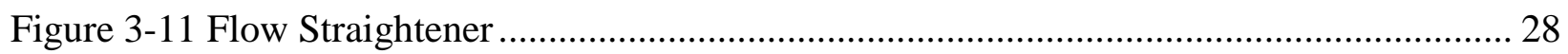

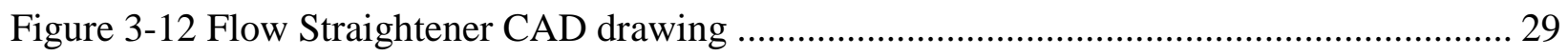

Figure 3-13 Flow Straightener in Test Tank CAD Drawing ..................................................... 29

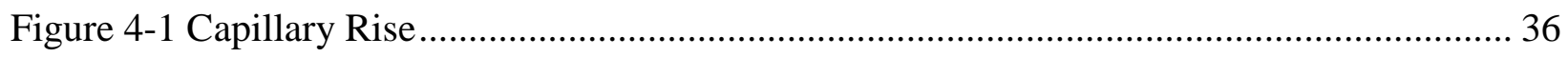

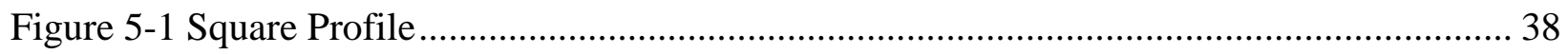

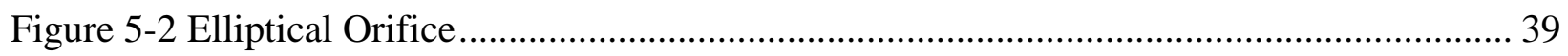

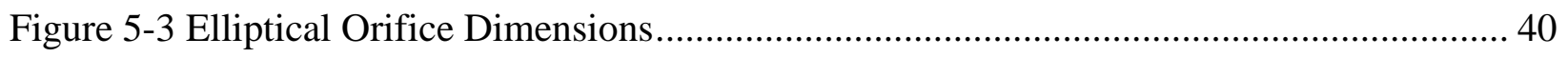

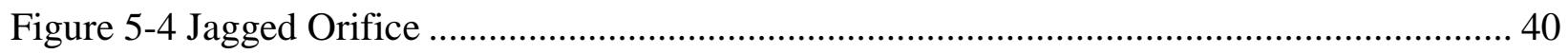

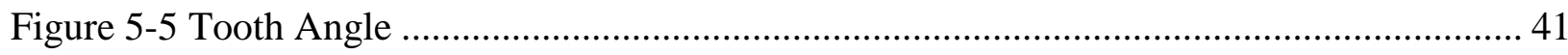

Figure 5-6 Irregular Orifices ........................................................................................ 42 


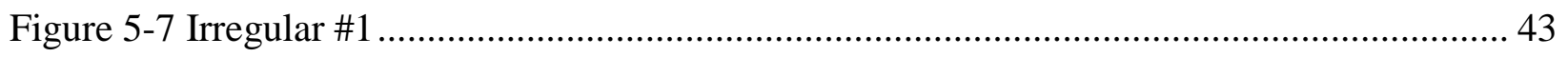

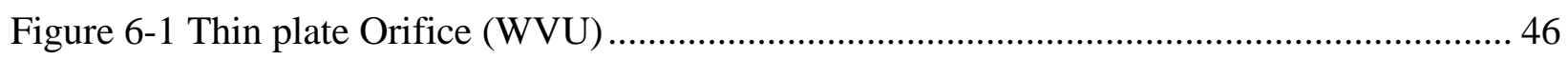

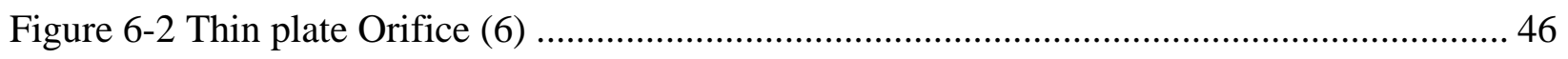

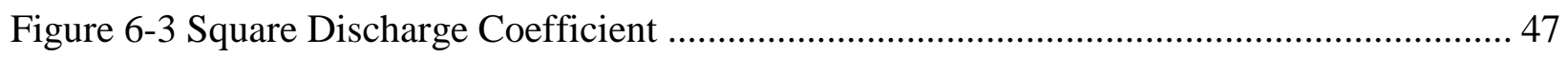

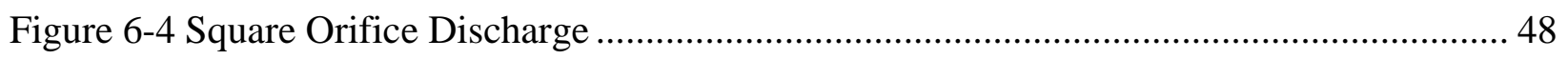

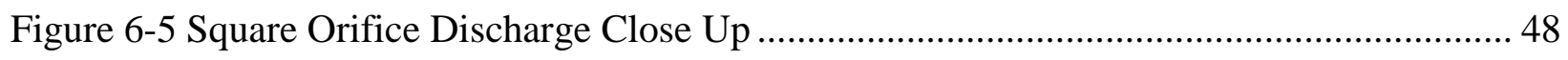

Figure 6-6 Square Inversion Stages Adapted from King (3) ...................................................... 49

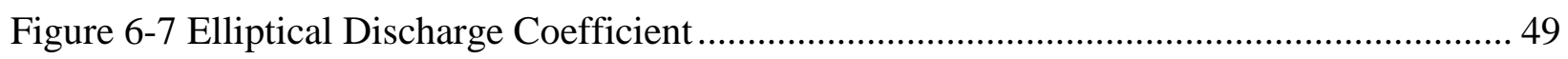

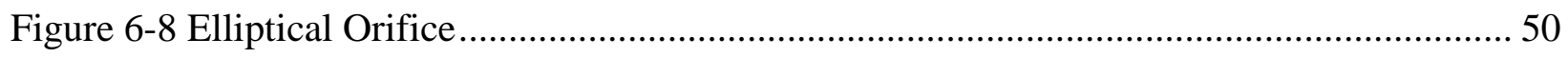

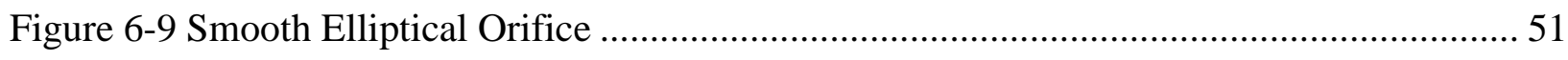

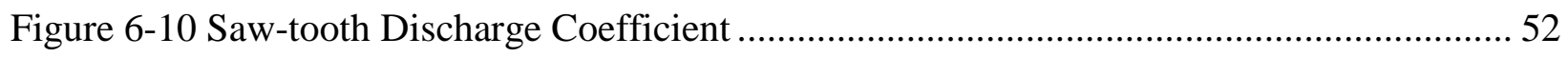

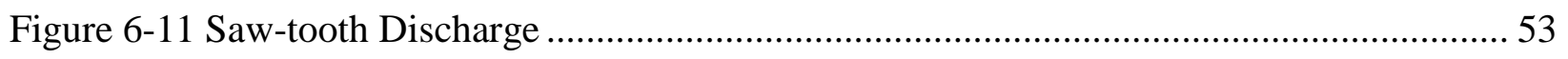

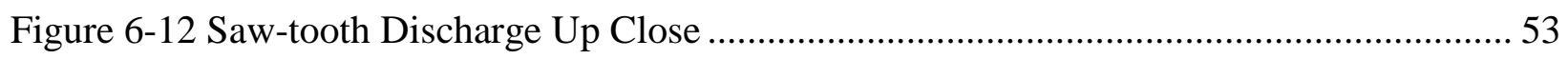

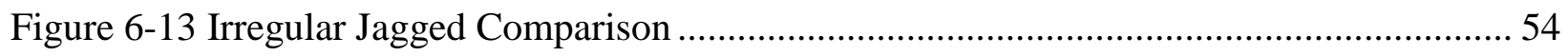

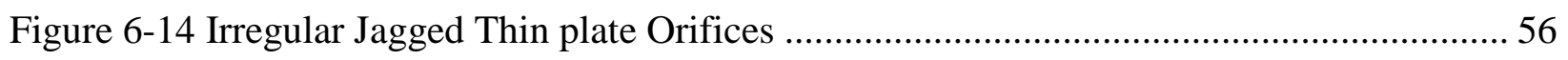

Figure 6-15 Tube Orifice Discharge Coefficients for 1", 3/4" and 1/2" Diameters .......................... 60

Figure 6-16 Discharge Coefficients for Tube Orifice Geometries as a Function of $l / d$................ 61

Figure 6-17 Tube Orifice with 1/d < 2.0 Which Gives Exit before Attachment ........................... 63

Figure 6-18 Tube Orifice with 1/d > 2.0 Which Places Exit After Attachment ............................. 63

Figure 6-19 Discharge Coefficients for Extruded Irregular Jagged Orifices with Varying $l / d$

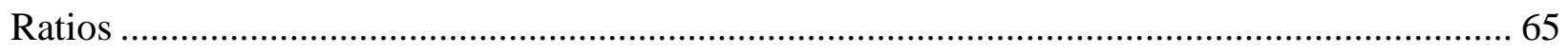

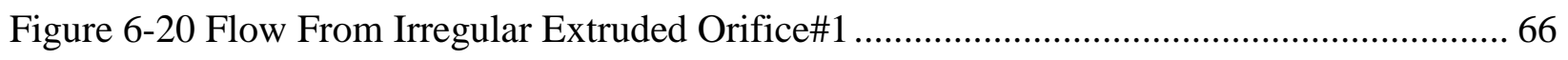

Figure 6-21 Flow From Irregular Extruded Orifice\#2 …............................................................ 67 


\section{Nomenclature}
$\mathrm{A}_{\mathrm{a}}$
actual area of orifice, $f t^{2}$
A
area of orifice, $f t^{2}$
$\mathrm{C}_{\mathrm{c}}$
coefficient of contraction
$\mathrm{C}_{\mathrm{d}}$
discharge coefficient
$\mathrm{C}_{\mathrm{v}}$
coefficient of velocity
d
diameter of orifice, $f t$
D
diameter of test tank, $f t$
g gravity, $\frac{f t}{\sec ^{2}}$
$\mathrm{h}$
head height, $f t$
gpm
gallons per minute
1
length of extruded orifice or tube, $f t$
$\dot{m}$
mass flow rate, $\frac{l b s}{s e c}$
$\mathrm{P}$
pressure, $p s i$
psi pounds per square inch
$\mathrm{P}_{\mathrm{w}} \quad$ wetted perimeter of orifice, $f t$
$\mathrm{Q}_{\mathrm{a}}$
actual volumetric flow rate, $\frac{f t^{3}}{\sec }$
Q
theoretical volumetric flow rate, $\frac{f t^{3}}{s e c}$
r
radius of piezometer, $f t$
Re Reynolds Number
$s$
standard deviation
$t$
time, seconds
$\mathrm{V}_{\mathrm{a}} \quad$ actual velocity of discharge, $\frac{f t}{s e c}$
V velocity of discharge, $\frac{f t}{s e c}$
Weight, $l b s$ 
$\rho \quad$ density, $\frac{\text { slugs }}{f t^{3}}$

$\sigma$

surface tension, $\frac{l b s}{f t}$

specific gravity of water 


\section{Chapter 1 Introduction}

\subsection{Background}

Controlling fluid flow has evolved over the years, from developing the simplest irrigation systems for crops to engineering inflatable flood defense systems. Understanding fluid flow properties and characteristics has made it possible to design sophisticated pneumatic and hydraulic systems that make everyday life possible. Many different types of past and existing flow systems make use of some type of orifice. This work was an investigation of discharge coefficients for standard and nonstandard orifice geometries.

As a fluid flows from a large body into an orifice, streamlines converge in the orifice. Without careful rounding of the orifice geometry, streamlines constrict to a smaller diameter than that of the orifice upon exiting. This is known as the minimum area or the vena contracta effect. At higher exit velocities the jet diameter becomes smaller. This generally occurs at $0.5 d$ ( $d$ is the diameter of the orifice) downstream of the orifice. This contraction can be seen in Figure 1-1. Upon exit, the jet is subject to the effects of friction with the outside fluid (typically air). This friction slows the jet, expanding the diameter.

The focus in this work was liquid exiting an orifice which forms a jet that is directed vertically downward into an open air environment. In this case gravity accelerated the jet, decreasing its area and contracting the stream. The higher jet velocity, the smaller the diameter of the jet. The jet is held together by surface tension.

It is well known that real fluid flow through orifices is not ideal. There is a friction factor or discharge coefficient that represents the loss of flow through an orifice compared to an orifice 
with no losses. The discharge coefficient, $\mathrm{C}_{\mathrm{d}}$, represents the ratio between actual and theoretical flow rates.

$$
C_{d}=\frac{Q_{a}}{Q}
$$

The actual flow rate must be found by measuring the amount of fluid passing through the orifice in a given time. It is known that a Thin plate circular orifice has a discharge coefficient of approximately 0.61 (1), as shown in Fig. 1-1.

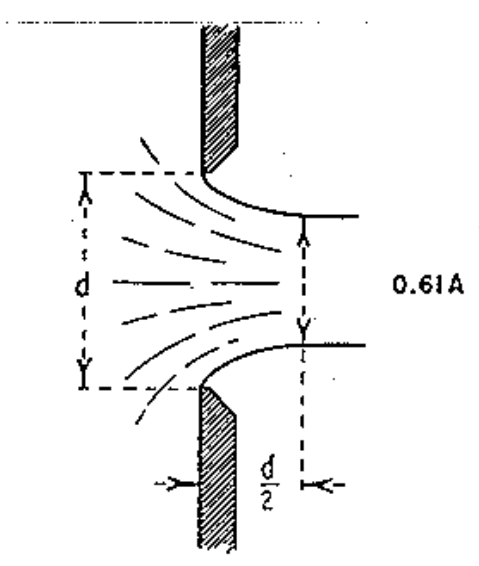

Figure 1-1 Flow through thin plate orifice (2).

The coefficient of contraction $\left(\mathrm{C}_{\mathrm{c}}\right)$, given by Eq. 1-2, is the ratio of the area of the orifice and the smaller fluid area just downstream of the orifice.

$$
C_{c}=\frac{A_{a}}{A}
$$

Downstream of the orifice, the flow profile contracts in the section known as the vena contracta. The contraction is caused by the inability for the flow to turn sharp corners such as a thin plate orifice as well as gravitational effects. The flow profile then slows and expands, which is caused by the frictional effects from outside air. 
The coefficient of velocity is the ratio of the actual and ideal fluid velocity. The actual velocity $\left(\mathrm{V}_{\mathrm{a}}\right)$, is found by measuring the exact velocity of the fluid as it flows through the orifice, to the ideal velocity, $V=\sqrt{2 g h}$. Where $\mathrm{g}=$ gravity and $\mathrm{h}=$ head.

$$
C_{v}=\frac{V_{a}}{V}
$$

The coefficient of contraction and coefficient of velocity can be combined to estimate the discharge coefficient by rearranging the following equations.

$$
\begin{aligned}
& \boldsymbol{Q}_{\boldsymbol{a}}=\boldsymbol{A}_{\boldsymbol{a}} \boldsymbol{V}_{\boldsymbol{a}} \\
& \boldsymbol{Q}=\boldsymbol{A V} \\
& \boldsymbol{Q}_{\boldsymbol{a}}=\boldsymbol{C}_{\boldsymbol{d}} \boldsymbol{Q}
\end{aligned}
$$

Combining the above flow rate equations and the coefficient of contraction and velocity yields the following.

$$
C_{d}=C_{c} C_{v}
$$

It is more important to recognize the coefficient of discharge rather than the coefficient of contraction or coefficient of velocity in regards to estimating the flow through an orifice to an open jet. $\mathrm{C}_{\mathrm{c}}$ is found by measuring the diameter of the exited flow. $\mathrm{C}_{\mathrm{v}}$ is found by measuring the exited velocity. $C_{d}$ is found by using the measured values of $C_{c}$ and $C_{v}$ or by measuring for $C_{d}$ alone. $\mathrm{C}_{\mathrm{d}}$ can be measured a couple different ways. The pressure differential between the inlet and outlet of the orifice plate can be measured to calculate the discharge coefficient. The measurement of the weight of fluid passing through the orifice for a given time or mass flow rate can also be used to obtain the discharge coefficient. $\mathrm{C}_{\mathrm{c}}$ becomes important with tubes because of 
the interaction with the fluid and the tube wall as the fluid profile starts to expand. A tube is a circular orifice that has been extruded three dimensionally. The length, diameter and Reynolds number play a vital role in this interaction and will be shown in more detail later in this document. $\mathrm{C}_{\mathrm{d}}$ is used primarily in this work, both $\mathrm{C}_{\mathrm{c}}$ and $\mathrm{C}_{\mathrm{v}}$ can be found from the measured $\mathrm{C}_{\mathrm{d}}$. $\mathrm{C}_{\mathrm{d}}$ is used to measure actual flow rates and is a good tool in this work to compare known $\mathrm{C}_{\mathrm{d}}$ values with irregular orifices.

Different orifice edges result in different discharge coefficients. An orifice with a square shoulder is known to have the same discharge characteristics as that of a sharp edge up until a length of $2.5 d$ (3). An orifice tube is classified as an orifice with a length of $2.5 d$ or greater (3).Up until $2.5 d$ the fluid inside of the tube is still contracted smaller than the diameter of the orifice. This transition stage is not clearly known and will be discussed further in this document. Although there are discrepancies in the literature, a previous study (4) has looked into other tube orifice testing as well as their in-house experiments. The study concluded that there is a peak at $2 d$ which is less than $2.5 d$. This peak can be seen in Figure 1-2; after $2 d$ the discharge coefficient approaches a constant. 


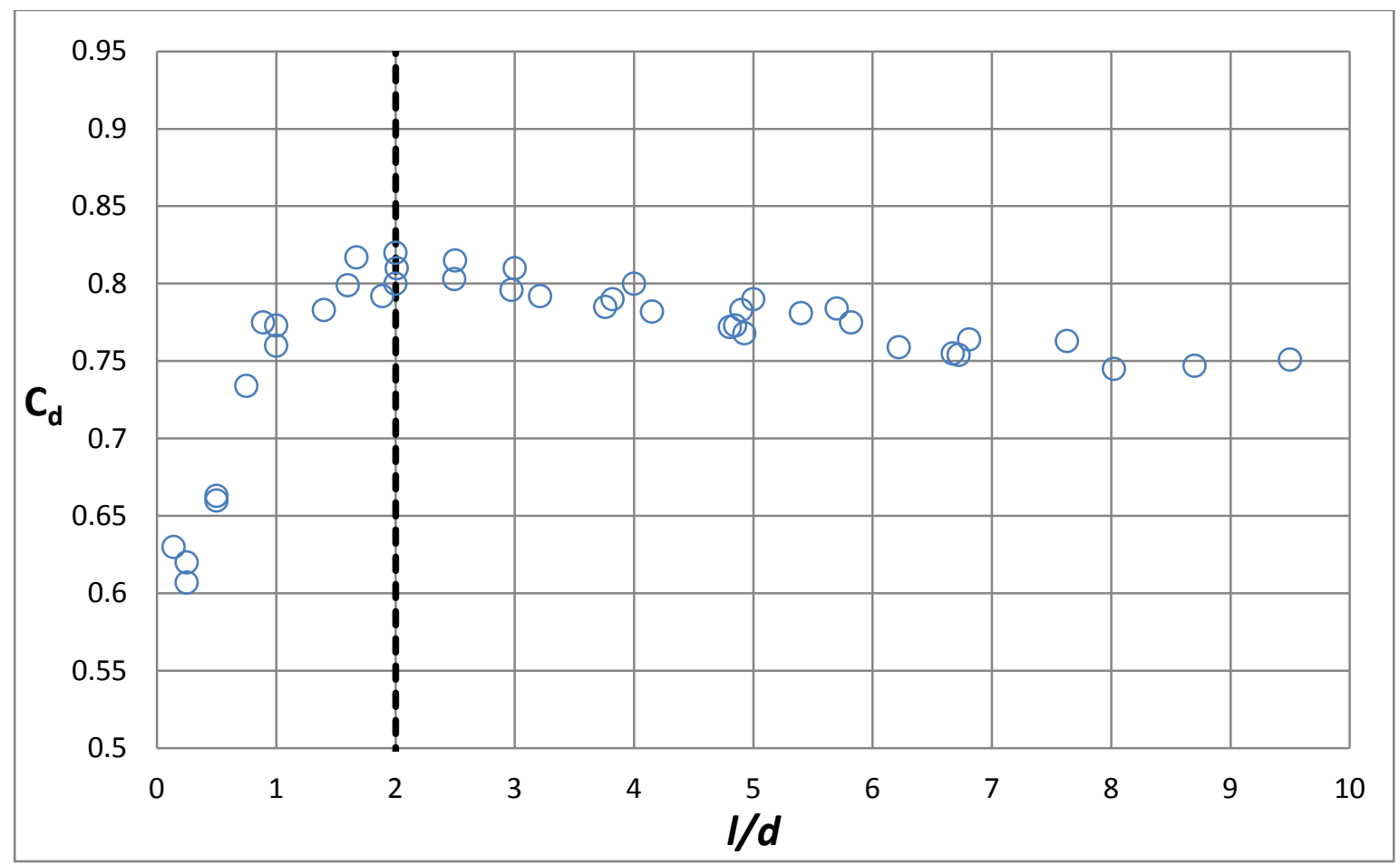

Figure 1-2 Tube Orifice Discharge Reference (4)

\subsection{Previous Research}

In 2010, the Indian Institute of Technology Roorkee built a large orifice testing apparatus to estimate sharp crested circular orifice discharge coefficients (5). The apparatus consisted of a large open channel with an orifice on the side. A water supply at one end provided water to the trough which filled up to a head height regulated by a sluice gate at the other end of the channel. 


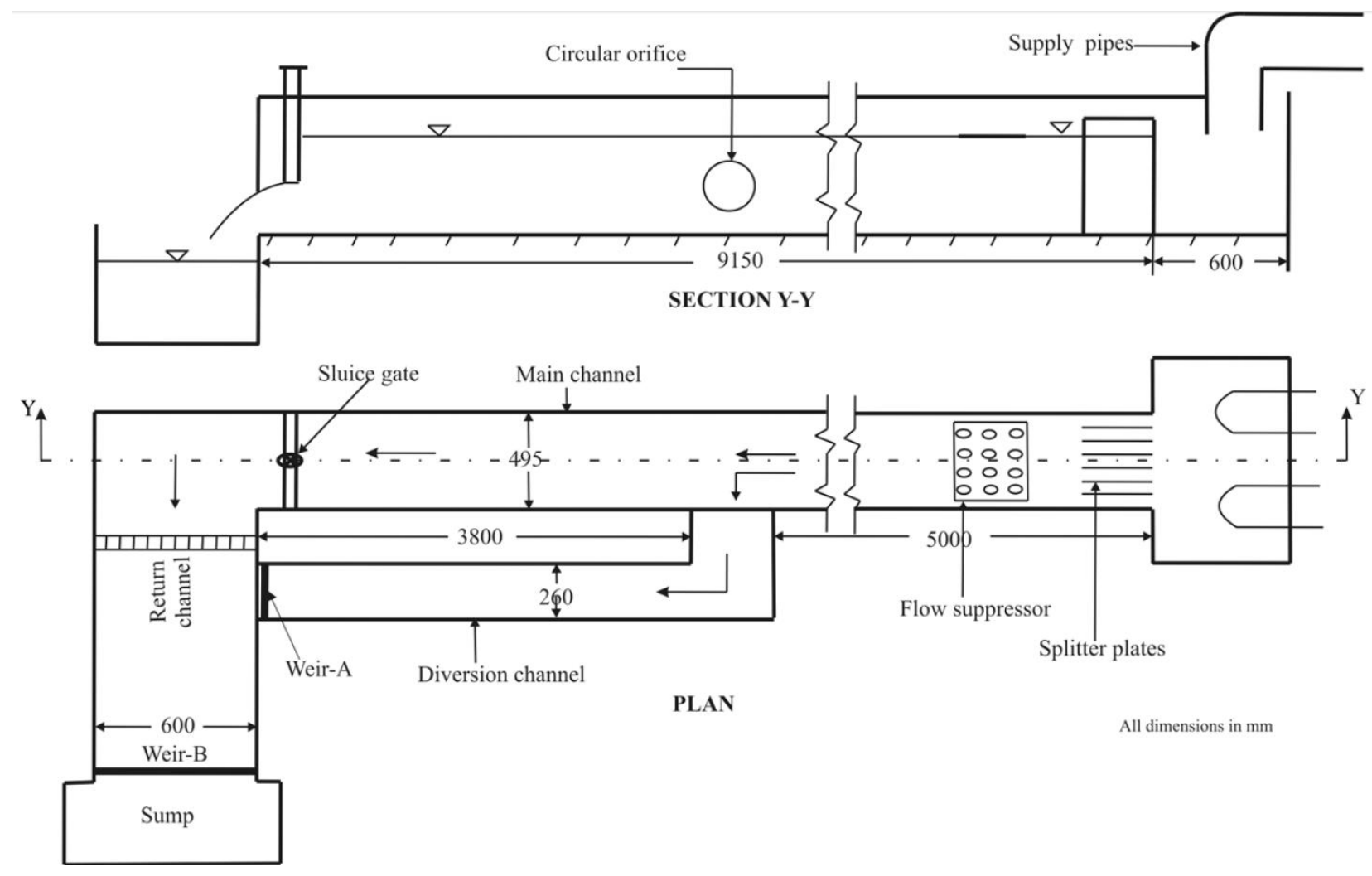

Figure 1-3 Discharge Coefficient Channel Diagram (5)

The water flowed through the orifice and discharged into the diversion channel as shown in Figure 1-3. The end of the diversion channel was equipped with a sharp-crested weir (A) (shown) which measured the flow. It is noted that the weir was calibrated using an ultrasonic flow meter. The test water was then collected in a sump to be recycled.

The discharge coefficient values were found to be a function of the Froude number, as shown in Fig. 1-4. Three separate trend lines were established according to the ratio of the width of the base of the channel and the diameter of the hole $B / D$. The higher the ratio, the higher the $C_{d}$. These values of $C_{d}$ ranged from $0.615-0.670$ agreeing with previous known coefficient data. The trend lines relating $B / D$ were similar in slope, giving a way to estimate $C_{d}$ based on the ratio and Froude number. Though this study provided detailed experimental results for the given 
discharge configuration. In general, there is limited research available in the field of measuring discharge coefficients.

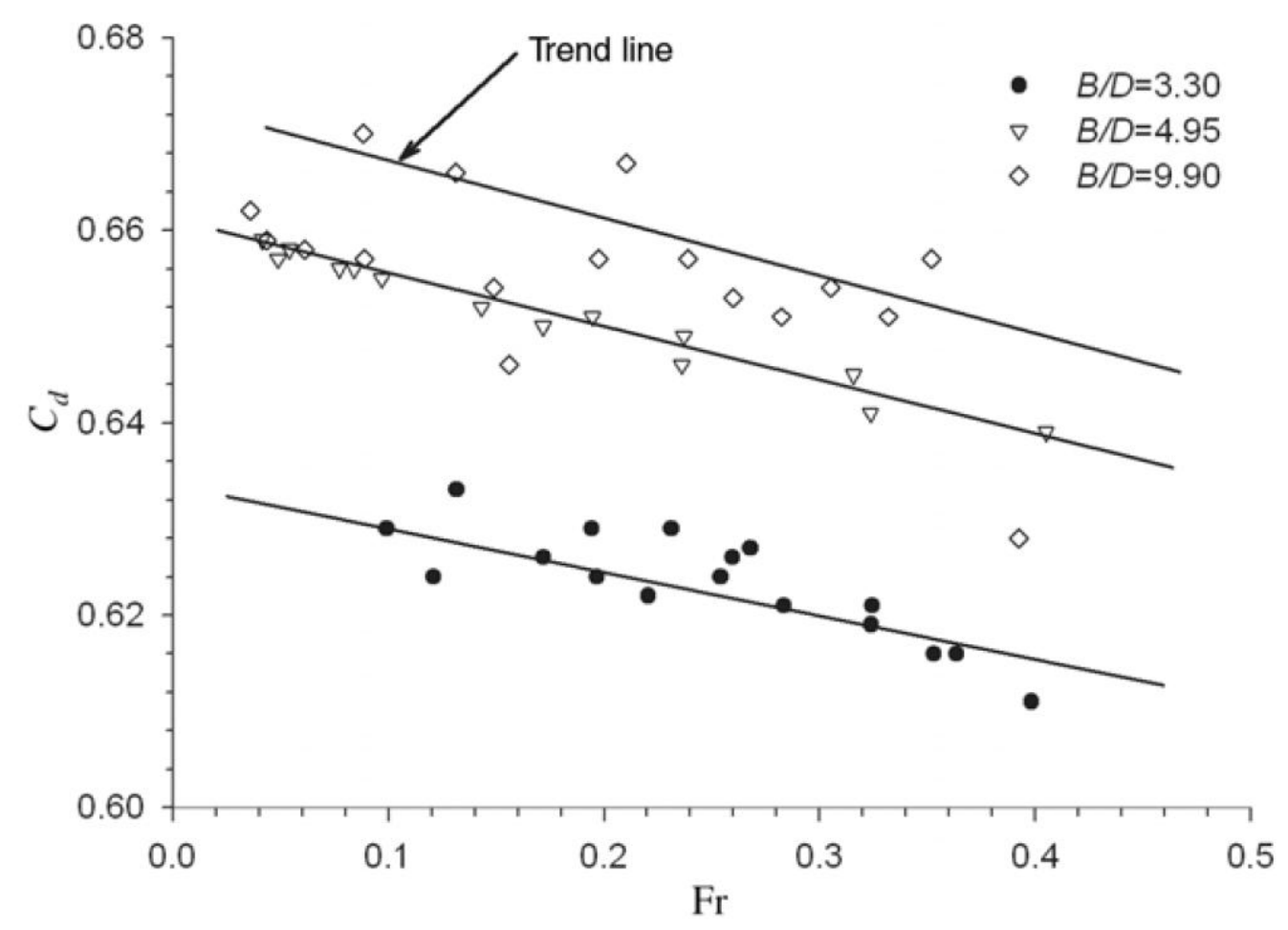

Figure 1-4 $\mathrm{C}_{\mathrm{d}}$ vs. Fr (5)

In general, orifices are characterized by their diameter ratio and angle of jet contraction $\beta$. The study at the Institute of Technology Roorkee was only interested in $\beta=90^{\circ}$. Figure 1-5 Orifice Diagram shows the diameter and angle of jet contraction definition. Also, Froude Number is typically used in channel flow such as the Institute of Technology Roorkee. 


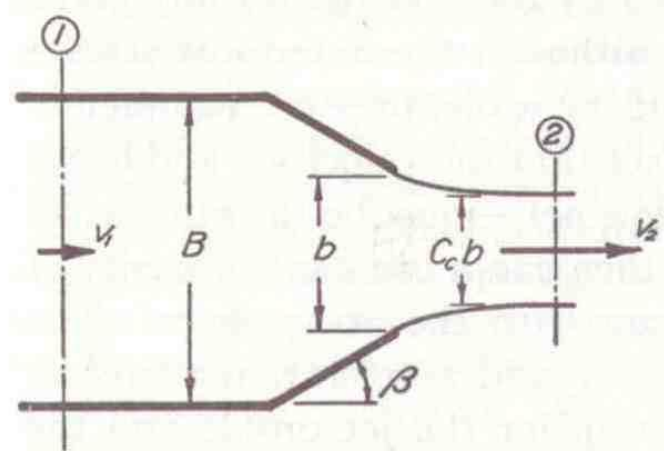

Figure 1-5 Orifice Diagram (7)

Rouse (6) performed an extensive study on standard orifice discharge coefficients. His study concluded that for $\beta=90^{\circ}$, with a diameter ratio $d / D \sim 0.0$, the discharge coefficient converged to 0.611 with increasing Reynolds number. The study was performed over a large range of Reynolds number from 0.1-1,000,000. Figure 1-6 Discharge Coefficient as a Function of Reynolds Number shows the experimental data obtained by Rouse, which is used as comparison data in the current study.

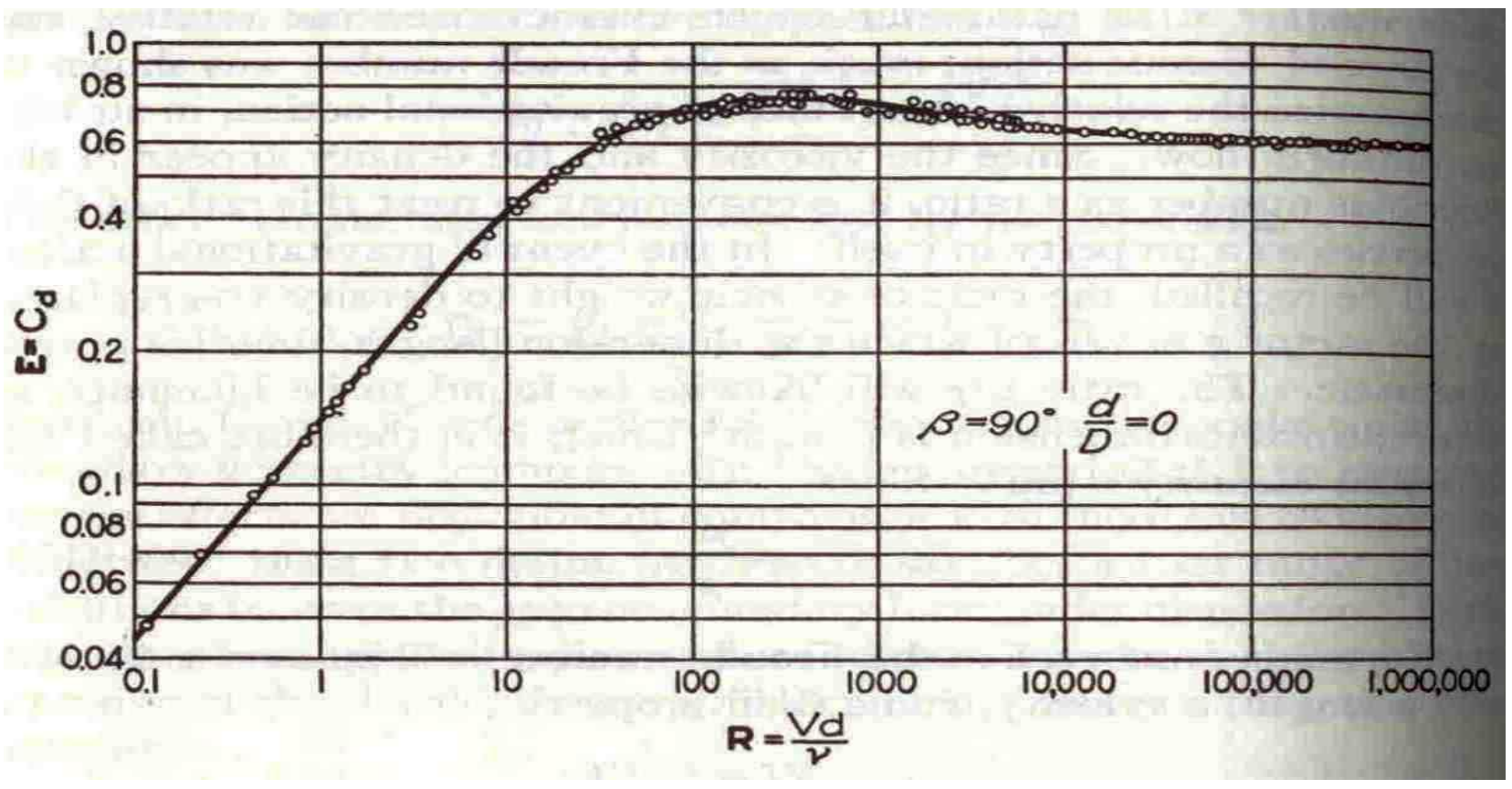

Figure 1-6 Discharge Coefficient as a Function of Reynolds Number (6) 
Additional orifice parameters include the orifice cross sectional geometry as well as the depth or extruded length. A majority of published results focus on the circular orifice geometry. A study was done by the University of Sheffield on the pressure drop across fractal-shaped orifices in pipe flow (8). The fractal geometry concept is used to the geometry of irregular shapes where an identical pattern repeats itself, self-similar, on an ever-diminishing scale (8). This is also known as Koch's snow flake which is taken to the fourth order. Figure 1-7 shows the fractal shapes used to conduct their experiments.

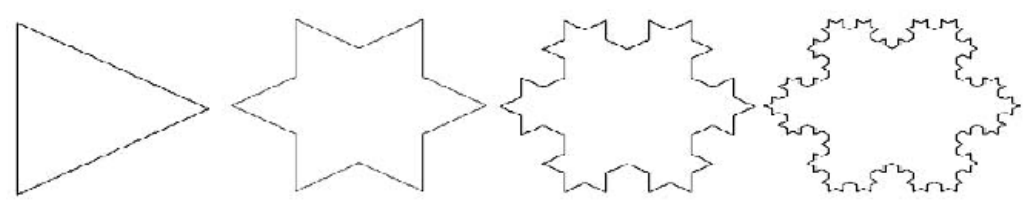

Figure 1-7 Fractal Shape Orifice (7)

The study compared fractal-shaped orifices with standard circular orifices of the same area in pipe flow. It was concluded that the fractal-shaped orifices resulted in a lower pressure drop than the standard circular orifice shape of the same area. They conclude that the decreased pressure drop is explained by fractal-shaped orifices enhance the mixing properties downstream leading to the pressure drop reduction. A lower pressure drop results in a higher flow rate which also means a higher discharge coefficient (if there were no losses, the discharge coefficient would be 1.0). They also concluded that the fractal-shaped orifices had a significant effect on the flow downstream and enhanced the mixing properties leading to the pressure drop (7). They made note that the lower pressure drop may result in a more sensitive flow meter which could be used as a more accurate method for measuring flows. 
The final orifice parameter that has significance to the current work is the thickness of the orifice; i.e. is the orifice a thin plate or does it approach a tube designation? Sufficient experimental testing has been done for incompressible flow through tube orifices. Figure 1-8 shows the difference between thin plate and tube orifices.

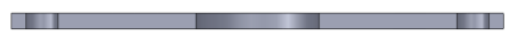

a.)

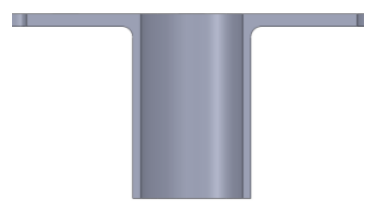

b.)

Figure 1-8 a.) Thin plate Circular Orifice; b.) Tube Orifice

The depth of the orifice can play a vital role in the discharge of the fluid. It is known that a thin plate circular orifice will have a coefficient of convergence $\left(\mathrm{C}_{\mathrm{c}}\right)$. This is how the profile of the fluid decreases just past the exit of the orifice. As the fluid slows down, the streams will begin to expand due to viscous drag affected by the air. The discharge will expand until it attaches to the tube walls. Figure 1-9 shows how the contraction takes place. When the flow does not reattach, it emerges as a jet, without tube wall attachment. The current study is on an open free jet discharging from an orifice where downstream mixing will not be able to take place. This type of discharge can be seen in Figure 1-10. Mixing downstream is only an issue in pipe flow when downstream flow interacts with the discharge flow.

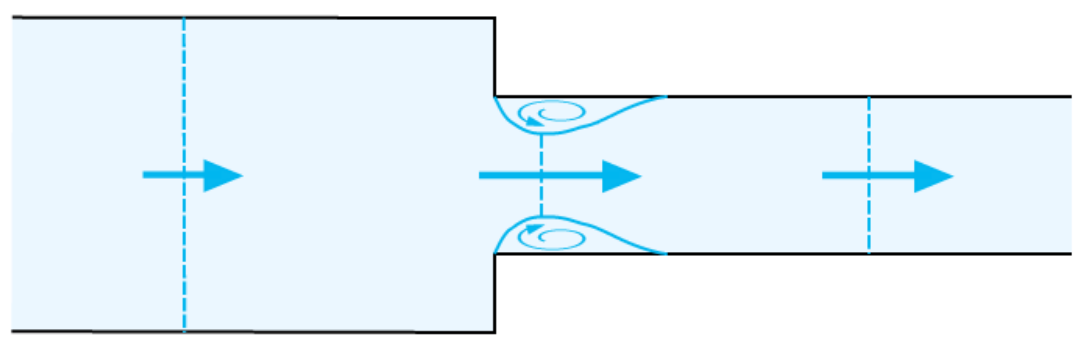

Figure 1-9 Discharge Contraction (8) 


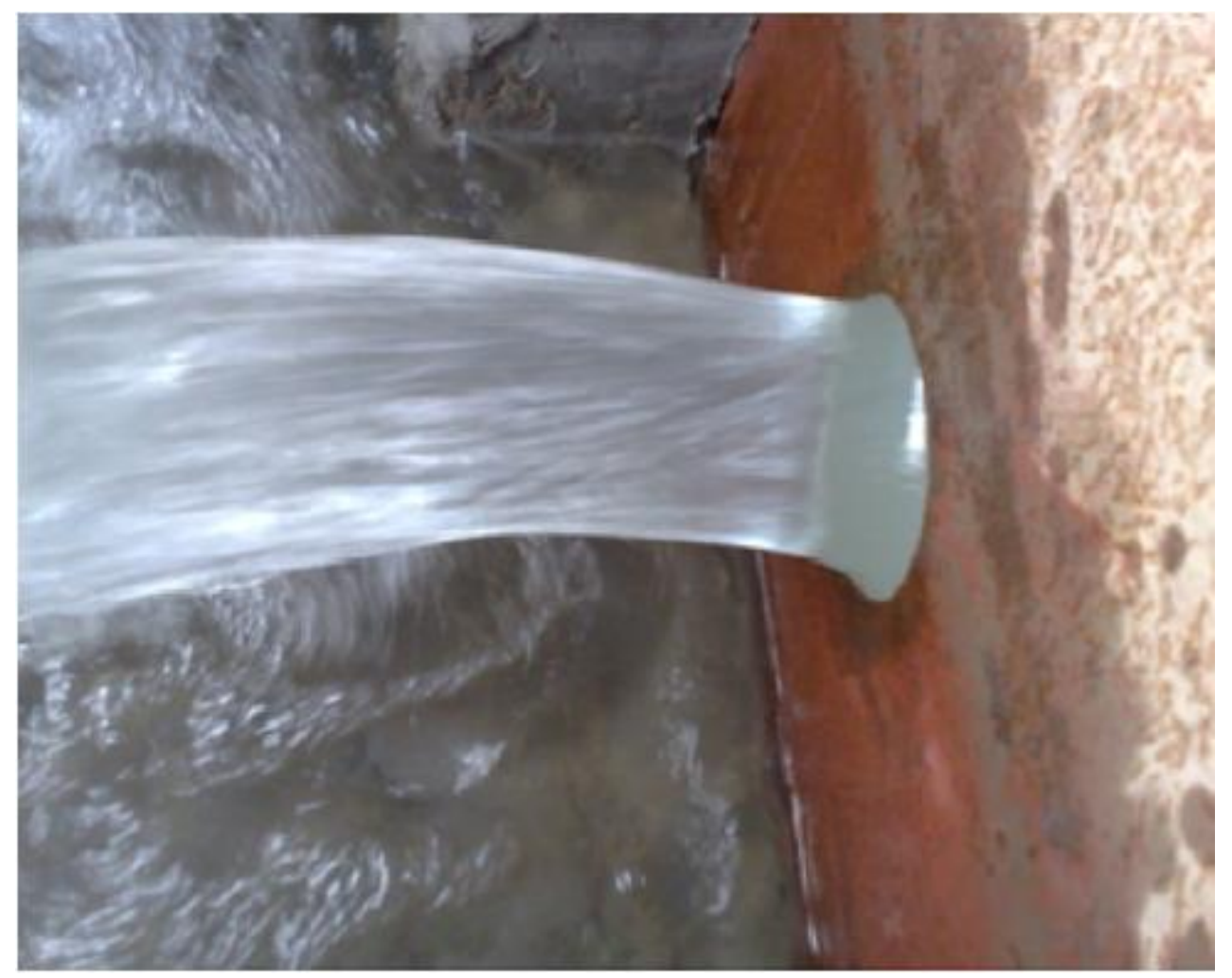

Figure 1-10 Side Orifice Flow (5)

An orifice tube is classified as an orifice with a length of $2.5 d$ (3). Although this classification is misleading, previous studies have concluded that in pipe flow the downstream mixing affects the discharge from the orifice causing the discharge coefficient to rise with diameters less than $2 d$. This mixing causes an early attachment to the tube walls. Shorter tubes with a small tube length until $2 d$ have been shown to grow until $2 d$. Tubes discharged into an open atmosphere are assumed to behave as a thin plate orifice until $2 d$. A study was done by Lichtarowicz, Duggins and Markland (4) investigating discharge coefficients through tube orifices in pipe flow. The study compared their discharge coefficient data with data collected by a number of other sources. Their apparatus was an orifice meter in pipe flow, therefore the orifice jet enters the flow downstream and not into an open jet (e.g. exiting out to the atmosphere). The data was collected 
for a Reynolds number from unity to $10^{4} . \mathrm{C}_{\mathrm{d}}$ was analyzed as a function of $l / d$. $l$ is the characteristic length of the orifice and $d$ is the hydraulic diameter of the orifice. To obtain a wide range of Reynolds number, they constructed two different testing apparatuses. One was built to test oils to achieve lower Reynolds number

In their conclusion, they state to avoid an $l / d$ less than 1.5 , since the discharge coefficient varies rapidly with $l / d$ below this value, and there is the possibility of hysteresis in operation (4). Their testing was valid for $l / d$ ranging from 2-10. For Reynolds number higher than $10^{4}$, the $C_{d}$ approaches convergence. For $l / d=2$, the $\mathrm{C}_{\mathrm{d}}$ approaches 0.810 whereas $l / d=10, \mathrm{C}_{\mathrm{d}}$ approaches 0.740. They note that this drop in $\mathrm{C}_{\mathrm{d}}$ occurs in a nearly linear fashion.

\subsection{Motivation for Research}

Although there has been acceptable discharge coefficient research for thin plate circular orifices, results for irregular orifices are quite limited. In addition, tube orifices have been studied in pipe flow but not as a free jet into an open environment. The focus in the past has been primarily aimed at sharp crested orifices and small square-edged orifices.

It is the objective of this work to quantitatively study the flow through orifice plates and orifice tubes as a free jet into the open environment. It is assumed that this discharge will not have any disturbance from downstream flow and not attach to the tube walls until $2 d$.

A major emphasis of this work includes orifices with unconventional shape and profile. These orifices may represent any kind of fault, crack or rupture that may occur in a fluids system and would likely not be a uniform geometry such as a circle. Estimating irregular orifice coefficients would make it possible to estimate losses and resulting flow rates due to a fluid system rupture such as a large scale piping breach underwater. 
Fluid may flow through an orifice or hole of any diameter. The problem is that thin plate orifices are not typical unless in an orifice metering device or a thin walled tank. There are many applications when the flow rate may be over or underestimated due to ignoring plate thickness and/or edge sharpness. It is already known that the tube orifice is quite different than the thin plate orifice, but how does an irregular geometry tube interact?

The current research investigates methods to understand discharge characteristics for orifices with longer characteristic lengths and non-circular orifice profiles. Methods to estimate orifices or holes in fluid systems will make it possible to more accurately understand practical fluid systems. More importantly it would make it possible to more accurately estimate losses and flow rates due to system failures. This gives the engineer an idea of the flow rate and how to prepare for the loss effects while a solution to fix the rupture is put in place.

\subsection{Brief Overview of Current Research}

Currently at West Virginia University, testing is being conducted to explore the discharge characteristics of thin plate orifices, tube orifices, uniform and irregular jagged orifice discharge coefficients, which are shown below in Figs. 1-11 through 1-14. The three that are within the box are of interest. It is of interest to see how the tube orifices behave in region between $l / d=0$ and $l / d$ $=2.5$. It is also of interest to examine how irregular orifices behave as a thin plate orifice as well as an irregular extruded orifice in an $/ / d$ region. Sharp-crested circular orifice data collected in house has shown good agreement with previous testing done by Rouse (6) by yielding a discharge coefficient which agrees with known discharge values. The comparison between West Virginia Universities experiments and Rouse (6) for thin plate circular orifice discharge coefficients can be seen in Figure 1-15 and Figure 1-16. For the other orifice geometries, there is little to no available data, so this work seeks to address this gap. 


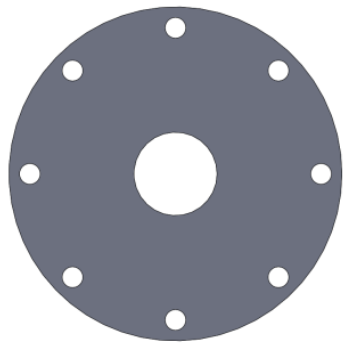

Figure 1-11 Circle

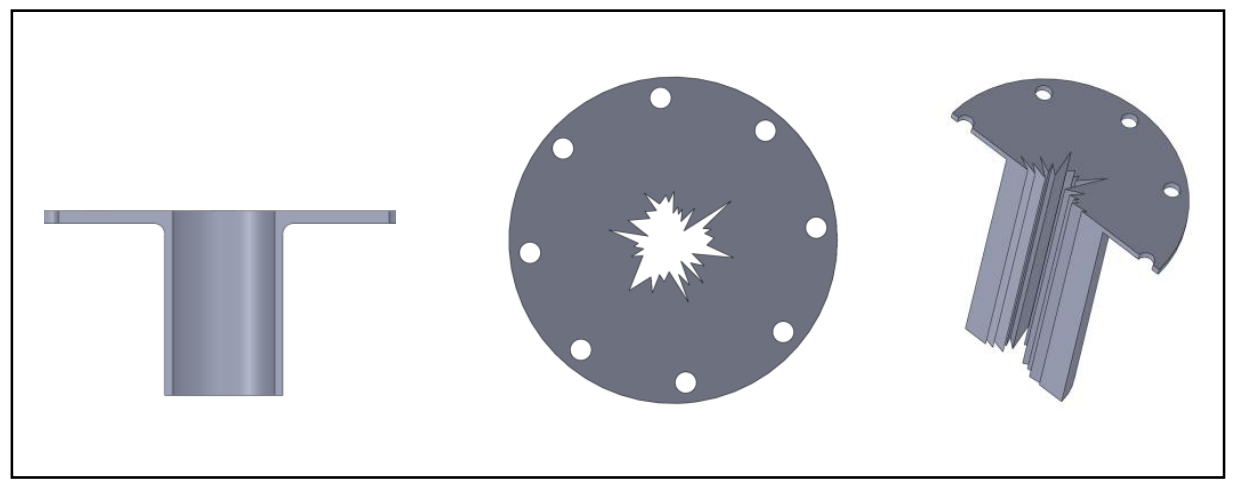

Figure 1-12 Tube

Figure 1-13 Jagged

Figure 1-14 Jagged Extruded

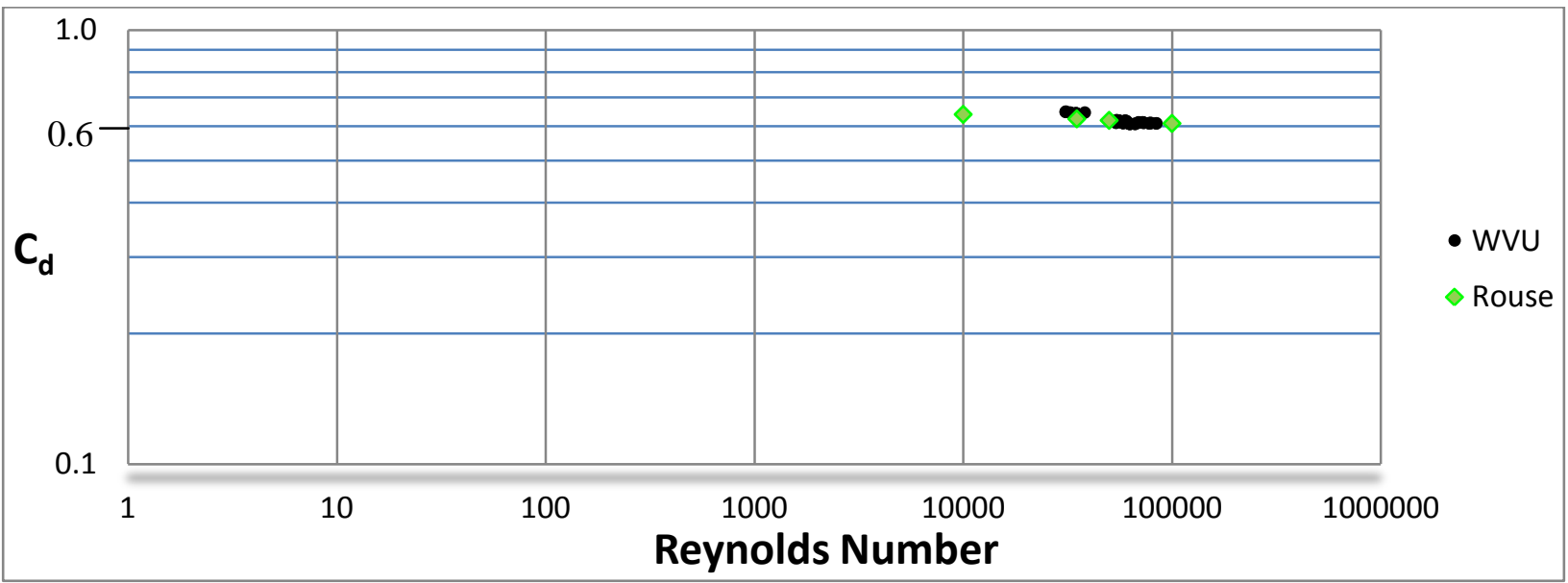

Figure 1-15 Thin plate Orifice (WVU)

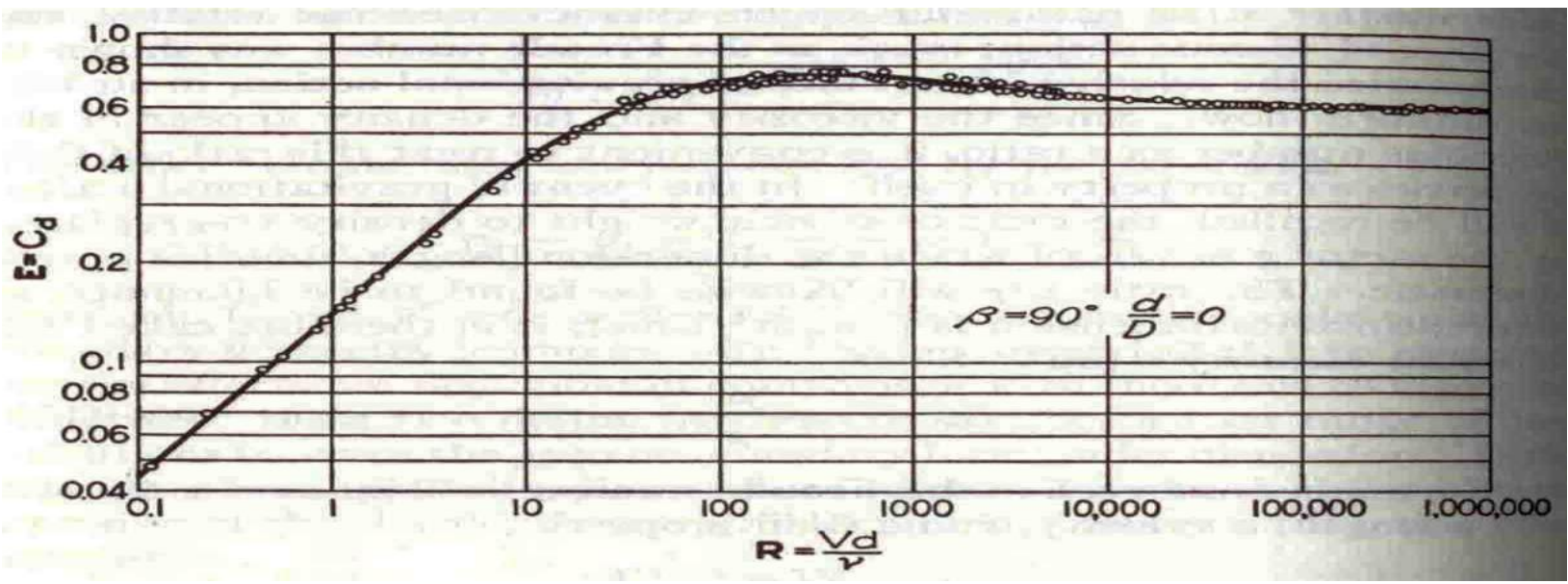

Figure 1-16 Thin plate Orifice (6) 
The test apparatus at WVU can produce heads from 18 to 33 inches which is a main contributor to the discharge velocity. The discharge velocity has a direct correlation to Reynolds Number which results in a limited range of Reynolds Number. In the realm of testing conducted at WVU, the discharge coefficient data matches closely with previous work done by Rouse (7). This gives an assurance of the accuracy of the current test apparatus. 


\section{Chapter 2 Orifice Selection}

\subsection{Tube Orifice}

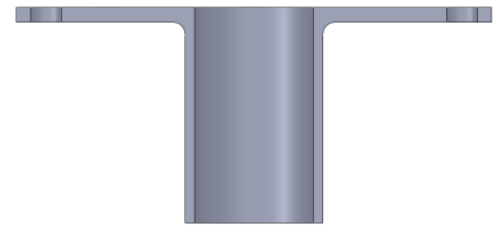

Figure 2-1 Tube Orifice

It is important to match current testing results with previously published data to ensure the results are valid. This study compared previous results done by Lichtarowicz et al. (4) with similar $d / D$ ratio and Reynolds number to current data. $d / D$ is the ratio of the test tank diameter $D$ to the orifice diameter $d$. The diameter $d$ selection is important due to uncertainty. A small orifice will result in higher error due to measuring diameter and lower flow rate; this will be explained further in the uncertainty calculation section of Ch. 4 . It is known for tube orifices, such as the one shown in Fig. 2-1, with lengths of $2 d$ fluid will attach to the tube walls thereby affecting the discharge coefficient. An $l / d$ less than 2.0 should result in the same discharge coefficient as for a thin plate orifice. Tube selection was based on $l / d$ values around 2.0 to verify this transition to attachment.

Orifices were developed in the CAD and built on the rapid prototype ABS printer at WVU. Tube orifices had diameters of $1 / 2 ", 3 / 4 "$ and 1 ". The length of the tubes was extruded according to the $l / d$ ratio desired ranging from 0.74 to 10 .

\subsection{Irregular Orifices}

Irregular orifices were designed by a trial method. A past study stated lower pressure differential occurred in their fractal orifice profiles (7). Those shapes were more consistent and uniform in design than the irregular geometries considered in this study. In the current study, an irregular orifice was sketched in CAD with similar total area as a 1-inch-diameter circular orifice but in a random sense. Four orifice profiles were selected according to their average interior angle. 
Figure 2-2 shows the four orifice profiles selected. The profile was first sketched with no exact shape in mind and adjusted accordingly to obtain a range of different average interior angles. Irregular orifices 1 and 2 were also extruded and then tested and compared to tube orifice data. The objective was to create a rupture to simulate a possible real life occurrence.

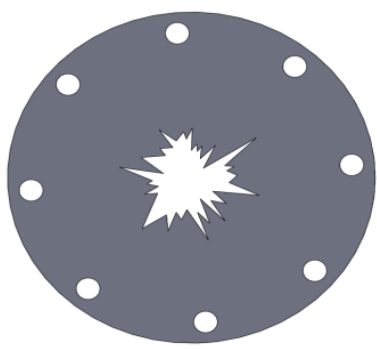

1.

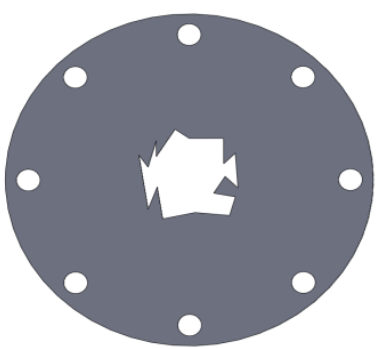

2.

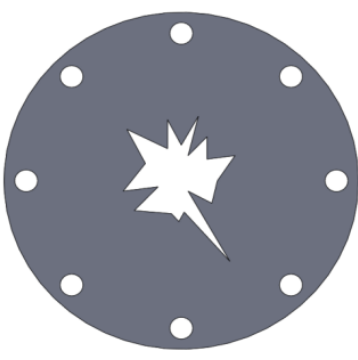

3.

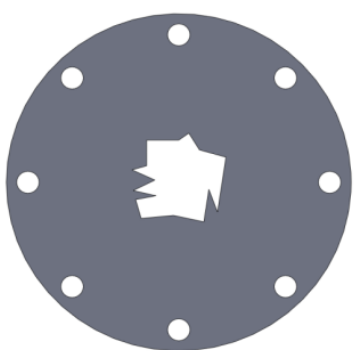

4.

Figure 2-2 Irregular Orifices 1.) 33 degrees. 2.) 60.5 degrees. 3.) 42.5 degrees. 4.) 74 degrees.

The entire area of the irregular profile was found using CAD including the small openings. Table 2-1 and Table 2-2 show the different orifices tested. Regular orifices such as thin plate circular, square and elliptical were tested to compare to previously tested data and confirm the accuracy of the apparatus. The irregular orifices were also compared against a saw-tooth orifice to compare the effects of saw-tooth vs. irregular shapes. The saw-tooth orifice is made up of 15 "teeth". Three saw-tooth orifice sizes were created with consistent dimensions. The number of teeth was kept constant; the tooth angle was also kept constant. This made it possible to test several saw-tooth orifices of identical area ratios. 
Table 2-1 Thin Plate Orifices

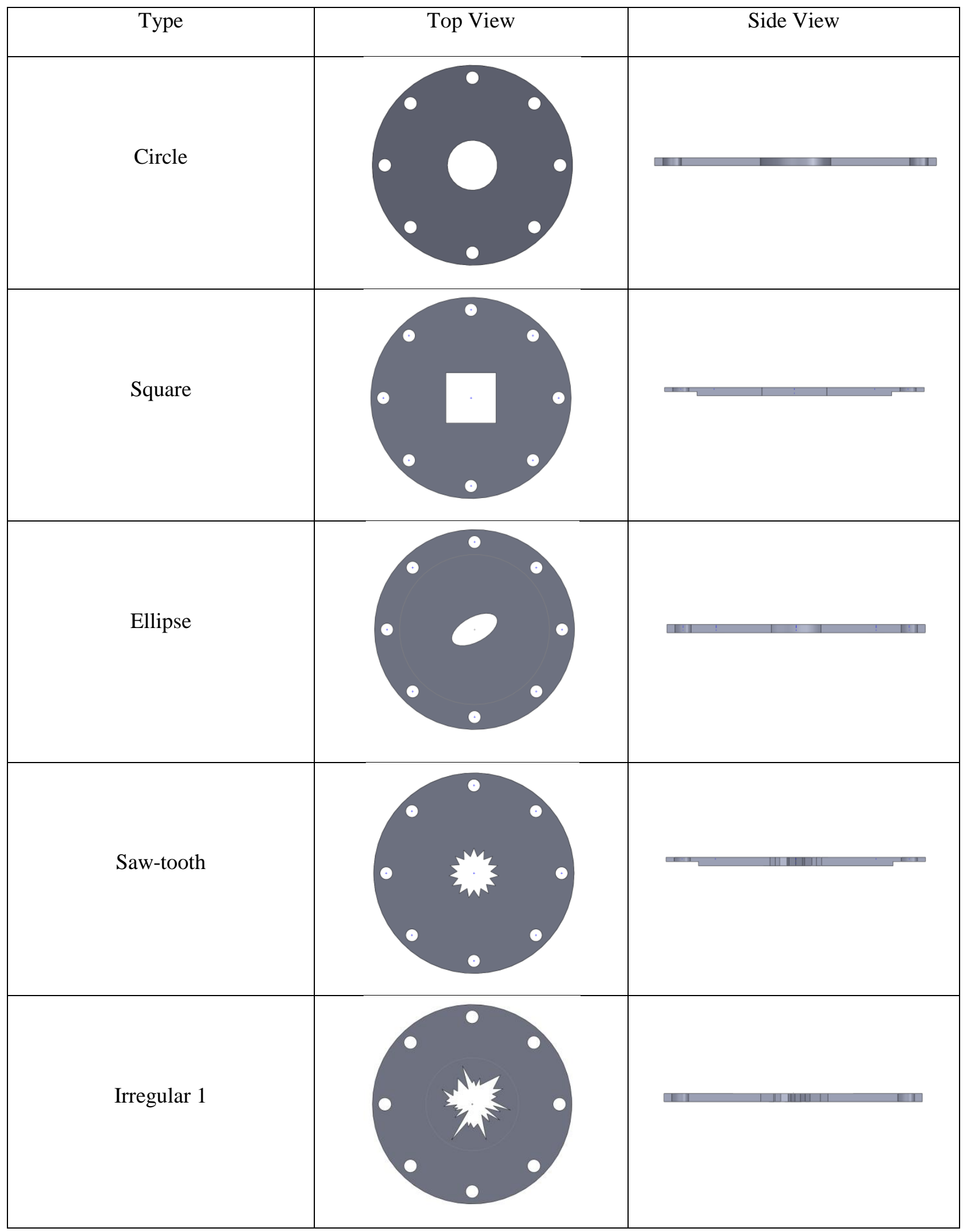




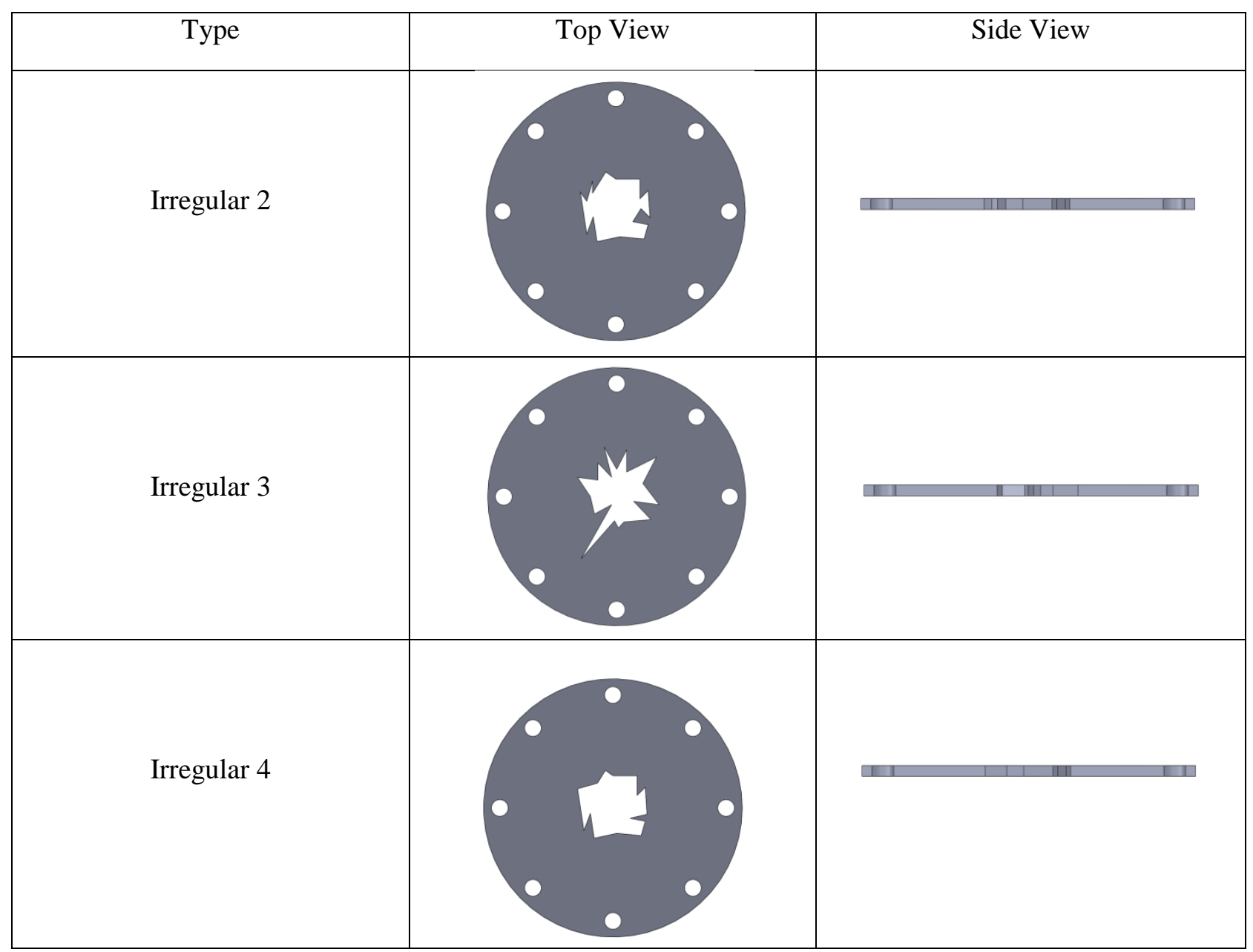


Table 2-2 Extruded Orifices

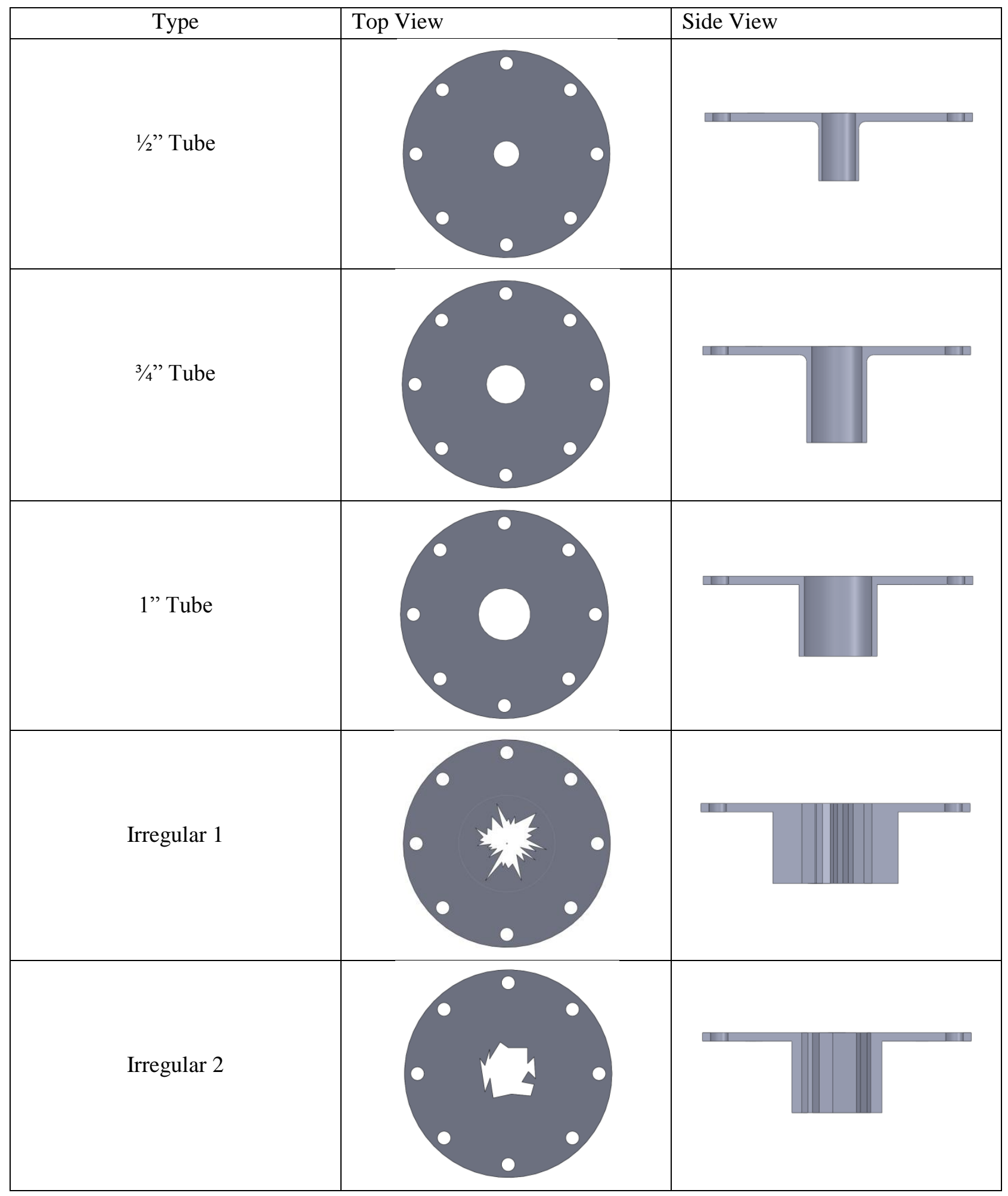




\section{Chapter 3 Rig Design and Test Methodology}

\subsection{Apparatus and Design}

The test facility is located at the West Virginia University Hangar at the Morgantown Airport where a multitude of research projects are carried out. Adequate space and tools were available for this project and the building of the test facility.

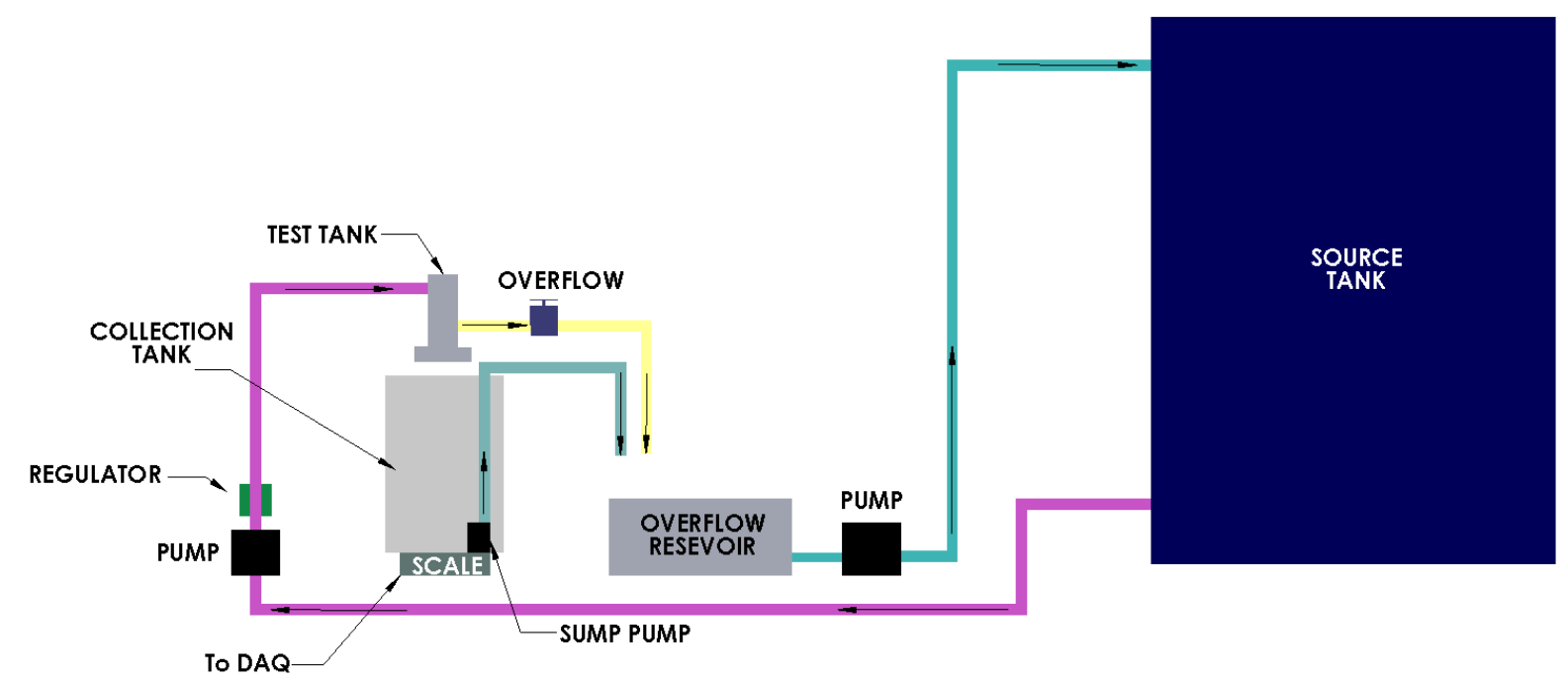

Figure 3-1Schematic of Test Facility

An objective of the design of the test apparatus was to make it simple. A schematic of the test facility can be seen in Figure 3-1. The basic idea was to create a test tank to maintain a constant head above the orifice. The test tank was filled by a supply line from a large source tank. The head height in the test tank was regulated by a ball valve on the side of the test tank. Orifice plates are installed in the bottom of the test tank and discharged into a collection tank directly below the test tank. In order to measure the mass flow rate, a scale was used to weigh the amount of water discharged through the orifice in a given time. The collection tank was installed on top of a calibrated scale. The scale was then wired to a data acquisition system to read the mass flow 
rate. Given the fact that many different orifice geometries were going to be tested, it was important to have the ability to swap orifice plates in a reasonable time. In order to make the plates easily swappable, a test bed was created and printed in the rapid prototype printer to hold the orifice plate and be easily installed in the bottom of the test tank. This is shown in the following figures; Fig. 3-2 through 3-5. Orifice plates were created in CAD and printed in WVU's three dimensional ABS (acrylonitrile butadiene styrene) printer.

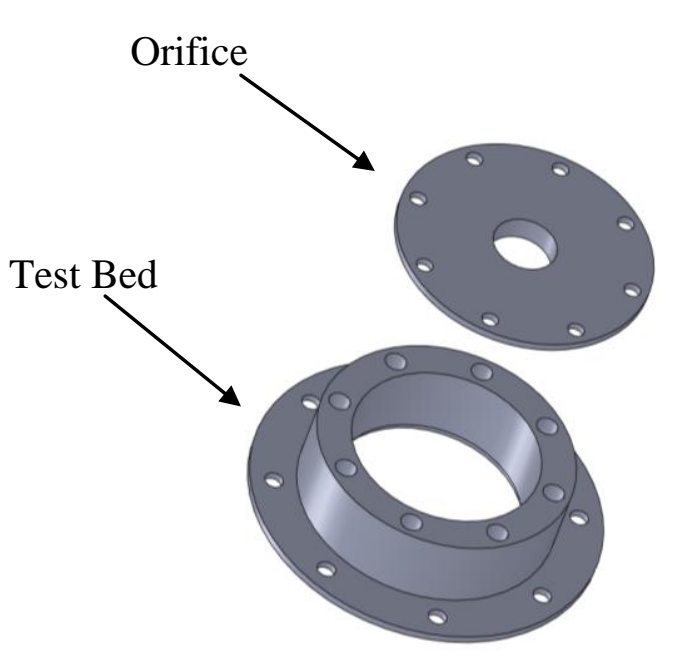

Figure 3-2 CAD Drawing of Orifice installation

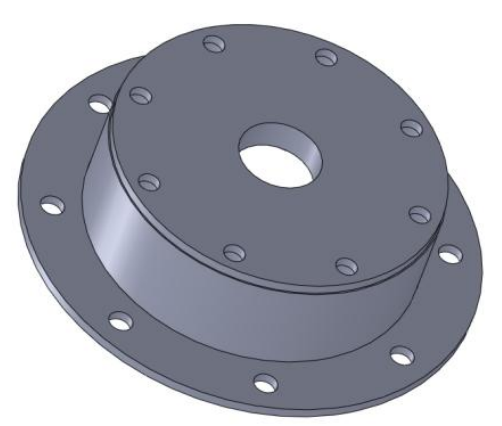

Figure 3-3 CAD Drawing of Orifice and Test Bed 


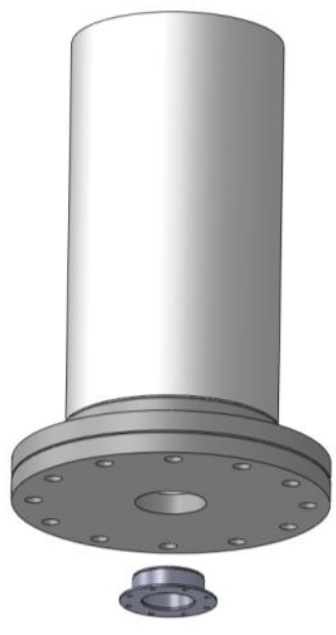

Figure 3-4 CAD Drawing of Test Bed installation in Test Tank

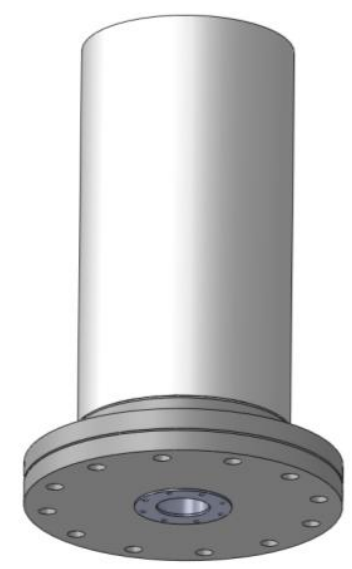

Figure 3-5 CAD Drawing of Test Bed in Test Tank

Both the orifice plates and the test bed were attached using quarter inch bolts which could be easily removed. To replace an orifice plate, the test bed was first removed and then the orifice plate could be replaced. To insure proper sealing, rubber gaskets were installed between the orfice plate and test bed. Another gasket was placed between the test bed and test tank. 


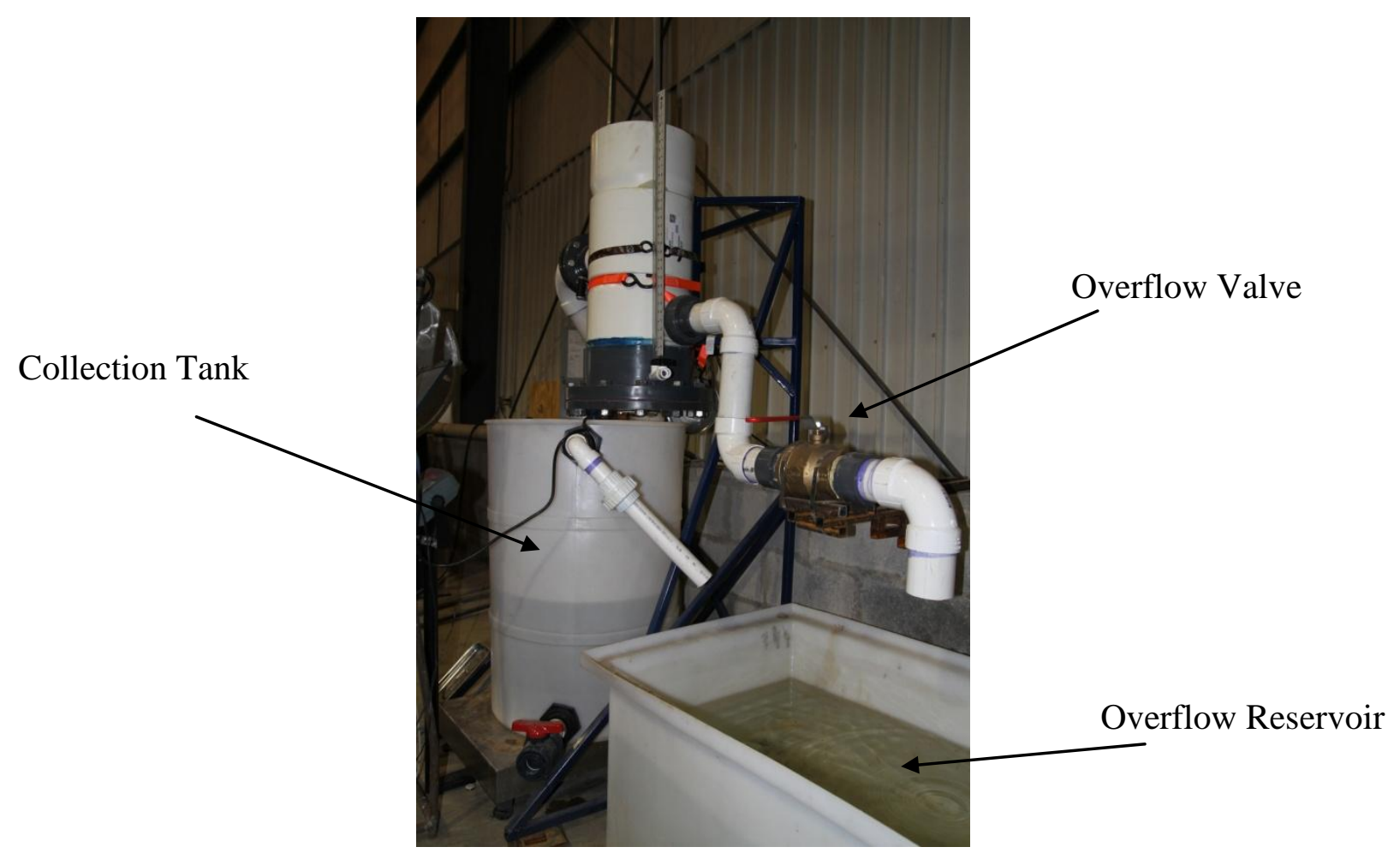

Figure 3-6 Test Apparatus

For the water above the orifice, the idea was to keep a constant head in the test tank as water was discharged through the orifice. Water was pumped into the test tank, and the height was regulated through an overflow valve on the side of the test tank. The overflow valve was a manually operated ball valve. The overflow valve was adjusted according the desired head read at the piezometer. Water was directed from the overflow valve into an overflow reservoir off to the side of the test tank (see Fig. 3-6). The overflow reservoir was equipped with a float switch which activated a pump when a predetermined level was reached. The catch basin re-circulated the water back into the large water source tank completing the circulation process. 


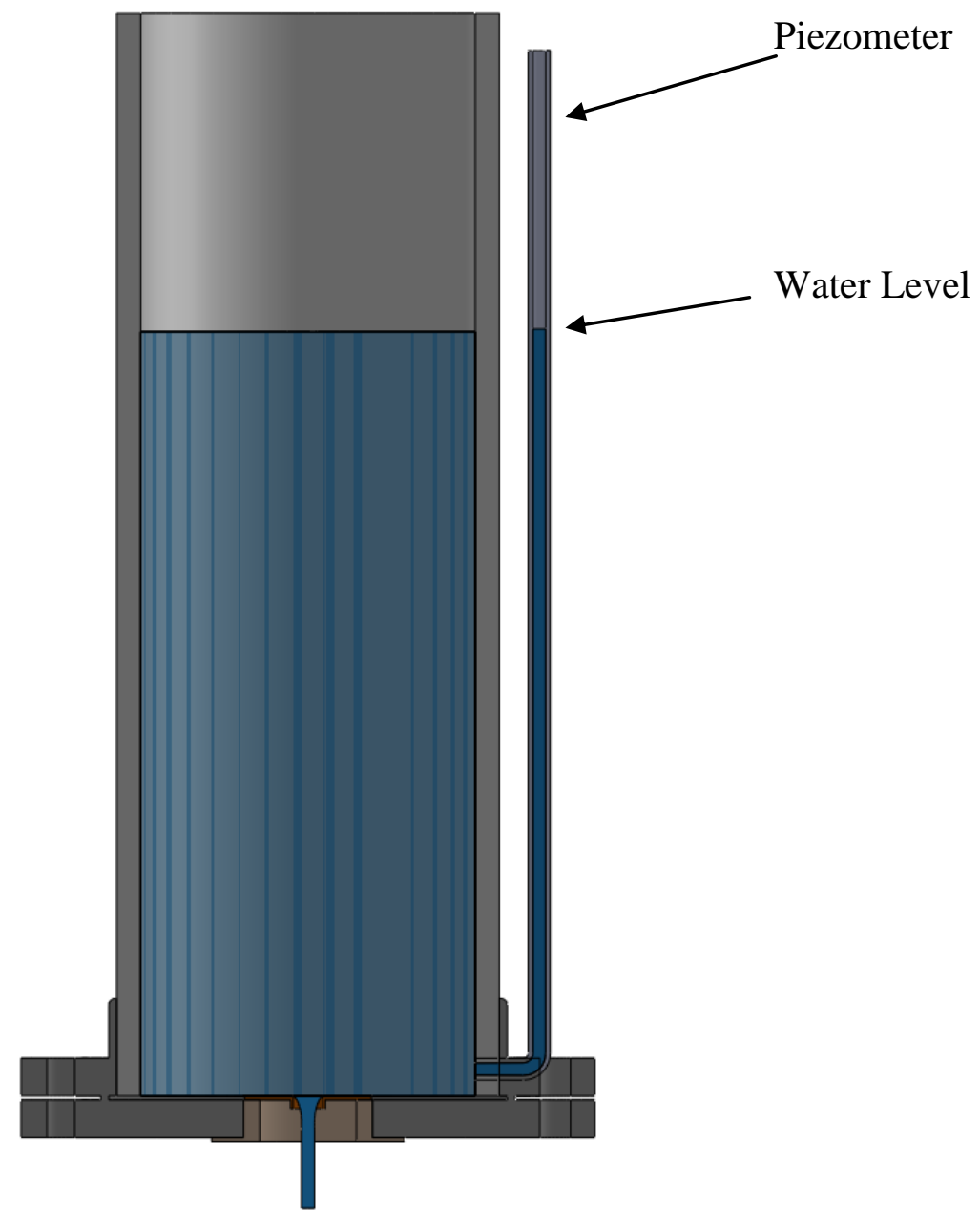

Figure 3-7 Test Tank Assembly

The head of water in the test tank was measured using a piezometer, as shown in Fig. 3-7. A ruler was installed and calibrated on the outside to measure the water level within the test tank. The ruler is not seen in the above figure but is attached to the side of the piezometer and is shown in Fig 3-8. 


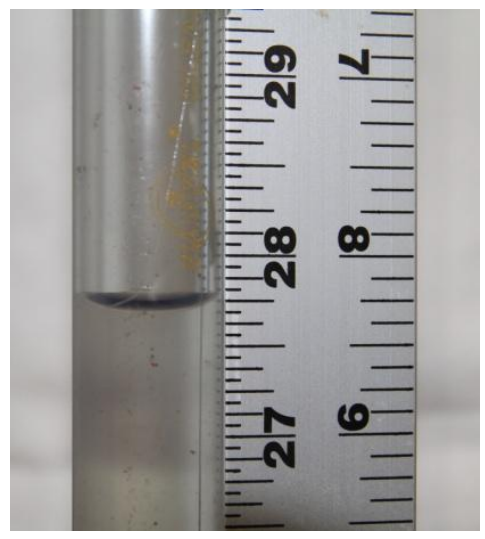

Figure 3-8 Piezometer Site Gauge

A sturdy structure was necessary to support the test tank to minimize vibration and disturbances. A one inch steel box tube structure was constructed to support the test tank (Fig. 3-9). The support structure was designed around the scale and collection drum to provide adequate room to remove the collection tank and scale. Design also took into consideration of the test tank itself to allow room to easily replace the test bed and orifices. Figures 3-9 and 3-10 show the structure and how the test bed and orifice are installed. 


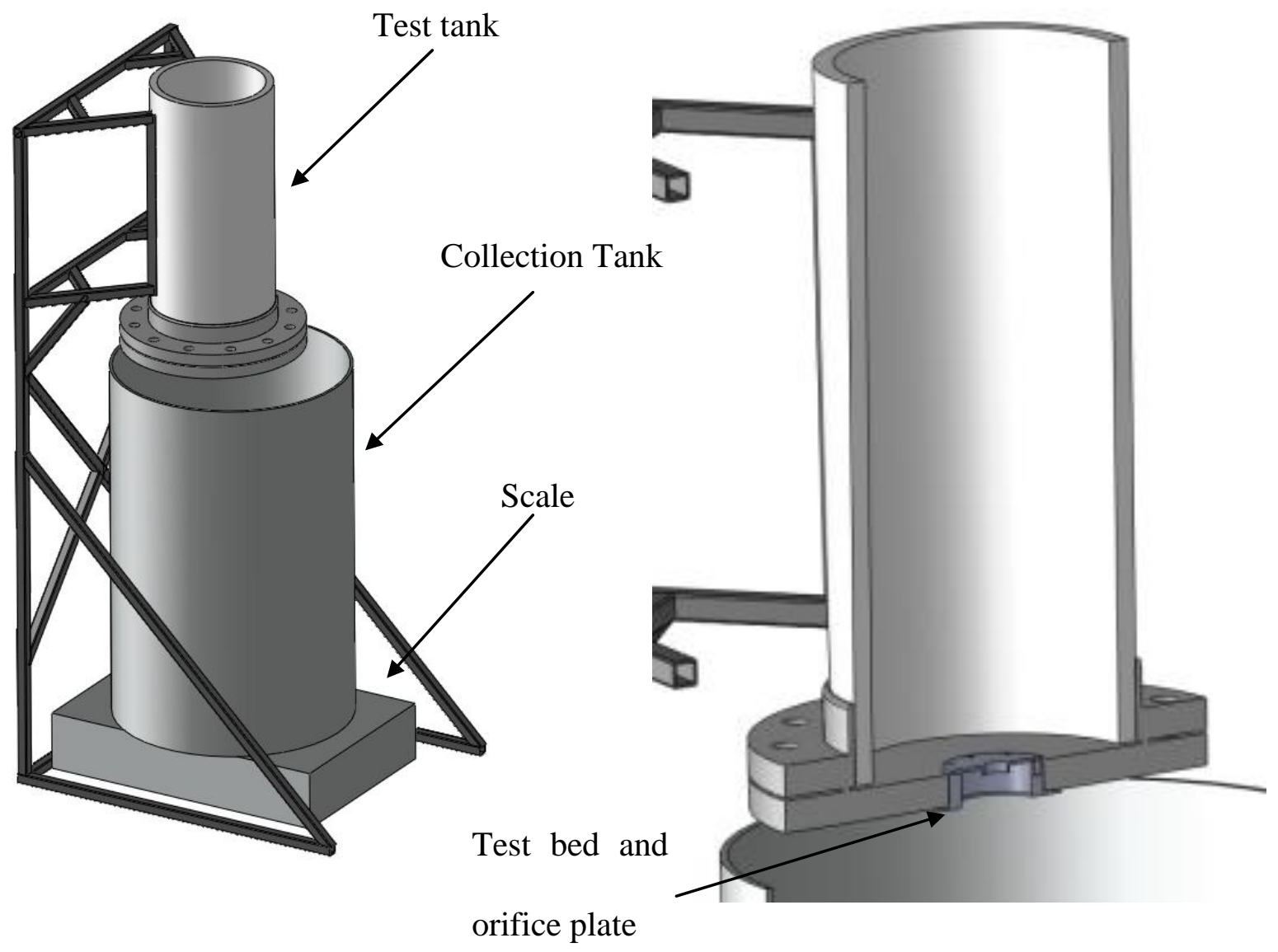

Figure 3-9 Test Apparatus

Figure 3-10 Test Tank

A recirculation system was necessary to re-use the water from the source tank considering the amount of water used to run the tests. This system consisted of three pumps to transport water from the source tank to the test tank, then a sump pump to pump out of the collection tank into the overflow reservoir. The overflow reservoir was equipped with a float switch used to trigger the overflow pump. The overflow pump was plumbed to the source tank to complete the recirculation process.

An Ohaus scale was used with a capacity of $600 \mathrm{lbs}$ and was installed below the collection tank. A read-out with a least count of $0.01 \mathrm{lbs}$ was output to the DAQ via RS232 serial port. The scale was zeroed before each test; therefore the sump pump did not affect the scale. The overflow 
reservoir was automatically kept empty with an installed float switch and pump which emptied into the source tank.

In order to stabilize flow, a flow straightener was installed in the test tank. The flow straightener was a honeycomb mesh that sat six inches above the orifice plate. The straightener was $1 / 2$ " thick with quarter inch holes. Without the straightener, the water would swirl creating a vortex through the orifice. The straightener can be seen in Figure 3-11 through Figure 3-14.

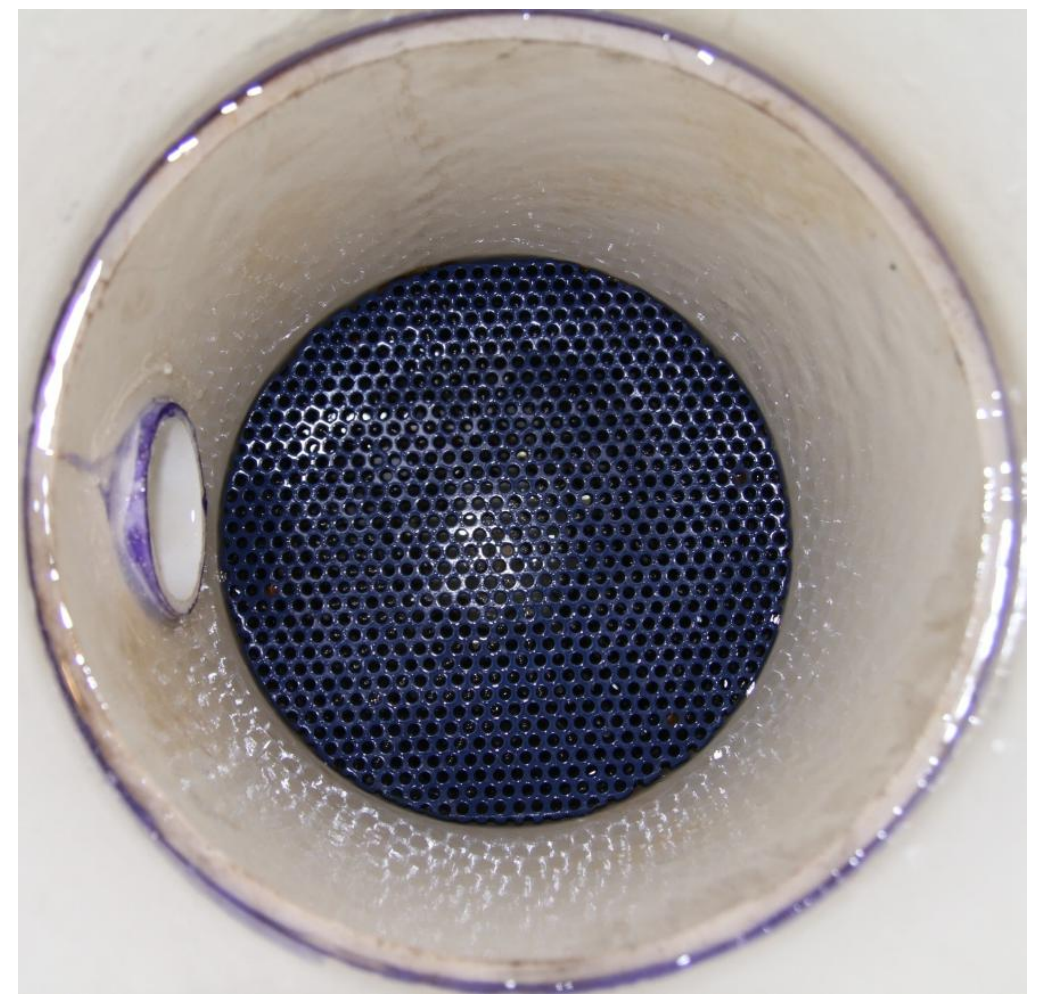

Figure 3-11 Flow Straightener 


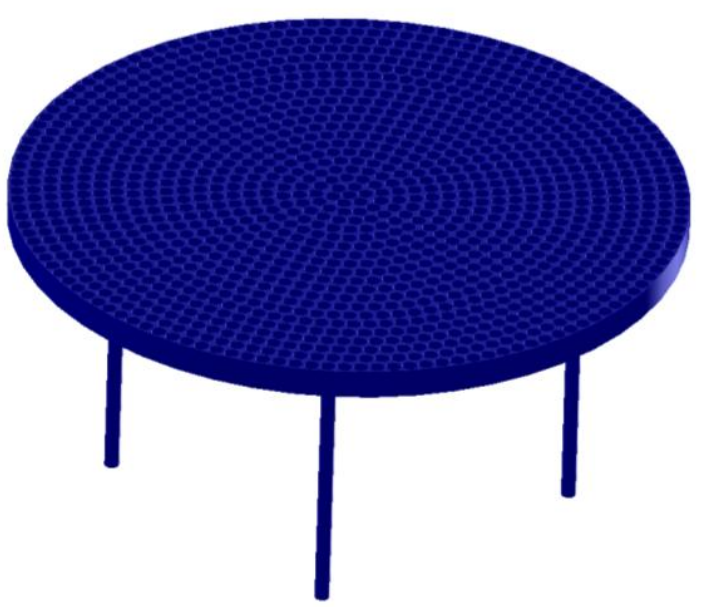

Figure 3-12 Flow Straightener CAD drawing

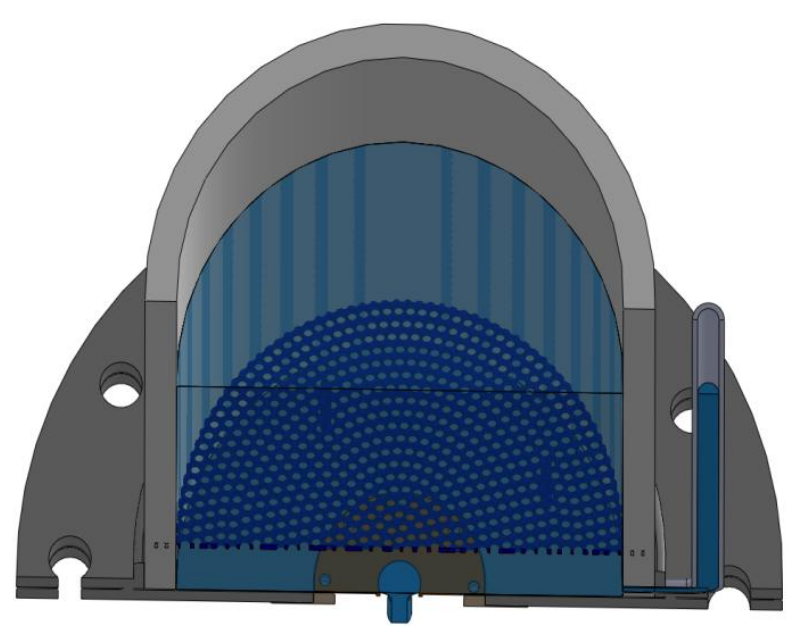

Figure 3-13 Flow Straightener in Test Tank CAD Drawing

It was important to ensure the flow straightener did not affect the discharge coefficient values. Therefore results were compared before and after the straightener was installed with minimum influence.

\subsection{Data Processing}

The discharge coefficient is the ratio of the actual flow rate $\left(Q_{a}\right)$ measured and the theoretical flow rate $(Q)$.

$$
\begin{gathered}
C_{d}=\frac{Q_{a}}{Q} \\
Q_{a}=A_{a} V_{a}=\frac{\dot{m}}{\rho} \\
Q=A V=A \sqrt{2 g h}
\end{gathered}
$$

Plugging in $\mathrm{Q}_{\mathrm{a}}$ and $\mathrm{Q}$ into the $\mathrm{C}_{\mathrm{d}}$ equation results in the following discharge coefficient equation:

$$
C_{d}=\frac{\dot{m}}{\rho \frac{\pi}{4} D^{2} \sqrt{2 g h}}
$$


The area was measured using a caliper with a 1/1000" precision. In the case of the saw-tooth and irregular jagged orifices, it was necessary to use CAD to find the area of the orifice profile.

The velocity was calculated by measuring the water head using the sight gauge on the side of the test tank along with local gravity.

$$
\begin{array}{r}
\boldsymbol{V}=\sqrt{\mathbf{2 g h}} \\
g=9.81 \frac{\mathrm{m}}{\mathrm{s}^{2}}
\end{array}
$$

The density was found by using a hydrometer and a thermometer. The hydrometer was factory calibrated at 60 degrees Fahrenheit. The hydrometer readout is in the form of specific gravity. Specific gravity is the density ratio between the sample of fluid in the experiment and the standard density of water at 60 degrees Fahrenheit. Since testing did not occur at 60 degrees Fahrenheit, the hydrometer measurement was used to find the test density. The temperature was recorded before testing and checked periodically as other tests were conducted. The hydrometer came with a correction table that was used to adjust the specific gravity measured.

$$
\text { S. G. }=\frac{\rho}{\rho_{H_{2} 0\left(60^{\circ} \mathrm{F}\right)}}
$$

The equation above shows that knowing the standard density of water and the specific gravity measured from the hydrometer, the density of water used in the experiment can be found.

\subsection{Experimental Procedure}

The first step to the procedure was to connect the scale to the computer and initialize the DAQ. The desired orifice was then installed. The orifice plates were installed in a removable test bed fashioned beneath the test tank as seen in Figure 3-2. A rubber gasket was used in between the orifice plate and the test bed to ensure sealing. The orifice bed was removed including the orifice 
plate as one unit. The orifice plate could then be swapped and reassembled. There was another rubber gasket installed between the test bed and the test tank.

A steady supply flow rate was used for all tests as an overflow valve was used to make adjustments to maintain a constant head in the test tank. The head was measured using the piezometer on the side of the test tank. The important step here was to make sure the test tank and piezometer reached equilibrium. The procedure was to check the head height, wait one minute and check the height again. If the head did not change, testing could begin. The collection tank was initially emptied by the sump pump draining into the overflow tank. This pump was also used while the test tank and piezometer reach equilibrium. It typically took several minutes for the test tank to reach equilibrium so the collection tank may have filled several times depending on the orifice size and flow rate. The collection tank was monitored to keep from overflowing and emptied accordingly since there was not a flow switch installed on this tank.

Once the test tank and piezometer reached equilibrium, the collection tank was drained to provide adequate volume for testing. The DAQ was then initiated and the head height recorded. In the mean time, the water temperature and specific gravity were recorded. The DAQ was stopped once the collection tank reached approximately the 30 gallon mark.

Each height was tested three times to ensure repeatable results. The head was measured before each test and monitored to ensure equilibrium and consistency. The same orifice was then tested at different heads regulated by the overflow valve.

An Excel spread sheet was used as a data sheet to record the head, specific gravity and temperature of each test sequence. The DAQ recorded each test as a text file which was read in Excel. The recorded text was the weight values from the scale over a period of time. Weight was 
recorded twice for each second. The weight (lbs) was then converted to mass in kilograms. The mass flow rate was then processed by finding the slope of the weight and time recorded.

The following basic test sequence was followed for each test:

1. Initialize DAQ and open Excel data sheet

2. Replace and install new test orifice

3. Empty collection tank*

4. Turn on water supply line

5. Adjust head height using overflow ball valve

6. Record density and temperature of test water

7. Begin data collection once test tank and piezometer reach equilibrium

8. Record head height

*collection tank may need to be drained during equilibrium period before testing 


\section{Chapter 4 Propagation of Uncertainty Analysis}

It is important to try to quantify the uncertainty of the experimental testing. Although the experiment was relatively simple and had a limited amount of input variables, it was still important to recognize the uncertainty to verify the accuracy of the experiments. Performing the propagation of uncertainty analysis shows how much uncertainty is associated in the entire experiment. It also gives an understanding to show where the majority of the error is coming from. The variables associated with the uncertainty include the measured head, fluid density, mass flow rate and the diameter or area of the orifice. Each experimental variable also has a variance value or precision (i.e. precision of measuring the head height $=1 / 16^{\prime \prime}$ ). These variables were then factored into the propagation of uncertainty Equation 4-2.

$$
C_{d}=\frac{\dot{m}}{\rho \frac{\pi}{4} D^{2} \sqrt{2 g h}}
$$

Below are the partial derivatives needed to perform the uncertainty analysis. The partial derivative of each variable is needed for the uncertainty equation. The partial derivatives were taken from the discharge coefficient Equation 4-1 above for each given variable. The partial derivates are then plugged into Equation 4-2:

- Partial derivative with respect to head height (h) $\mathrm{C}_{\mathrm{d}}(\mathrm{h})=\frac{-\dot{m}}{2 \rho \frac{\pi}{4} D^{2} \sqrt{2 g} * h^{3 / 2}}$

- Partial derivative with respect to density $(\rho) \quad \mathrm{C}_{\mathrm{d}}(\rho)=\frac{-\dot{m}}{\rho^{2} \frac{\pi}{4} D^{2} \sqrt{2 g h}}$

- Partial derivative with respect to mass flow rate

$$
\mathrm{C}_{\mathrm{d}}(\dot{m})=\frac{1}{\rho \frac{\pi}{4} D^{2} \sqrt{2 g h}}
$$


- Partial derivative with respect to orifice diameter $\mathrm{C}_{\mathrm{d}}(\mathrm{d})=\frac{\dot{m}}{-2 \rho \frac{\pi}{4} D^{3} \sqrt{2 g h}}$

$$
\Delta C \boldsymbol{d}=\sqrt{\left(\Delta \dot{\boldsymbol{m}} * \boldsymbol{C}_{\boldsymbol{d}}(\dot{\boldsymbol{m}})\right)^{2}+\left(\Delta \rho * \boldsymbol{C}_{\boldsymbol{d}}(\boldsymbol{\rho})\right)^{2}+\left(\Delta \boldsymbol{D} * \boldsymbol{C}_{\boldsymbol{d}}(\boldsymbol{D})\right)^{2}+\left(\Delta \boldsymbol{h} * \boldsymbol{C}_{d}(\boldsymbol{h})\right)^{2}}
$$

\subsubsection{Uncertainty Values}

The uncertainty variance values $(\Delta \dot{m}, \Delta \rho, \Delta D, \Delta h)$ were selected by the precision associated with the measurement devices used in the experiment (i.e. the scale readout was to the tenths place). Each variable was selected accordingly.

$$
\Delta \dot{m}=0.05 \frac{l b}{s e c} \quad \Delta \rho=0.1 \frac{l b}{f t^{3}} \quad \Delta D=\frac{0.005}{12} f t \quad \Delta h=\frac{\frac{1}{16}}{12} f t
$$

The constant values used are from experimental inputs used in actual experiments. The head, orifice diameter, mass flow rate, density and gravity were all used in discharge coefficient calculation. Thus, these experimental factors were used in calculating the uncertainty of the experiments.

$$
\mathrm{h}=2 f t \quad \dot{m}=1.01 \frac{\mathrm{lb}}{\mathrm{sec}} \quad \mathrm{D}=\frac{1}{12} f t \quad \rho=62.2 \frac{\mathrm{lb}}{f t 3} \quad \mathrm{~g}=32.2 \frac{\mathrm{ft}}{\mathrm{sec}^{2}}
$$

The mass flow rate and density are both shown in pound mass. The scale read out was in pounds therefore the density used was in pound mass to obtain the correct units.

$$
\Delta C d=+/-0.003
$$

Using the uncertainty and constant values along with the uncertainty equation Eq. 4.2, the overall experimental uncertainty for this testing is found to be 0.003 . This appears to be reasonable. The 
majority of the error comes from the accuracy of the scale and the measuring of the diameter/area of the orifices. The accuracy of the scale is factored into the mass flow rate. This is due to finding the slope of the weight recorded over time in order to find the mass flow rate. The weight (lbs) is then converted into slugs.

\subsection{Standard Deviation}

It is also important to calculate the standard deviation in a sample of tests performed. The standard deviation (s) shows how much variation there are in-between experimental tests. A lower standard deviation means a more repeatable experiment. The following standard deviation was calculated on three separate days of testing for a 1" circular orifice at different temperatures ranging from 37.4 to 53.6 degrees Fahrenheit. Equation 4-3 is the standard deviation equation. $N$ is the number of samples evaluated. $x$ is the value of each sample and $\bar{x}$ is the mean of the samples evaluated.

$$
s=\frac{1}{N-1} \sum_{i=1}^{N}\left(x_{i}-\bar{x}\right)^{2}
$$

$$
s=0.000222
$$

This assures that the testing rig and results are repeatable to less than $10 \%$ the uncertainty value found above. The $(s)$ found is to the ten thousandths place which is low enough to determine the experimental standard deviation can be considered negligible.

\subsection{Capillary Rise}

Capillary rise in the piezometer was calibrated with a particular volume of water in the test tank.

The head height was measured inside of the test tank and the piezometer was calibrated 
accordingly. This calibration technique ruled out capillary rise effects. These effects were important to note for uncertainty hysteresis in the apparatus. The following calculations are for the capillary rise effects associated in the piezometer.

$$
\begin{gathered}
\Delta \boldsymbol{h}=\frac{\mathbf{1}}{\gamma} \frac{\mathbf{2 \sigma}}{\boldsymbol{r}} \\
\Delta h=\frac{1}{62.2\left(\frac{l b}{f t^{3}}\right)} \frac{2\left(0.00503\left(\frac{l b}{f t}\right)\right)}{0.02083(f t)} \frac{12 i n}{1 f t} \\
\Delta h=0.09291^{\prime \prime}
\end{gathered}
$$

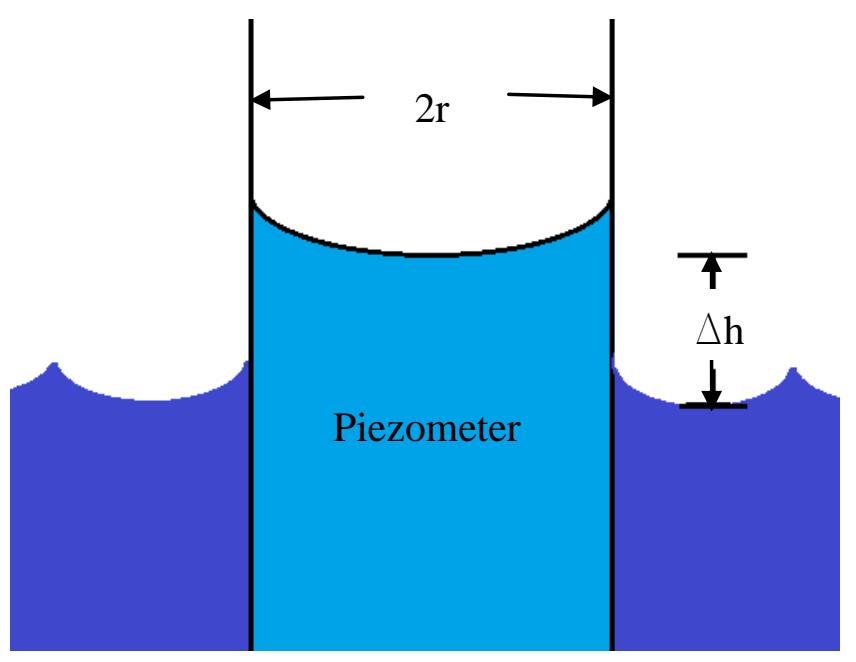

Figure 4-1 Capillary Rise

The capillary rise effect on the discharge coefficient is $\Delta C_{d}=+/-0.001$. This rise is negligible since the piezometer was installed and calibrated based on the actual height of water in the test tank. The test tank was filled and the head was measured in the test tank; the piezometer was then calibrated to read the head in the test tank. Although it is important to notice the effect it could have on the discharge coefficient if not accounted for in the experimental measurement. 


\section{Chapter 5 Area vs. Hydraulic Diameter}

When working with uniform orifice geometries, it is standard to use either the diameter or the hydraulic diameter in the calculation of the orifice area for the discharge coefficient. There exists an equation for the hydraulic diameter of non-circular uniform shapes. However, in this study, discharge coefficient testing was also conducted for irregular geometries, where calculation of a hydraulic diameter becomes difficult. Part of this effort involved a comparison of uniform to irregular orifice geometries. Therefore, a method was needed to characterize the orifice geometry for meaningful consistent comparison.

The hydraulic diameter for a circular orifice is the same as its geometric diameter, $d$. Other shapes do not have a diameter, and hence the need for the hydraulic diameter. The idea of the hydraulic diameter is to relate non-circular shapes to a circle. The hydraulic diameter is generally found by using the orifice's perimeter (p) and area (A) dimensions and is seen in equation 5-1.

$$
d_{h}=\frac{4 A}{P}
$$

It is not realistic to compare other shapes to a circle when it can be seen that these orifices produce a different discharge rate than a circle of the same area. It can be seen in Appendix-A the comparison between hydraulic diameter and the actual area of the orifice. The goal behind the hydraulic diameter is to find a diameter that relates a non-circular orifice to circular orifice. Therefore finding a hydraulic diameter gives one a tool to create a non-circular orifice that can produce the same discharge rate as a circular orifice. In this comparison, it is important to see the difference between different orifices and how they compare to circular orifices. In doing this comparison, it is important to use only the area to compare the different orifices. This allows an 
honest comparison between two different orifices with different profiles showing how the profile affects the discharge coefficient between two orifices of the same area.

\subsection{Square}

The hydraulic diameter of a square is based on the area of the square and its wetted perimeter (equation defaults to the standard diameter when applied to a circle). Upon substitution, the square hydraulic diameter, $d_{h}$, is equal to $\mathrm{L}$, as given in Fig. 5-1. Therefore the hydraulic diameter is the same as the length of one side of the square as seen in Equation 5-2.

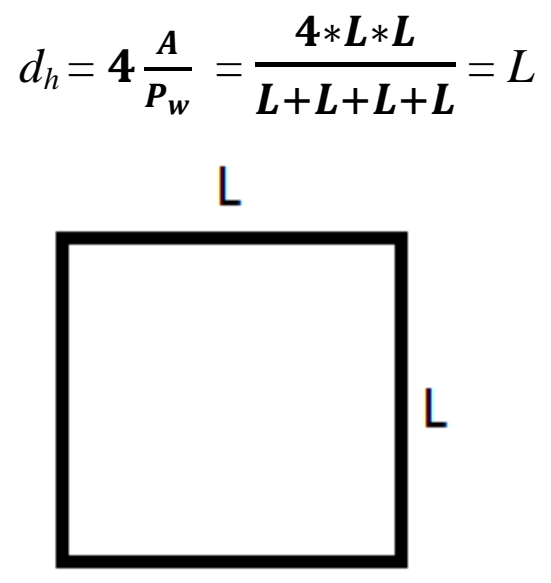

Eq. 5-2

Figure 5-1 Square Profile

$L$ is plugged into the area term of the discharge coefficient equation as shown below in Equation 5-3 (similar to the diameter of a circular orifice).

$$
A=\frac{\pi}{4} d_{h}^{2}
$$

This gives a smaller area than if the actual area were to be used and this creates a higher discharge coefficient than if the actual area were to be used. Since cross-sectional area is such an important parameter in flow rate and discharge coefficient, it seems that the use of hydraulic diameter may not be optimum in this study. The actual area of the square orifice was used 
instead in this thesis in order to compare the difference in discharge coefficients amongst all orifice profile areas.

\subsection{Elliptical}

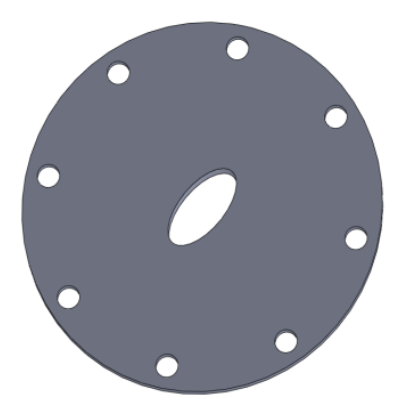

Figure 5-2 Elliptical Orifice

The elliptical orifice template is shown in Fig. 5-2. The hydraulic diameter of an ellipse has been referred to as in Equation 5-4 (9):

$$
d_{h}=\frac{1.55 A^{0.625}}{P_{w}^{0.2}}
$$

The area is the actual area of the orifice along with the wetted perimeter. This hydraulic diameter equation is used to match circular discharge coefficient to elliptical.

The general discharge coefficient Equation 5-1 was also evaluated. A comparison was conducted between the two hydraulic diameter equations resulting in similar hydraulic diameters within 9\%. It was found in this study that the actual area was a more applicable parameter to use in the discharge coefficient calculation than the hydraulic diameter. Therefore, this work used the actual area of the ellipse profile and was directly used in the discharge coefficient equation. The basic area equation of an ellipse was used to find the area of the ellipse as seen in Equation 5-2.

$$
A=\pi a b
$$

Eq. 5-5 
The larger and smaller orifice dimensions, as shown in Fig. $5-3$, were: $\mathrm{a}=1.25 " \mathrm{~b}=0.625$ ” where $\mathrm{b}=\mathrm{a} / 2$. Orifice $\# 2$ was smaller with $\mathrm{a}=0.75$ ". A comparison between the actual area and the hydraulic diameter will be seen in the results section.

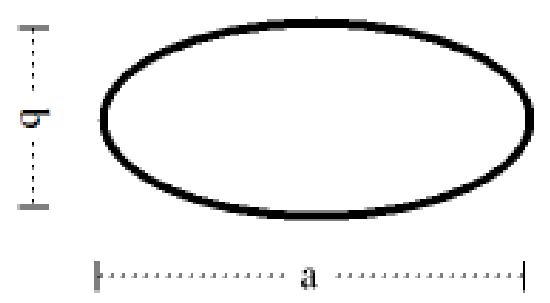

Figure 5-3 Elliptical Orifice Dimensions

\subsection{Uniform and Irregular Jagged Orifices}

The area of the uniform and irregular jagged orifices was used instead of classifying a hydraulic diameter to be consistent with the rest of the thesis. For the discharge coefficient, it seemed more important to compare actual profile areas versus their discharge.

\subsubsection{Saw-tooth Orifice}

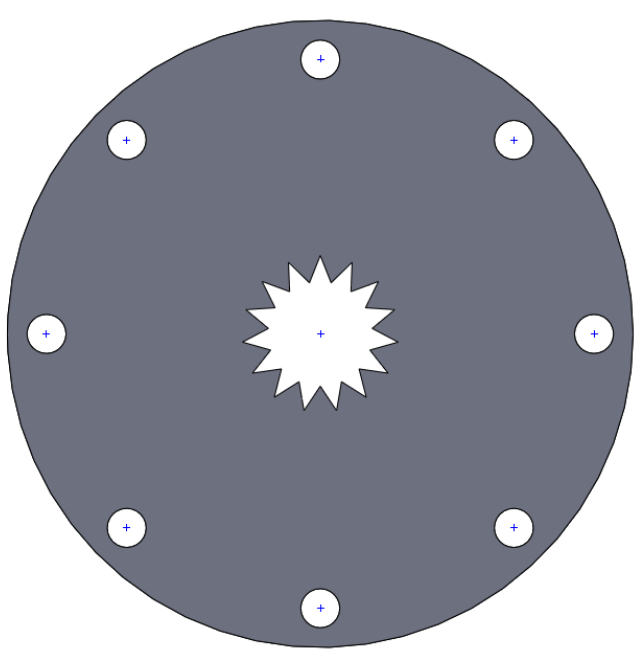

Figure 5-4 Jagged Orifice 
The jagged orifice was a uniform saw-tooth profile, as shown in Fig. 5-4. The orifice was created in three area sizes with the same characteristic lengths. The tooth depth was proportional to the change in the outside diameter of the orifice. Each orifice had the same tooth angle of 33.72 as shown below in Fig. 5-5.

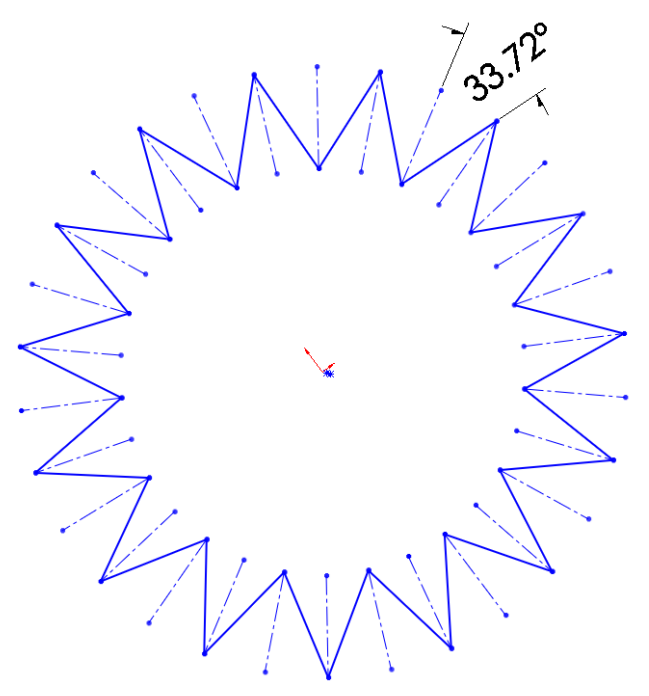

Figure 5-5 Tooth Angle

Each orifice was made up of 15 teeth. The outside diameters of the tested orifices ranged from diameters of 0.75 to 1.25 inches. The area was found using CAD.

Since there was not a special equation for finding the hydraulic diameter for a saw-tooth profile, the area of the jagged orifice was directly plugged into the discharge coefficient equation, as shown below in Equation 5-6. The area is directly plugged into the discharge coefficient equation.

$$
C_{d}=\frac{\dot{m}}{\rho\left[\frac{\pi}{4} D^{2}\right] \sqrt{2 g h}}
$$




\subsubsection{Irregular Orifices}

\subsubsection{Thin plate Irregular}

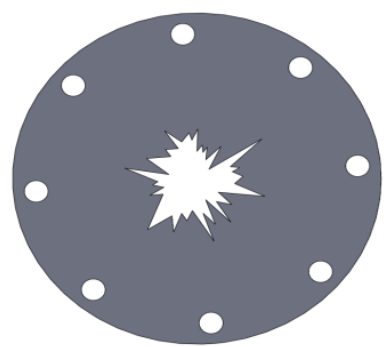

1.

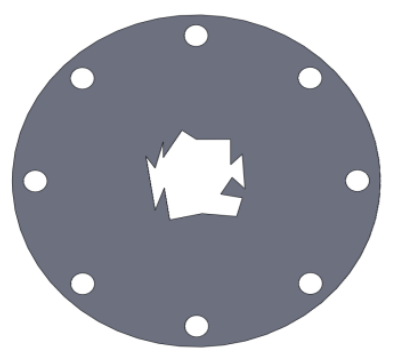

2.

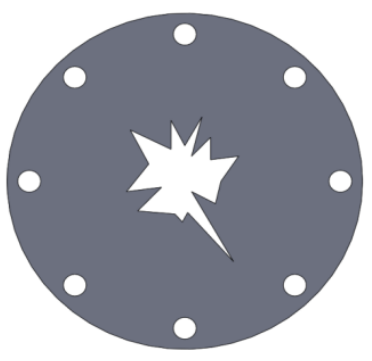

3.

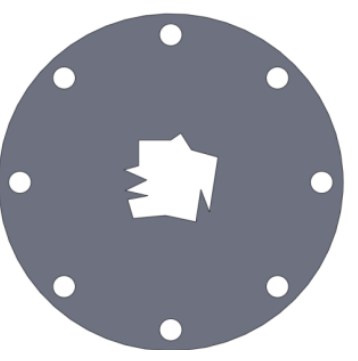

4.

Figure 5-6 Irregular Orifices

The irregular orifices discussed earlier were created without any shape in mind but to create profiles with different interior angles.

Figure 5-6 shows the irregular orifices tested. Like the saw-tooth orifice, the area of the entire orifice profile was used in the discharge coefficient equation. Therefore there was not a direct hydraulic diameter. The objective was to use a hydraulic diameter that is convenient for computation. Three methods were evaluated to solve for a hydraulic diameter. One of which; as stated previously for the saw-tooth orifice was to evaluate the area of the profile for an equivalent circular diameter using the area of a circle equation. The second approach was to scribe the inner most diameter and the outer most diameter of the irregular profile and average the two measured diameters. The third approach was to use the general hydraulic diameter equation seen in equation 5-1. A comparison was computed to evaluate which method was more effective and consistent. Using the area of a circle approach for irregular orifice \#1; the discharge coefficient $\left(C_{d}=0.705\right)$. Using the scribed circle method; a discharge coefficient was found to be $\left(C_{d}=0.659\right)$ which is lower than the area of a circle method. Using the general hydraulic diameter equation 5-1, a discharge coefficient $\left(C_{d}=9.032\right)$. The general equation results an 
absurd value which was discarded due to its incomparable discharge coefficient. The scribed circle method seems feasible until it was evaluated for irregular orifice \#2 which was found to have the opposite effect. The area of a circle method for orifice \#2 was found to be $\left(C_{d}=0.658\right)$ compared to the scribed circle method found as $\left(C_{d}=0.743\right)$. In conclusion, the discharge coefficient for orifice \#1 obtained a smaller discharge coefficient using the scribe circle method compared to orifice \#2 which had a larger discharge coefficient. Therefore the scribed circle method is discarded due to inconsistency. Finally, solving the equivalent diameter from area of the irregular orifice profile was selected to be used in the discharge coefficient analysis.

\subsubsection{Extruded Irregular}

The extruded irregular orifice was an extruded version of the thin plate orifices above. The two orifices selected were orifice \#1 and \#2. This provided a sample of both ends of the interior angle spectrum from a large average interior angle \#2 of 60.5 degrees to \#1 with an average interior angle of 33 degrees. Figure 5-7 shows a cut away view of irregular orifice \#1 that had been extruded.

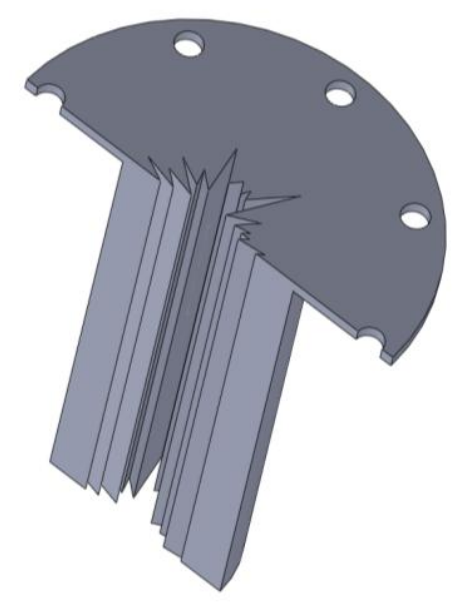

Figure 5-7 Irregular \#1 


\subsection{Reynolds Number}

Reynolds Number is a dimensionless number which is a measure of the ratio between inertia and viscous forces. Reynolds Number is used to characterize different flow regimes such as laminar and turbulence. The Reynolds number was found by using the actual area to find an equivalent diameter of the orifice and shown below in Equation 5-8. The area of each orifice was measured, and then the equivalent diameter was found using the area of a circle equation. The area that was used in the discharge coefficient equation was also used to find an equivalent diameter. Therefore the area was found and used in the area of a circle equation to find that particular equivalent circular diameter. The diameter was found by using the area of a circle equation as seen in Equation 5-7.

$$
\begin{gathered}
d=\sqrt{\frac{4 A}{\pi}} \\
\text { Reynolds Number }=\frac{Q_{a} d}{v A_{a}}
\end{gathered}
$$




\section{Chapter 6 Results of Orifice Testing}

\subsection{Thin plate Orifices}

A Thin plated orifice is an orifice that has a plate thickness of $0.5-2.0 \%$ of the adjacent pipe diameter (10). The thin plate orifices tested had a thickness of $0.125 \%$. The adjacent pipe had an internal pipe diameter of 12 ", therefore the orifice plate thickness was $1.04 \%$ of the adjacent pipe thickness and within the range specified above. The Thin plated orifices investigated are compared to Reynolds number.

\subsubsection{Circle}

The investigation of thin plated circular orifices was to obtain assurance that the test apparatus was accurate. It was important to compare circular orifice discharge coefficients tested at WVU with previous work. Rouse (6) has investigated circular thin plate discharge coefficients at length. His work is shown in Figure 6-2; represented as discharge coefficient as a function of Reynolds number. Due to limitations within WVU's test apparatus, only a small range of Reynolds number was tested. These limitations were due to limited head height and orifice size capability. 


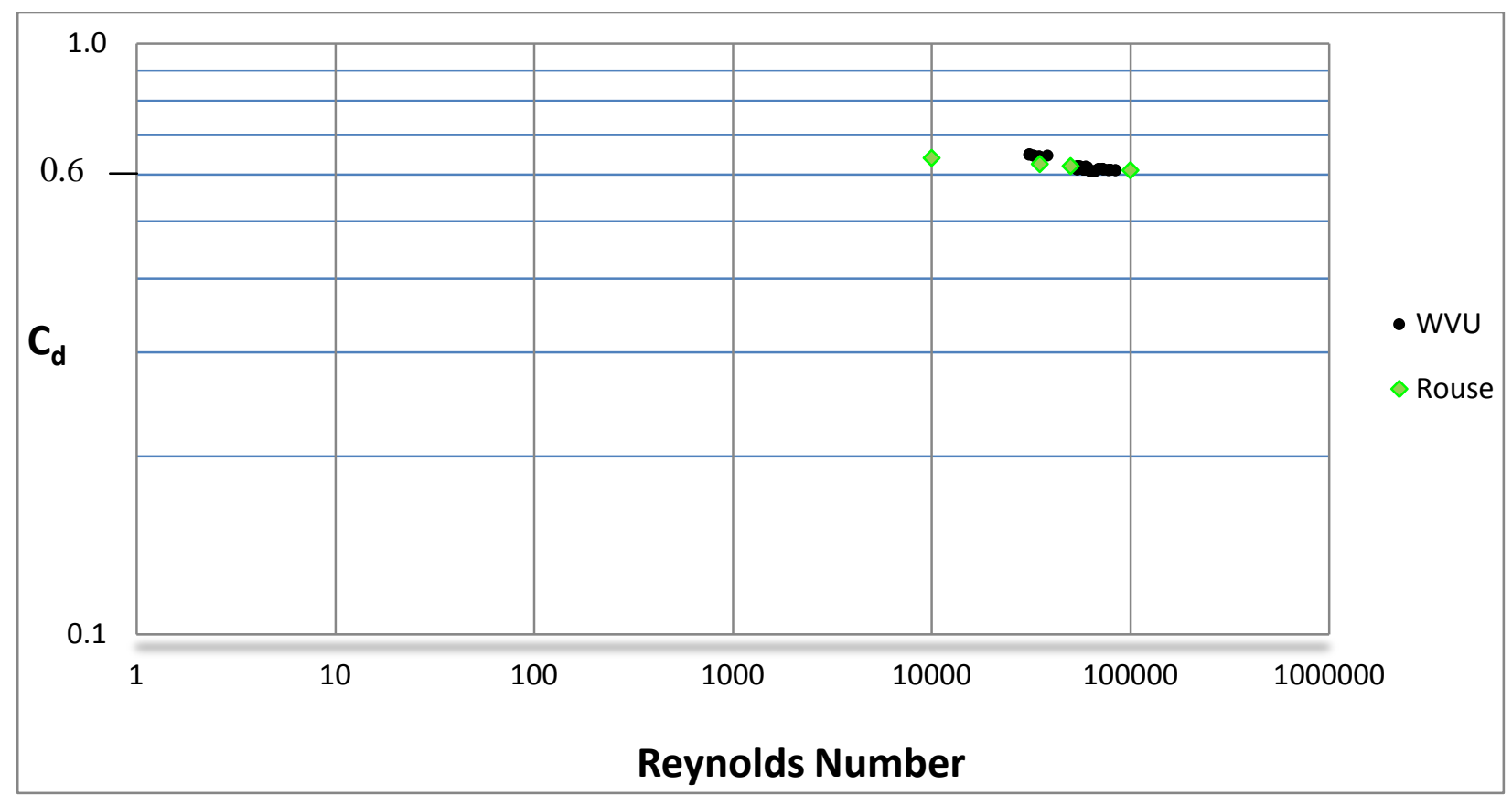

Figure 6-1 Thin plate Orifice (WVU)

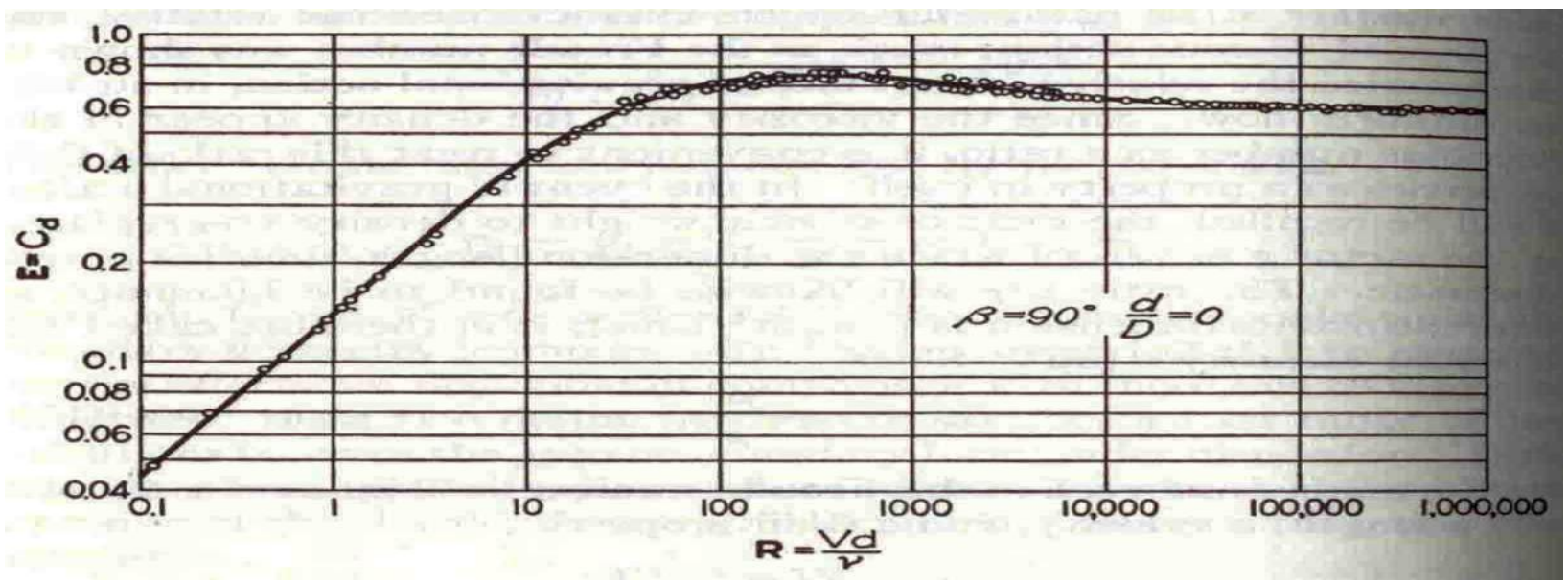

Figure 6-2 Thin plate Orifice (6)

Figures 6-1 and 6-2 show the comparison between Rouse (6) and WVU's experimental results. Based on the range of Reynolds number tested at WVU, the data recorded matches the previous work by Rouse. 


\subsubsection{Square}

The square orifices investigated had side lengths of $3 / 4$ " and 1". These orifice lengths and testing at different head allowed for testing on a range of Reynolds number. Although the range of Reynolds number is small, it provides enough range of discharge coefficient as a function of Reynolds number on one order of magnitude. Figure 6-3 shows a plot of the square discharge coefficients investigated compared against Reynolds number.

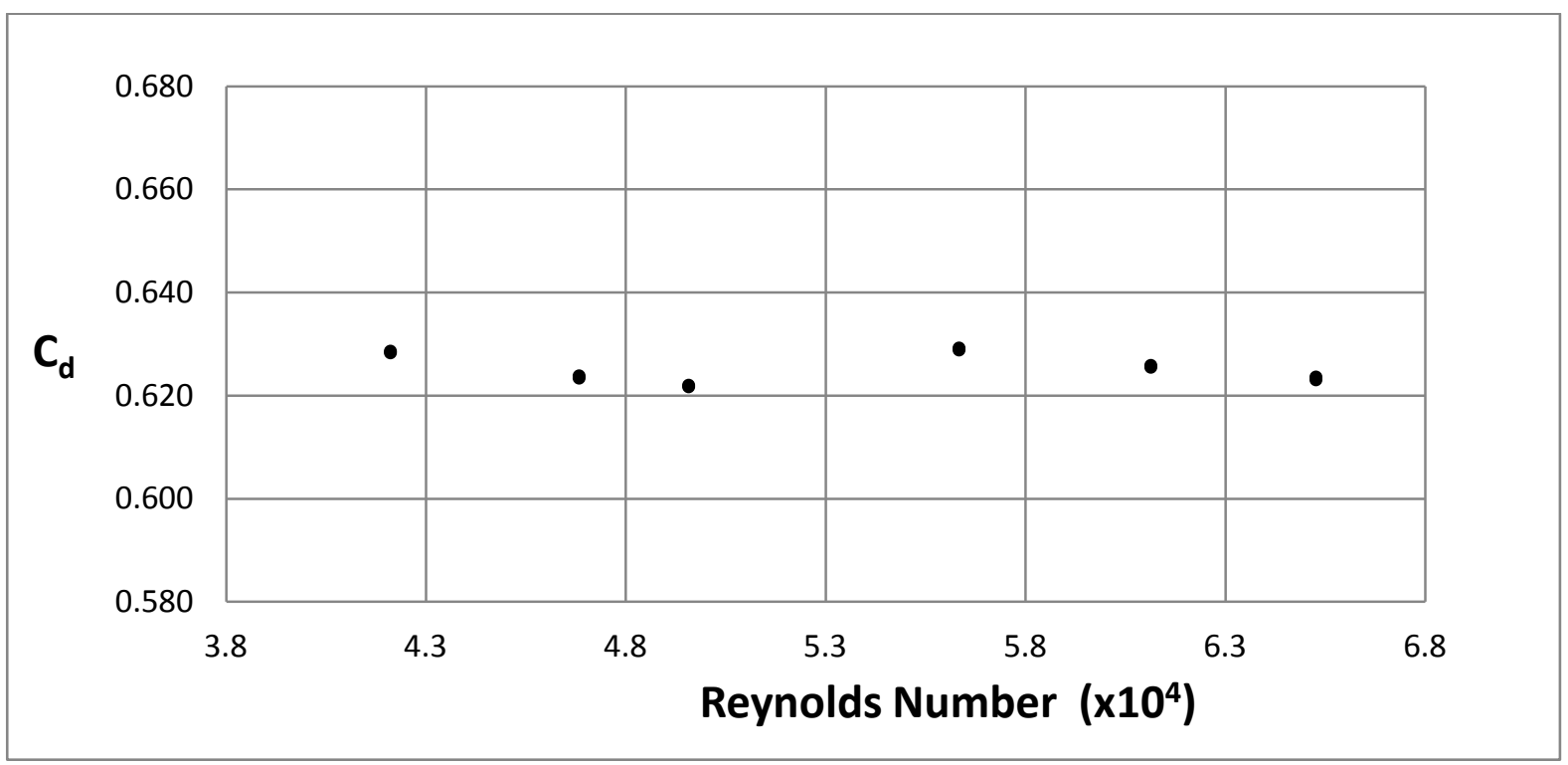

Figure 6-3 Square Discharge Coefficient

It can be seen that the discharge coefficient for the measured square orifice had some variation due to experimental variation for this range of Reynolds number but quite consistent at this scale. Each data point was tested 2-3 times giving the same result and within the uncertainty range. All of the data points were averaged to give $C_{d}=0.625$. 


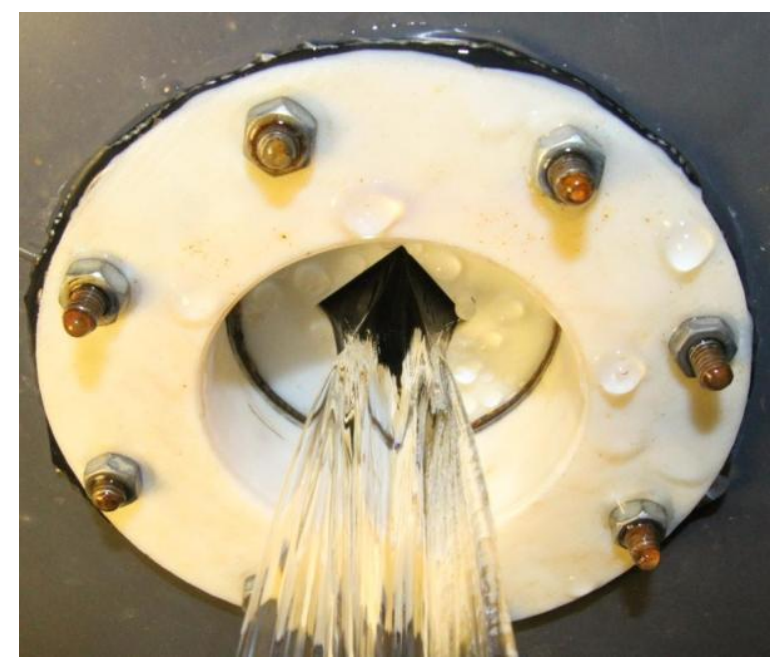

Figure 6-4 Square Orifice Discharge

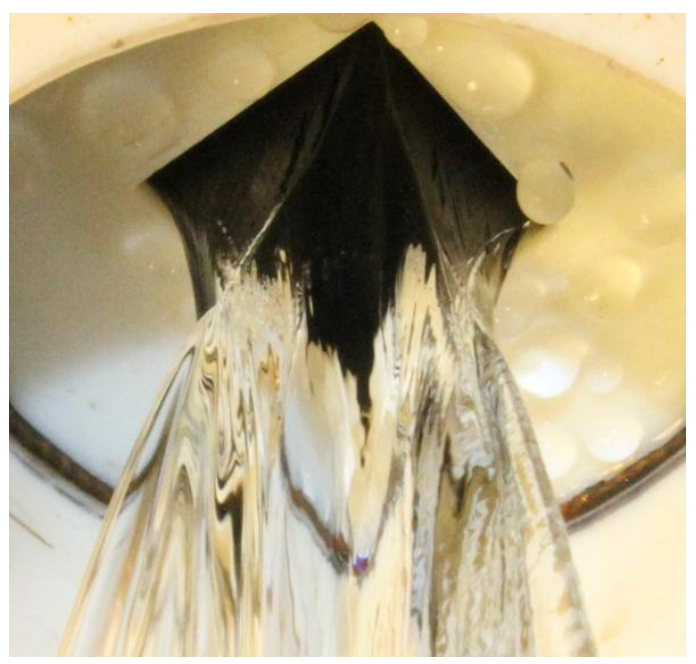

Figure 6-5 Square Orifice Discharge Close Up

The discharge from the square thin plate orifice creates a unique profile as shown in Figs. 6-4 and 6-5. The flow converges from the four sides. Each side merges together and creates a jet that forces the flow axially. This convergent area results in an inversion of the original square profile. This resultant shape is a cross that grows as the fluid falls and slows. Literature states that this inversion phenomenon repeats itself as the discharge falls for laminar flow (3). This experiment shows that the inversion continues to fan out as the flow falls into the collection tank. King (3) states that the inversion goes through four stages and repeats itself as long as wind or air friction is not an interference. These stages can be seen in Figure 6-6. As the flow begins to merge together, the flow profile initially takes the shape of an octagon. Further downstream the flow takes the shape of a cross as the four jets are created axially. The jet then thins creating a thin tee cross section. The short distance to the collection tank may not give the discharge a long enough distance to repeat through this cycle; therefore the repetition of the inversion was not seen within this experiment. 

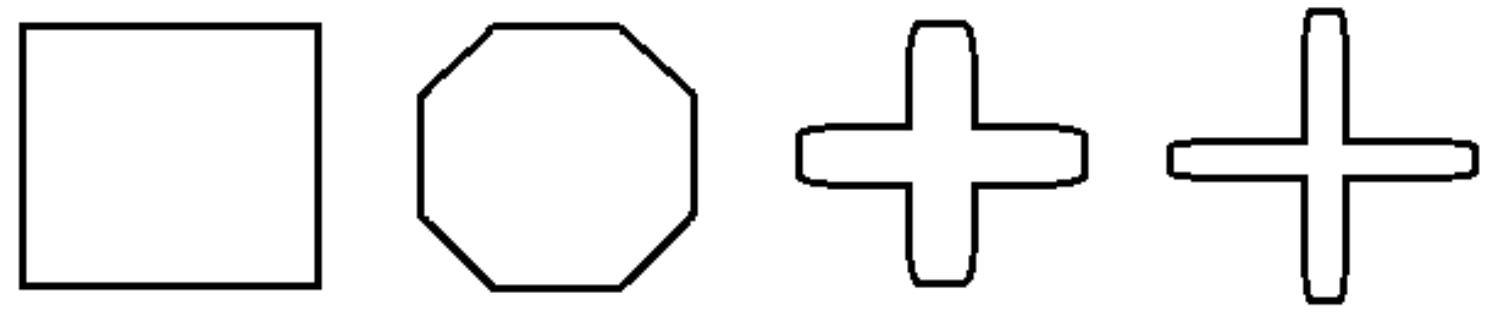

Figure 6-6 Square Inversion Stages Adapted from King (3)

\subsubsection{Elliptical}

The elliptical orifices tested had; the length (2a) of $1 / 2$ ", 1" and 1-1/4". Again, each elliptical orifice was tested at different head heights to create a range of Reynolds number. The elliptical data collected was the most inconsistent of all of the testing investigated as shown in Figure 6-5.

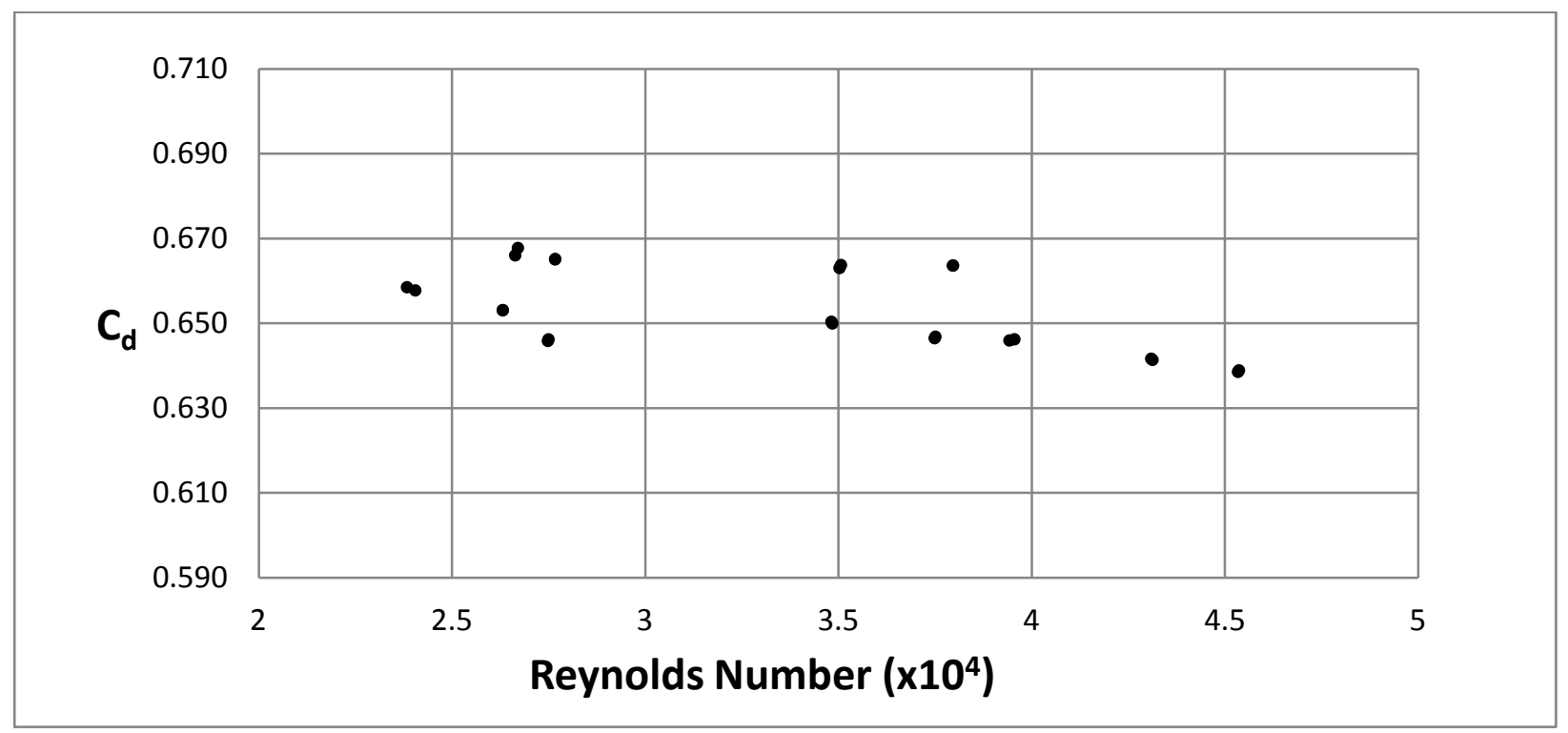

Figure 6-7 Elliptical Discharge Coefficient

It can be seen that there seems to be a trend along this range of Reynolds number. As Reynolds number along this range increases, the discharge coefficient decreases. All of these data points were tested repeatedly. This inconsistency does not allow for a good justification of the discharge coefficient of an ellipse. The characteristic length/diameter in the Reynolds number 
equation for an ellipse was found by using the area of the ellipse. The area of the ellipse was found and then the equivalent circular diameter was found from that area. That equivalent diameter was then used in the Reynolds number equation.

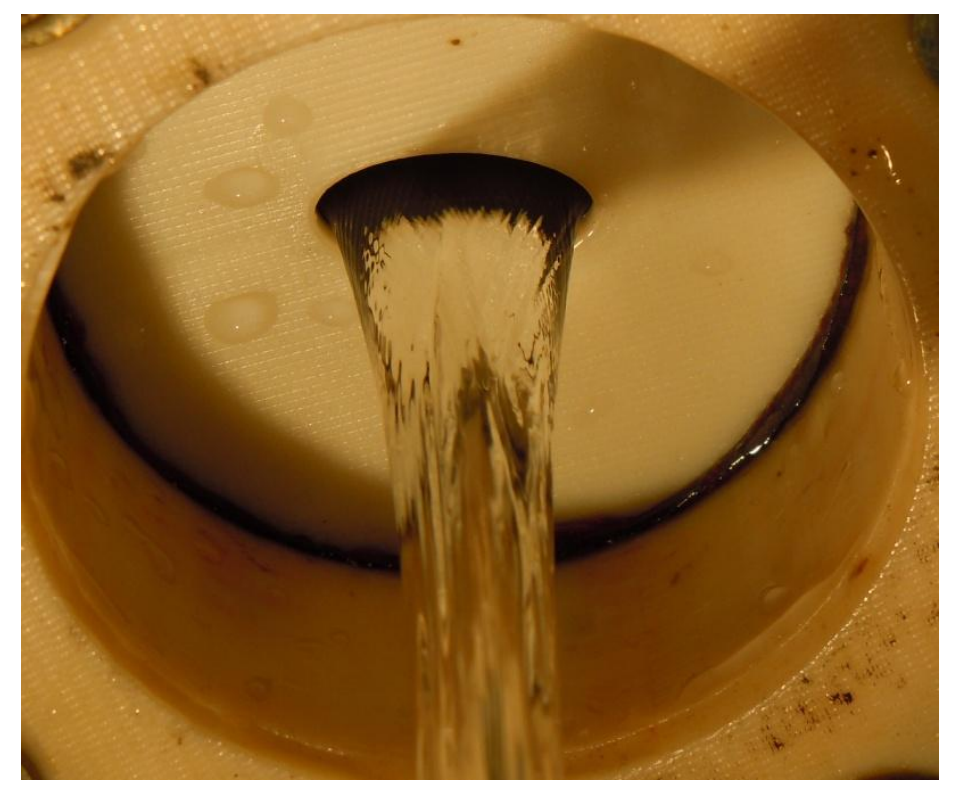

Figure 6-8 Elliptical Orifice

Figure 6-8 shows a picture of the discharge for an elliptical orifice. Mach lines are visible coming from the edges of the orifice. These mach lines are created from the surface roughness from the orifice plate. Two separate 1" elliptical orifices were created, one was kept as is from the printer and the other was sanded down using 320 grit sandpaper. The sanded orifice (can be seen in Figure 6-9) did not have mach lines thus created a smooth discharge. 


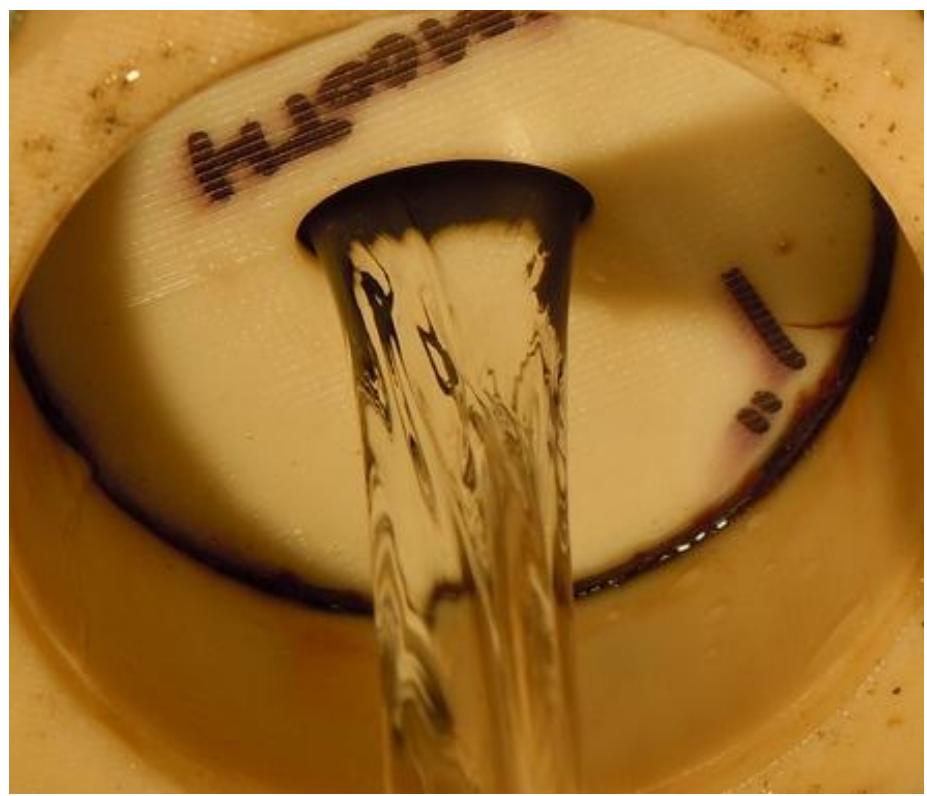

Figure 6-9 Smooth Elliptical Orifice

It was also of interest to see the effect the smooth orifice had on the discharge coefficient. The smooth orifice did not have a considerable effect on the discharge coefficient. The discharge coefficient differences as a function of surface roughness were within the uncertainty realm and are considered negligible.

It is also important to note another parameter that may be influencing the mach lines such as capillary or supercritical waves. Capillary criteria can be calculated by computing for the velocity in which capillary velocity is critical $\left(V_{c r}\right)$ as seen in equation 6-1. If the discharge velocity from the orifice is greater than the critical velocity then the waves could be influenced by the capillary criteria.

$$
V_{c r}=\sin (\phi) \sqrt{\frac{2 \pi \sigma}{\rho \lambda}}
$$


$V_{c r}=1.252 \mathrm{~m} / \mathrm{s}$ which is less than the velocity of the discharge $(V=2.15 \mathrm{~m} / \mathrm{s})$ from the orifice resulting in a possibility for the mach lines seen in Fig.6-8.

\subsubsection{Saw-tooth}

The saw-tooth orifice was created as a saw tooth profile with 15 uniform teeth. Different sizes were created but had the same design ratios. The parameters were increased by a ratio of increase of the outside diameter of the orifice.

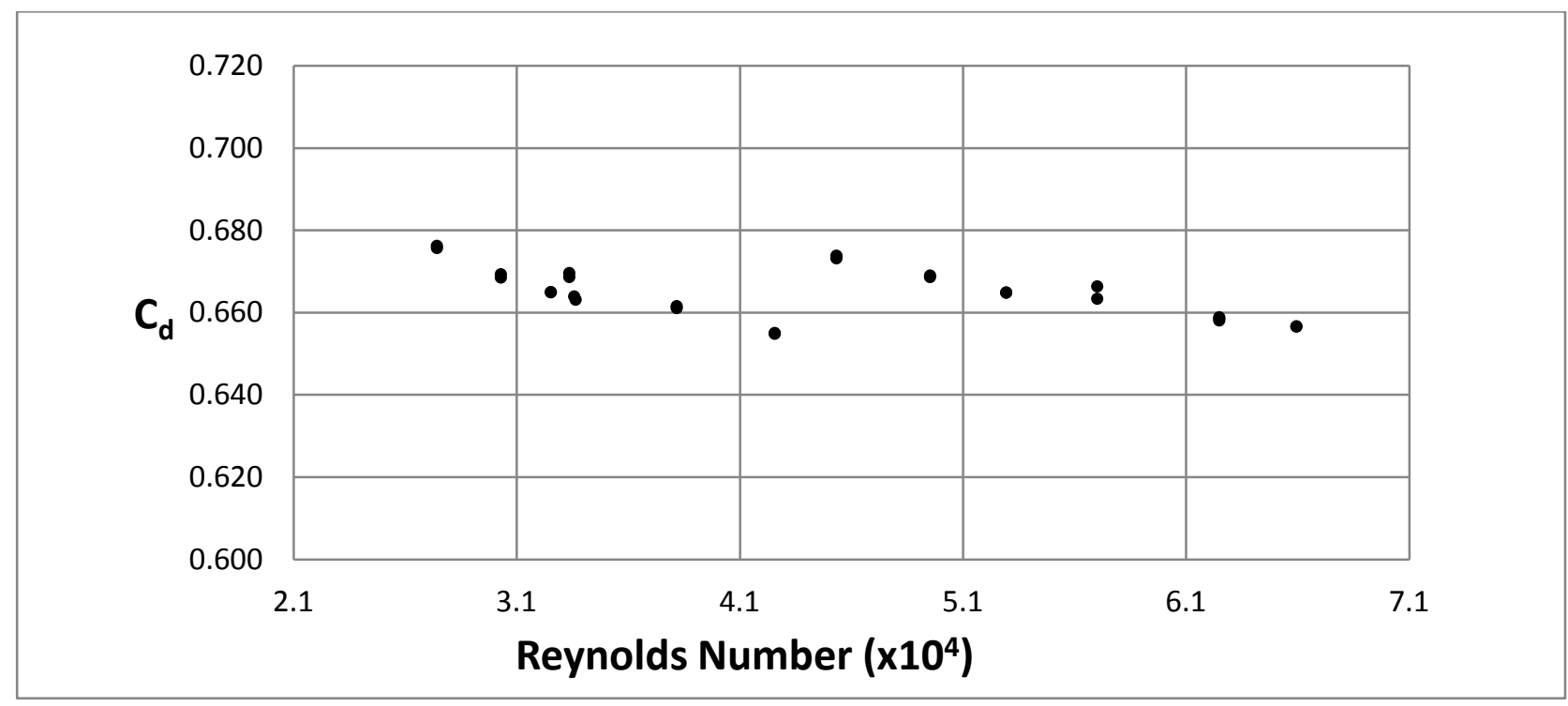

Figure 6-10 Saw-tooth Discharge Coefficient

The saw-tooth profile was studied to further investigate the results from A. Abou El-Azm Aly et al. (7) where it was concluded that fractal-shaped orifices result in lower pressure drop across the orifice plate and thus a higher discharge coefficient compared to a circular orifice of the same area. Although the jagged profiles studied here were different, the current results showed a higher discharge coefficient than that of standard circular orifices of the same area. The experimental data from this discharge testing is shown in Fig. 6-10. In this case, the results agree with the previous study. The Reynolds number was evaluated in the same way as the elliptical 
orifice. The area of the jagged profile was found and an equivalent circular diameter was found for that area. That diameter was then used in the Reynolds number equation. The average $C_{d}$ is 0.665 in this region of Reynolds number. This is a $5.30 \%$ increase more than a thin plate circular orifice discharge coefficient resulting in more flow rate for the same area. Consider a leak in a fluid system with a circular thin plate orifice. The flow rate from the orifice is 100 gallons per minute and it drains a 2,000 gallon tank. This would take 20 minutes to drain. A saw-tooth orifice of the same area would take 19 minutes to drain.

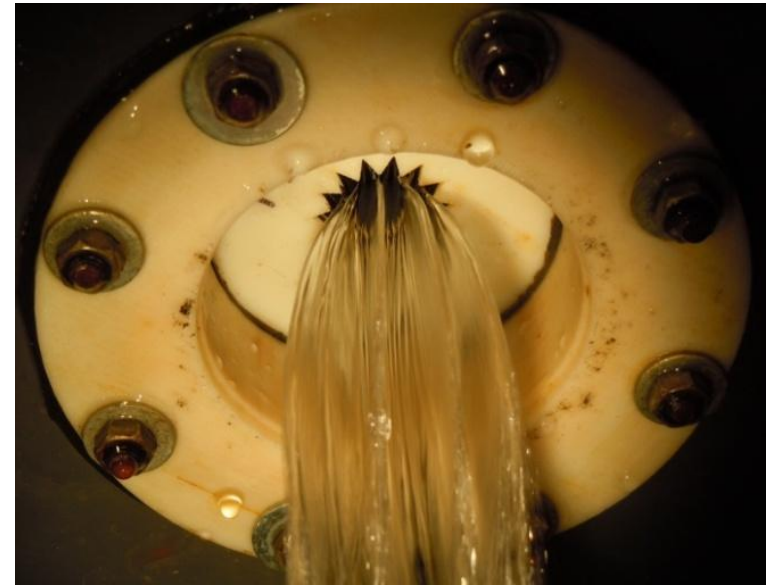

Figure 6-11 Saw-tooth Discharge

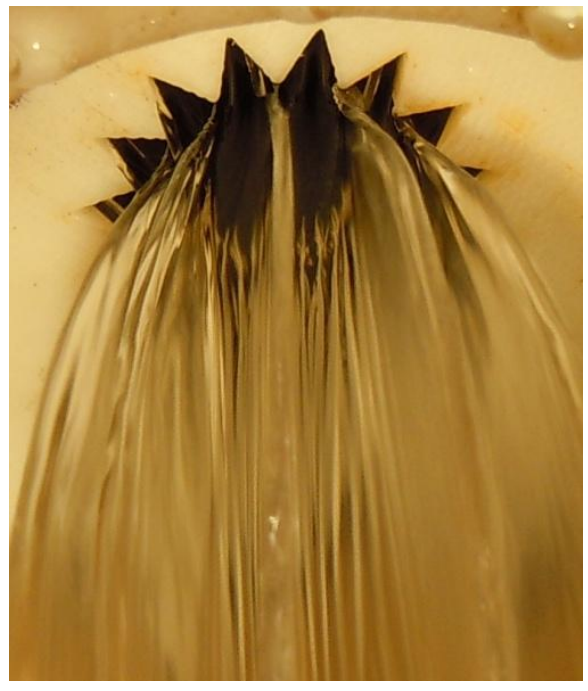

Figure 6-12 Saw-tooth Discharge Up Close

The above photographs (Figs. 6-11 and 6-12) show the jet from the saw-tooth orifice. The teeth from the orifice create notches in the discharge which was from the streamlines passing over the edges of the teeth. As the flow comes together between the teeth; the flow fans out creating a discharge shape that resembles the jagged profile. This creates a void in flow between each of the teeth. This void was intriguing considering the cause of the increased discharge coefficient. It was assumed that the percentage total area decrease created by the teeth would be the same 
percentage increase in discharge coefficient compared to a circular thin plate orifice. This was not the case. The area created by the voided teeth was calculated and the difference in the outside area and the area of the total teeth in void was evaluated and the difference was $14.2 \%$. It is still of question for the reason of the increase discharge coefficient.

The jagged profile created can be seen as initially laminar and transitions to turbulent downstream resulting in drops exiting from the fan. The jet fans immediately from the orifice unlike the circular orifice which converges $\frac{d}{2}$ downstream. The term "fan" means the flow expands axi-symmetric as the discharge travels downstream from the orifice plate. The jagged orifices higher discharge coefficient is ideal for mixing effects downstream as well as creating higher flow rates. Mixing effects could be used for possible applications requiring mixing of fluids.

\subsubsection{Irregular Jagged Thin Plate}

Four irregular orifices were tested with different average interior angles. This was to investigate the effect of the irregular jagged profile angles had on the discharge coefficient.

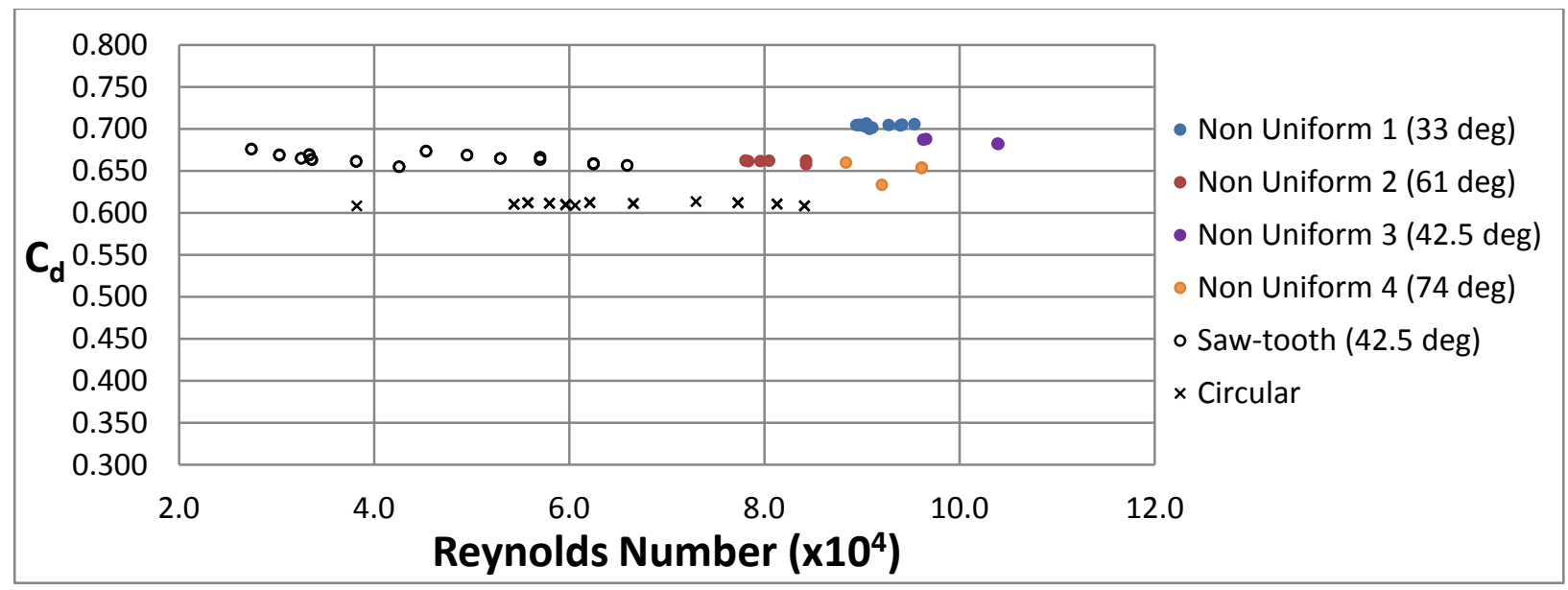

Figure 6-13 Irregular Jagged Comparison 
Figure 6-13 shows the results of these tests at various Reynolds numbers. Results from the sawtooth and circular orifices for are shown for comparison. The circular orifice produced the lowest discharge coefficient values across the Reynolds number domain. The two irregular jagged orifices with the largest average interior angles (orifice \#2 and \#4) resulted in similar discharge coefficients and are similar to the saw-tooth results; all of which are above the circular results. The discharge coefficient is dependent on the area of the orifice. This area difference was of concern so a circular orifice was created that had the same area as irregular orifice \#1. The circular orifice was investigated and the resulting discharge coefficient was the same as the other circular orifices tested. A jagged orifice that had the same area as a circular orifice produced a higher discharge coefficient.

The two irregular orifices with the smallest average interior angles showed a distinct increase in discharge coefficient $\left(\sim 12.5 \%\right.$ increase more than circular orifice) and produced the highest $C_{d}$ values from all of the geometries promoting a higher flow rate and lower pressure drop across the orifice.

The average discharge coefficient values for the irregular jagged orifices are given in Table 6-1. These values can be compared to the average circular orifice discharge coefficient of 0.623 . Flow visualization photographs for each of these orifices are presented in Fig. 6-14. The photographs clearly show regions of the orifice openings that do not have any water flow, similar to the sawtooth geometry. Orifices \#1 and \#3 have the smallest average interior angle and have a higher discharge coefficient. It can be seen that orifice \#2 and \#4 have large average interior angles and have lower discharge coefficients. These lower discharge coefficients are similar to the discharge coefficient found in the saw-tooth orifice discharge coefficient. 
Table 6-1 Irregular Orifice Discharge Coefficients

\begin{tabular}{|c|c|}
\hline Orifice \# & $\boldsymbol{C}_{\boldsymbol{d}}$ \\
\hline 1 & 0.704 \\
\hline 2 & 0.661 \\
\hline 3 & 0.685 \\
\hline 4 & 0.657 \\
\hline
\end{tabular}
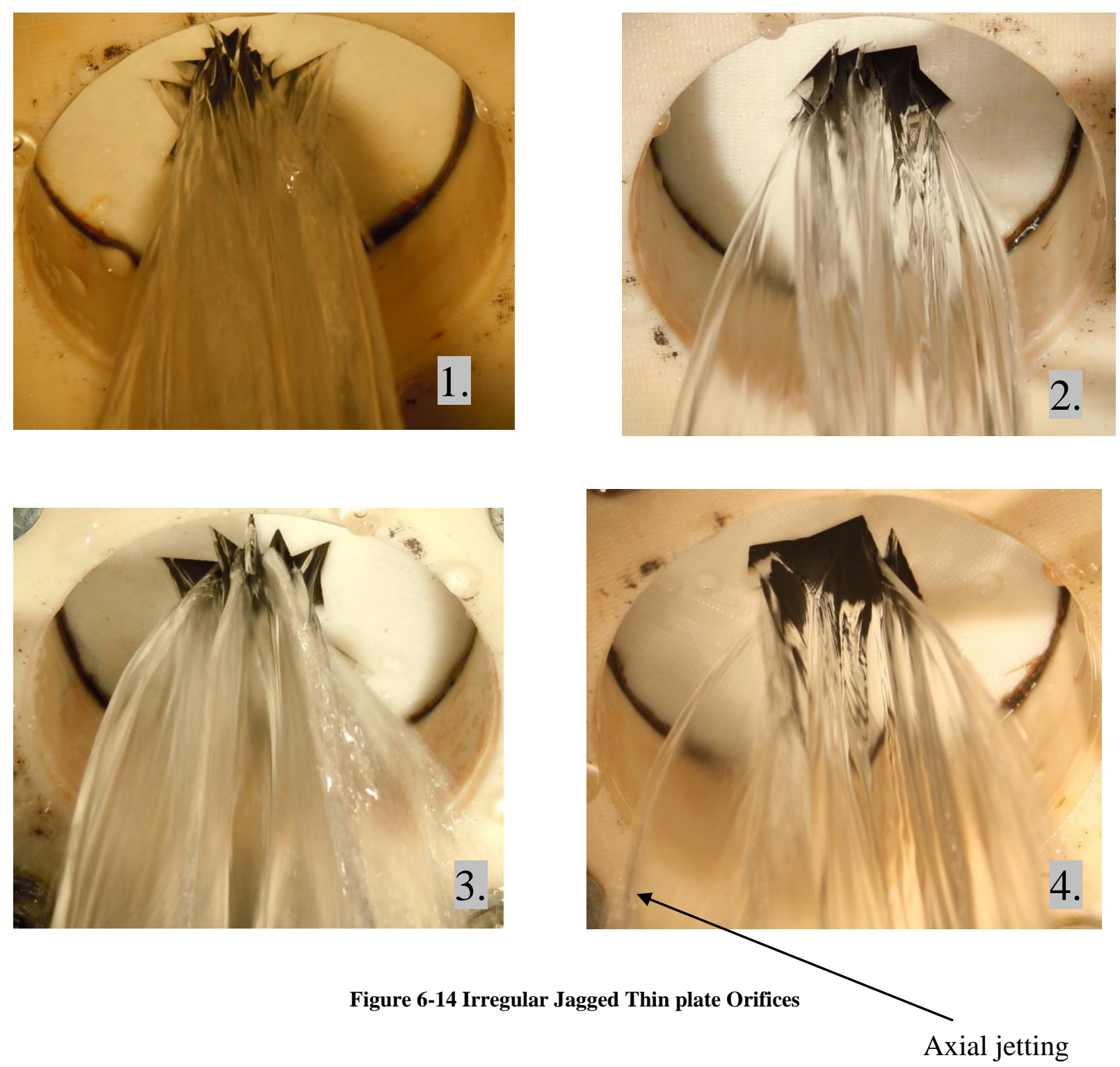
Intuitively, it would seem that the irregular orifice geometries should not produce higher discharge coefficients than, say, the circular orifice, especially with no water flow in regions of the orifice opening. Therefore, questions remain on these discharge coefficients for the irregular shapes. There are two hypotheses that may shed light on the unexpected discharge coefficient of the thin-plate irregular orifices. The first is the effect the axial jetting (see Fig. 6-14) may have on the head height measurement used in calculating the theoretical velocity. From previously discussed results, the head height, $h$, was measured down to the orifice opening. To make use of the Bernoulli equation and assume that the water exits as a "free jet" with pressure equal to atmospheric, the streamlines should be straight. This is generally the case for the standard circular orifice, but from Fig. 6-14, this is clearly not the case for the irregular orifice. Therefore, it was proposed to add the additional head to the discharge coefficient equation downstream when the flow becomes parallel to the vertical axis. This would be where the axial jet reaches its maximum axial expansion and the fluid uniformly begins to flow parallel to the vertical axis. This can be seen in Fig. 6-14. The jetting can be seen for each of the irregular orifices. For each of these orifices, it is unclear from the photographs at what point the axial expansion stops and the streamlines are approximately straight. Therefore these distances were estimated and added to the original head values. The estimated increased head and corrected discharge coefficients $\left(\mathrm{C}_{\mathrm{d} \text {, corrected }}\right)$ can be seen in Table 6-2.

Table 6-2 Axial Head Effects

\begin{tabular}{|c|c|c|c|}
\hline Orifice \# & $\begin{array}{c}\text { Increased } \\
\text { Head }\end{array}$ & $\mathbf{C}_{\mathbf{d} \text {, original }}$ & $\mathbf{C}_{\mathbf{d} \text {, corrected }}$ \\
\hline 1 & $3.5^{\prime \prime}$ & 0.704 & 0.66 \\
\hline 2 & $3.5^{\prime \prime}$ & 0.661 & 0.618 \\
\hline 3 & $2.5^{\prime \prime}$ & 0.685 & 0.654 \\
\hline 4 & $2 "$ & 0.650 & 0.633 \\
\hline
\end{tabular}


The increased head does not affect the discharge coefficient as much as predicted. The original discharge coefficient values are listed in order from highest discharge to lowest (\#1, 3, 2, 4). Increasing the head was predicted to obtain discharge coefficients that were more equal in comparison to each of the irregular orifices. It was also predicted to obtain discharge coefficient values that result more similar to circular discharge coefficients. The estimated head adjustment was not precise and estimated based on the photos taken in Fig. 6-14. This hypothesis will need further testing in the future by obtaining more accurate measurements of when the streamlines become straight after the exit and possibly measuring the discharge velocities downstream to confirm this effect and to characterize such orifices to better understand flows through irregular shaped profiles. The goal behind this approach was to characterize discharge coefficients for irregular orifices based on their axial discharge fanning increasing the head.

Another possible hypothesis is a reduced frictional effect through the generation of a slip velocity. In viewing photographs and video of the water discharge through the irregular shapes, there appeared to be an unsteady swirling of water on the inner side of the orifice in some regions of the opening where no water was exiting. It was speculated that there may be a "water bearing" being developed at some crevices of the irregular shapes. The water bearing would be a type of fixed swirl created above the entrance of the orifice creating a slip velocity allowing the fluid to more easily flow through the irregular orifice. It is unclear in the current experiment to visually check for such a phenomena and would require modifications to the test apparatus to confirm such a case. Future work should include a clear discharge tank to investigate this possibility. 


\subsection{Extruded Orifices}

Extruded orifices in this thesis are tubes and irregular orifices. Tubes are circular orifices that are not pipe flow and not a Thin plate orifice and extruded jagged orifices are a representation of a rupture or hole in a thick wall. This type of extruded irregular orifice is related to another project being conducted at WVU. It was of interest to investigate flow rates in which a rupture may occur and the amount of time it will take a large pipe to fill under a certain head pressure through the ruptured hole or orifice. It was of interest to investigate the effect an extruded orifice had on a irregular profile to relate to this project. This was then to be compared to tube orifices tested in house as well as other tube orifice studies performed by Lichtarowicz et al. (4).

\subsubsection{Tubes}

A tube orifice is a circular cross section orifice that is extruded. The extruded length is related to $l / d$. The length is the length of the extruded orifice and the diameter is the diameter of the orifice. $l / d$ is used as a function to the discharge coefficient $C_{d}=f(l / d)$. It was found by Lichtarowicz et al. (4) that the discharge coefficient peaks at $(l / d=2)$. It was of interest to see how a tube orifice behaved discharging into the open atmosphere in comparison with Lichtarowicz et al. (4) in pipe flow. 


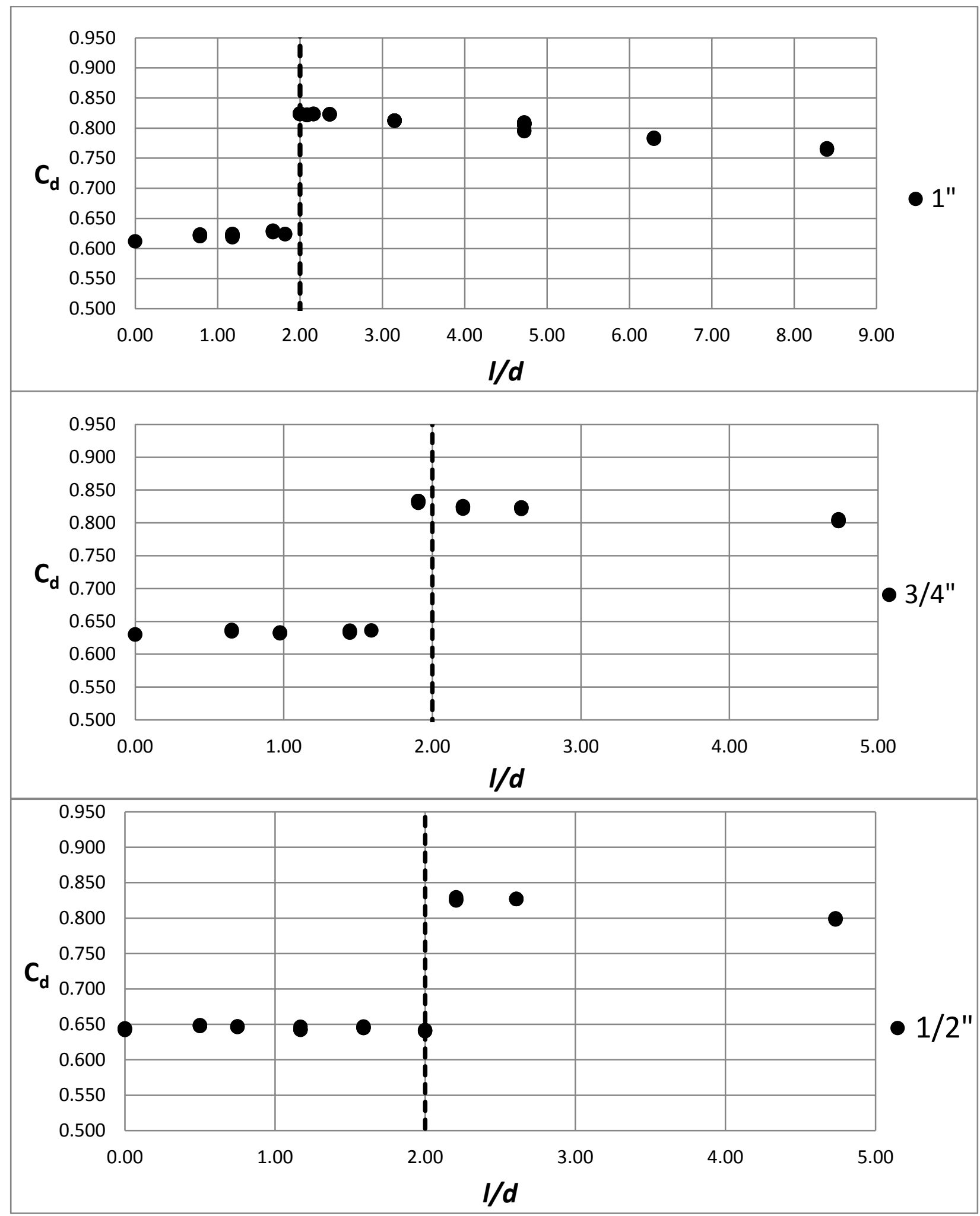

Figure 6-15 Tube Orifice Discharge Coefficients for 1", 3/4" and 1/2" Diameters 
Figure 6-15 shows testing for tube orifices of $1 \frac{1}{2} ", 3 / 4$ " and 1 " diameters. This plot shows that for each of the orifices there is a distinct jump at 2 diameters.

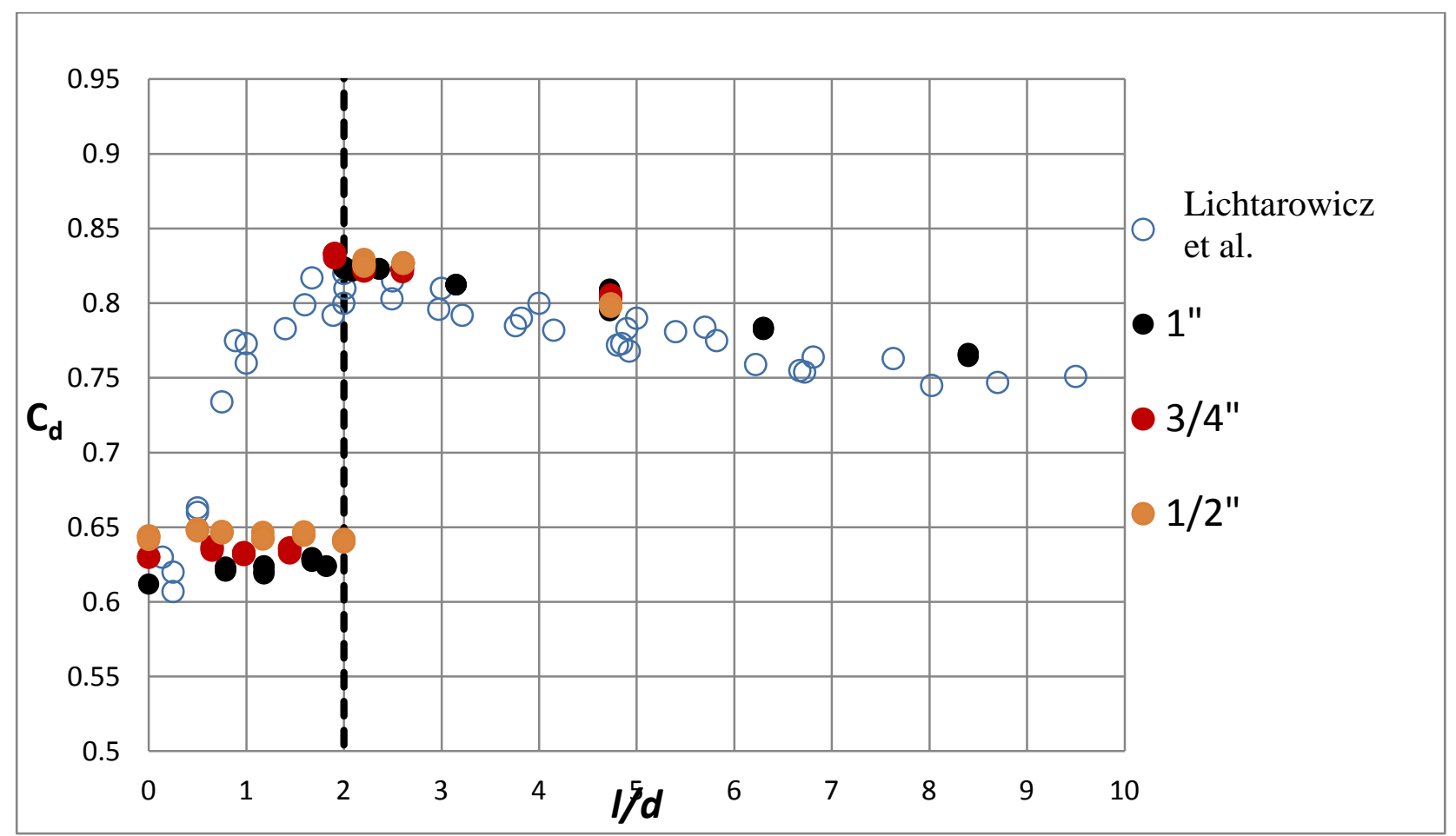

Figure 6-16 Discharge Coefficients for Tube Orifice Geometries as a Function of $l / d$

Figure 6-16 Discharge Coefficients for Tube Orifice shows the discharge coefficient of tubes as a function of the ratio $l / d$. Three tube diameters were tested along a range of $l / d$ ratios from 0.79 to 8.4. Diameters used were $d=1 / 2 ", 3 / 4 "$ and 1". As shown in Table 6-2, the discharge coefficient was slightly different between $1 / 2$ " and 1 " diameter circular thin plate orifices - the $l / d=0$ data location. $l / d=0$ is considered a Thin plate orifice.

Table 6-3 Circular Thin plate Orifice $l / d=0$

\begin{tabular}{|c|c|}
\hline Diameter & $\mathbf{C}_{\boldsymbol{d}}$ \\
\hline $1 / 2^{\prime \prime}$ & 0.64 \\
\hline $3 / 4^{\prime \prime}$ & 0.63 \\
\hline $1 "$ & 0.61 \\
\hline
\end{tabular}


Lichtarowicz et al. (4) data was also included in Figure 6-16. The two experiments were different in the sense that (4) tested tube orifices in a pipe as a metering device. The current experiment was also a tube orifice, but the exit was a free jet into the open atmosphere. This comparison showed that the results were quite different for $l / d$ values ranging from approximately 0.1 to 2.0 . Lichtarowicz et al. (4) experiments consisted of $1 / 2$ " diameter tubes in pipe flow using orifice plates measuring up and downstream pressures. The results showed that for the pipe flow study, there was an interaction with the downstream flow and the tube wall attachment creating a steady rise in discharge coefficient between $l / d$ from 0.0 to 2.0. The open atmosphere jet was quite different; it is seen that this $l / d$ range behaves like a standard thin plate orifice until two diameters in length. The discharge coefficient held fairly constant until an abrupt transition occurred. Figure 6-17 shows the discharge before wall attachment. The transition was drastic at two diameters where the flow attaches, with approximately a $24 \%$ jump in the discharge coefficient. The flow area changed due to the change in velocity; as the velocity decreased downstream, the area of the jet increased due to the venturi effect. Figure 6-18 shows tube discharge after wall attachment occurs. 


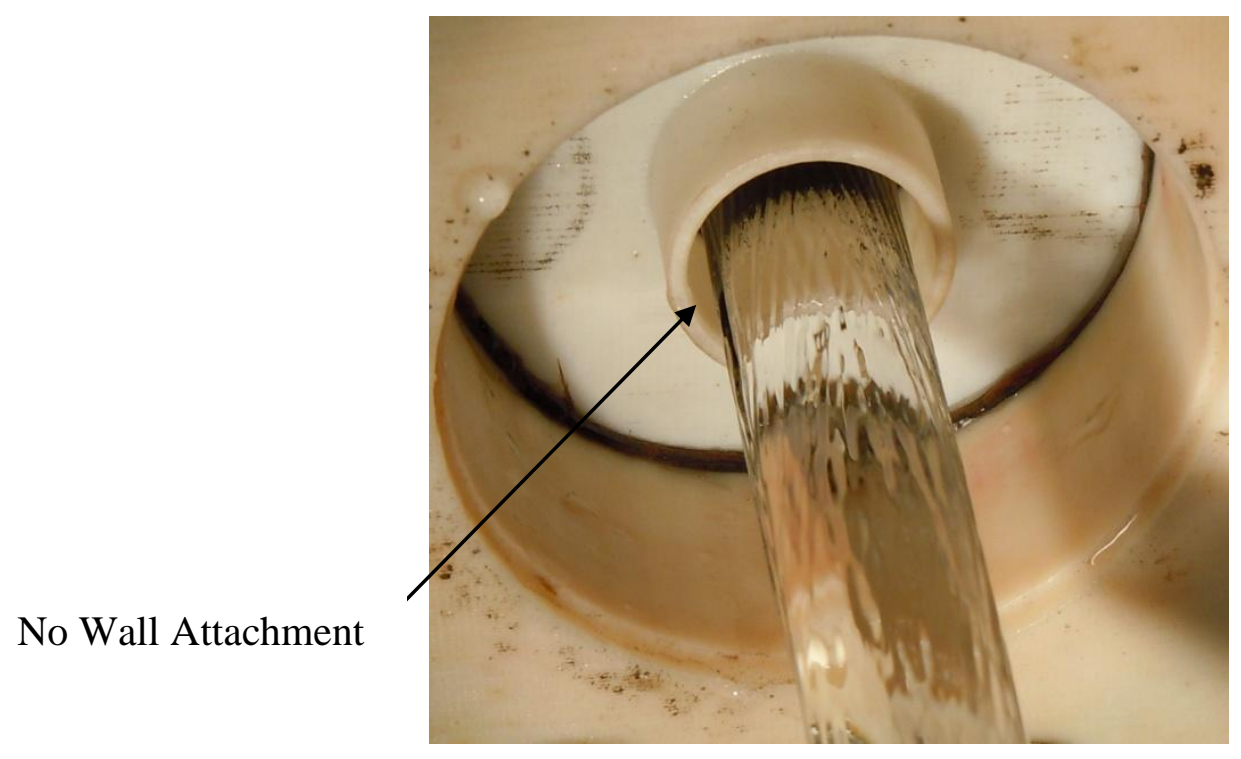

Figure 6-17 Tube Orifice with $1 / d<2.0$ Which Gives Exit before Attachment

Wall Attachment

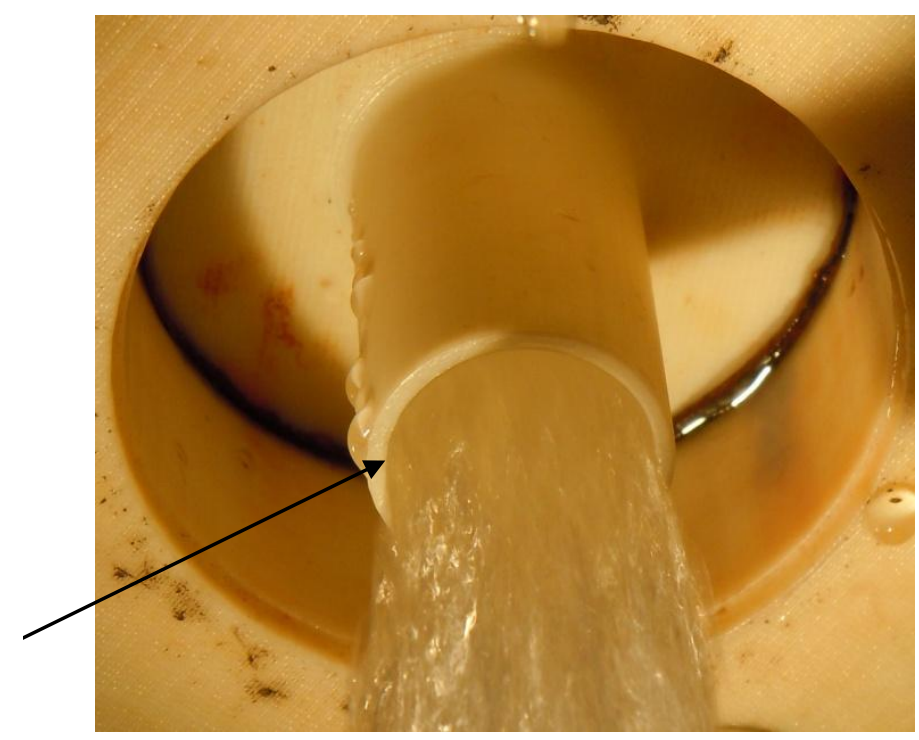

Figure 6-18 Tube Orifice with 1/d > 2.0 Which Places Exit After Attachment 
Figure 6-16 showed that it takes the jet two diameters to reach full wall attachment. For $l / d$ values in the range of 2.0 to 10.0 , the behavior was the same between the two experiments and the discharge coefficient steadily decreases.

It is important to discuss the pressure head in relation to $l / d$. Since there is no wall attachment until two diameters, the length of the orifice did not affect the pressure head. However, once attachment occurred, the length of the orifice must be factored into the head pressure. In this case, a "for loop" was used in the data processing to account for head pressure after 2 diameters. The "for loop" was used in the processing which searched for data that was tested before and after 2 diameters. If it found the tube was less than 2 diameters long, it would calculate the discharge coefficient as a thin plate orifice and use only the head pressure above the orifice entrance. If it determined the orifice was more than 2 diameters, it would add the length of the extruded orifice to the head pressure.

\subsubsection{Irregular Jagged Extruded}

Extruded irregular orifices were of interest to relate to a more natural rupture that could occur in fluid systems. Thin plate irregular profiles were extruded such as the tube orifices to compare discharge coefficient values as a function of $l / d$. 


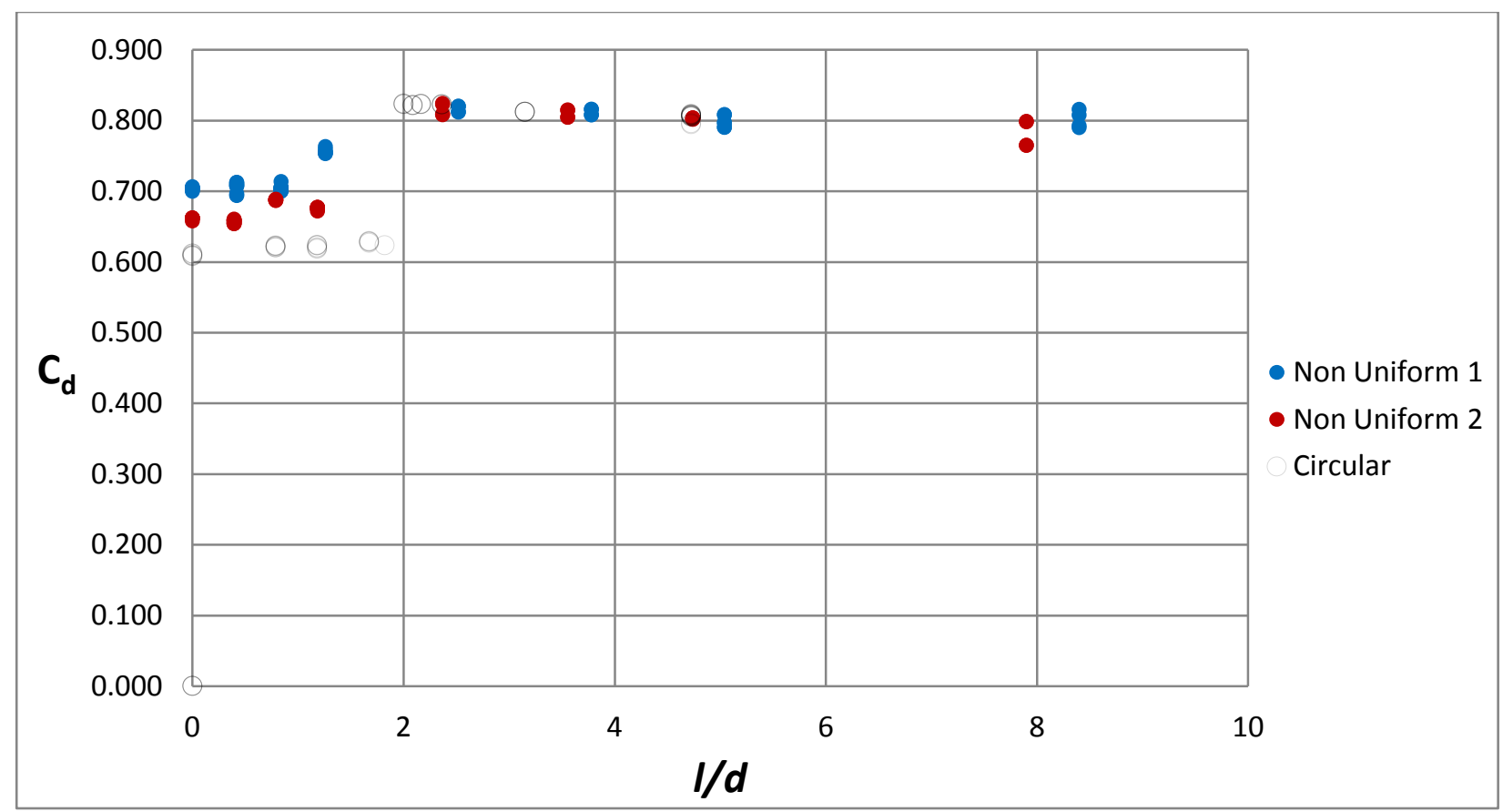

Figure 6-19 Discharge Coefficients for Extruded Irregular Jagged Orifices with Varying l/d Ratios

Two of the irregular jagged geometries were selected to extrude into irregular tube geometries to investigate the discharge coefficient characteristics. Figure 6-19 shows the relationship between the extruded irregular orifice \#1 and \#2 and the circular tube orifices discussed earlier. The numbering format is the same as used as the thin plate irregular orifices. The irregular orifices peaked at two diameters as seen in the circular tubes. There is a difference however; the irregular orifices transition to turbulent immediately at the entrance which triggers initial wall attachment. Figure 6-20 shows the turbulence discharging from the extruded irregular orifices. This attachment results in a different transition as the discharge coefficient approaches 2 diameters. It looks as if there is a constant discharge coefficient at low $l / d$ values until a jump. The low $l / d$ values are not consistent enough to say for sure how this transition occurs in this experiment. One possible explanation is that the irregular geometry is causing an earlier transition to turbulence, though this study did not produce conclusive data to support this idea. Although, after two diameters; the irregular orifices closely matched tube orifices as they reached a 
converged value. It is important to note the method to find the $l / d$ values used in Fig. 6-20 and Fig. 6-21 for the irregular orifices. The hydraulic diameter was approached in the same manner as for the thin plate irregular orifices; the area was found in CAD and substituted directly into the discharge coefficient equation. An effective diameter was then extracted from the area value found in $\mathrm{CAD}$ using the area of a circle equation. That diameter was then used in calculating the $l / d$ values. In addition, as before, the length of the orifice was added into the head height used in the discharge coefficient equation to account for the added height.

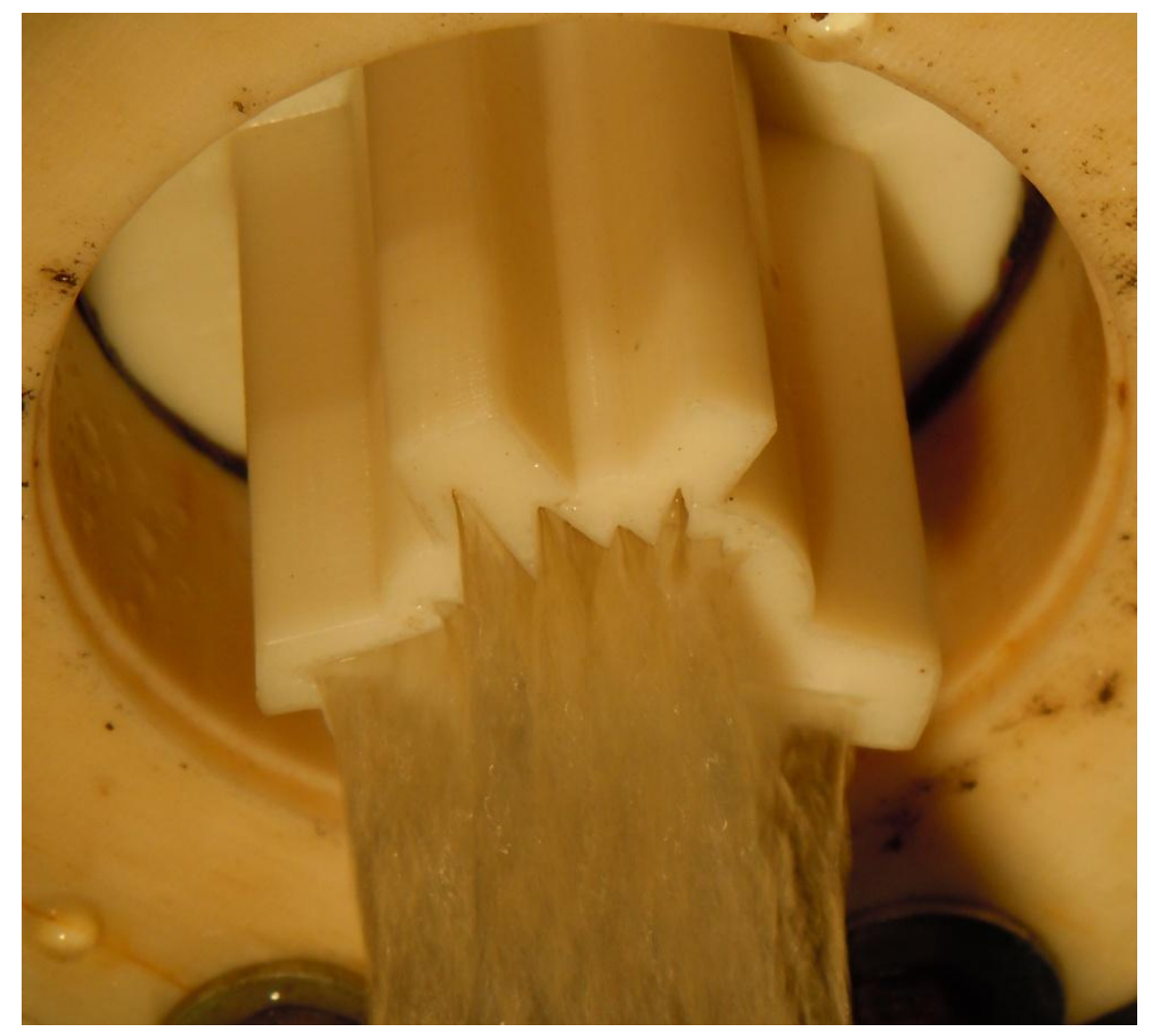

Figure 6-20 Flow From Irregular Extruded Orifice\#1 


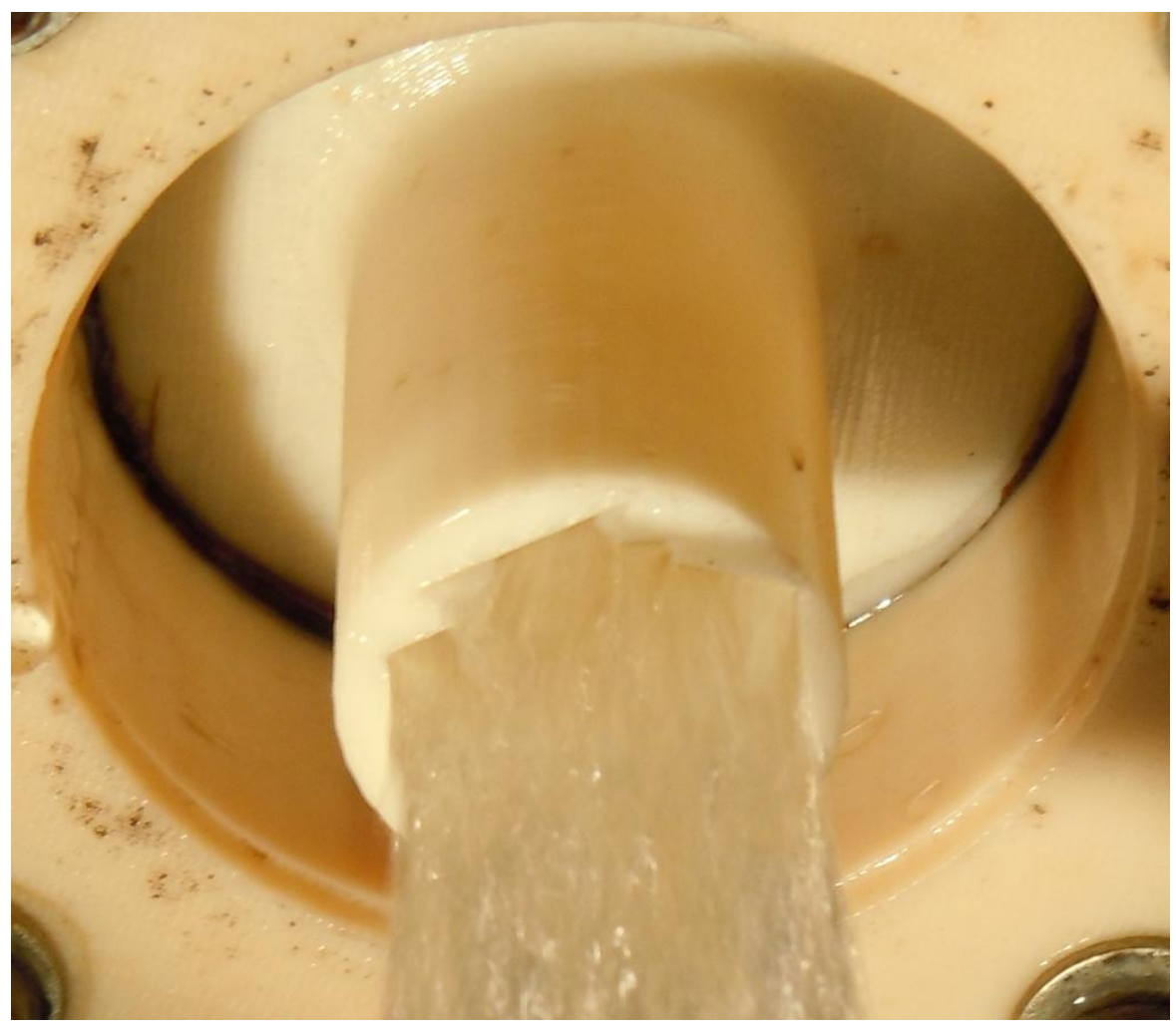

Figure 6-21 Flow From Irregular Extruded Orifice\#2 


\section{Chapter 7 Conclusions of Study and Recommendations for Future Work}

\subsection{Tube}

A standard short tube has been classified as a tube with a length of 2.5 diameters by King (3). It is shown from the results found that there is attachment before $2.5 d$. The jet attaches at $2 d$. It is assumed that the differences between $2.0 \mathrm{~d}$ and $2.5 \mathrm{~d}$ are used to make up for the application uncertainty. Lichtarowicz (4) confirms that the discharge coefficient peaks at $l / d \sim 2$. The difference is in WVU's experiment as a free jet into the open atmosphere vs. Lichtarowicz (4) in pipe flow. The downstream fluid must be influencing the discharge from the orifice causing intermediate attachment before $2 d$. There is a distinct difference in the flow between WVU and Lichtarowicz et al.(4) apparatus. Pipe flow orifices are different because there is flow interaction with downstream flow with the discharge from the orifice. This creates an interaction in tube flow causing the discharge coefficient to rise in the $l / d[0: 2]$ regime. This is assumed to be an intermediate attachment where the $l$ must be included in the discharge coefficient equation for $l / d$ $[0: 10]$.

It can be seen above that free jet into the atmosphere acts as a thin plate orifice from $l / d[0: 2]$ and then the fluid attaches to the tube walls as anticipated. Once the attachment occurs, a turbulent fluid structure is formed. It is assumed that there is no attachment before $2 d$; therefore the head pressure used in the discharge coefficient is an issue. The length of the tube must be added to the head pressure after $2 d$. Before $2 d$ the tube length is neglected since there is no attachment. The code used to process the collected data included a conditional statement that included the extra head pressure after $2 d$. Equation $7-1$ is the discharge coefficient used before there is wall attachment. Equation 7-2 is the discharge coefficient equation used after wall attachment has occurred and the length of the orifice is added to the head pressure. 


$$
\begin{aligned}
C_{d} & =\frac{\dot{m}}{\rho A \sqrt{2 g h}} \\
C_{d} & =\frac{\dot{m}}{\rho A \sqrt{2 g(h+l)}}
\end{aligned}
$$

\subsection{Irregular Thin Plate Orifices}

The study from A. Abou El-Azm Aly et al. (7) helped with the evaluation of irregular orifice profile discharge coefficients. There results concluded that fractal shaped orifices produced a lower pressure drop between up and downstream of the orifice plate in pipe flow. This result concludes that there should be a higher discharge coefficient on fractal shaped orifices resulting in a higher flow rate than a circular orifice of the exact area. Four irregular shapes were created in the ABS printer at WVU and tested for a small range of Reynolds number. The result was conclusive with the previous study and a higher discharge coefficient was determined. The four orifices were classified by their average interior angle. The smaller the average angle, the more radical in profile, resulted in a higher discharge coefficient.

Two hypotheses have been formed to better understand the increased discharge coefficients for irregular thin plate orifices. The first is the advanced head created by the axial jetting expansion downstream from the orifice. Estimating the axial jetting is to be determined with future testing. Measuring the distance downstream where the axial jetting ceases and transitions to a uniform vertical flow will allow a better understanding of this hypothesis.

It is also assumed that there may be some kind of a water bearing above the orifice creating a slip velocity causing the higher discharge coefficient. There is no proof that this is actually 
happening. Future testing recommendations include building a new apparatus that is able to view above the orifice to visibly check for this water bearing. It would be important to check to make sure the same discharge coefficients can be obtained to confirm results.

\subsection{Irregular Extruded Orifices}

It can be seen that irregular extruded orifices behave similarly to tube orifices after two diameters in length. The difference is the region from $l / d[0: 2]$ where the discharge coefficient rises with $l / d$ and peaks at $l / d \sim 2$. This is due to initial turbulence effects as the fluid exits the mouth of the orifice triggering wall attachment. It can be seen that for $l / d[0: 2]$, the discharge coefficient varies. Sharp edge irregular $l / d=0$ can be estimated for the orifices average interior angle. The intermediate range from [0:2] can be predicted to rise with $l / d$ but this transition is not completely understood. Those orifices can be assumed to behave like a circular tube orifice after $l / d \sim 2$. It is important to note that in the range of $l / d[0: 2]$ the entire area is calculated into the discharge coefficient, although the entire area is not wetted by the jet in the thin plate orifice. Although the entire area is not wetted, a higher discharge coefficient is found in comparison to a circular orifice of the same area. This effect is intermittent because the flow will attach and then break away and create a void in the flow and is not constant. The void will fill and then detach periodically in the range $l / d$ [0:2]. It is uncertain how this affects the discharge coefficient since the tests have been repeated and the results are consistent for different $l / d$ in this regime.

$1 / d$ [2:10] wets the entire perimeter of the orifice and does not create voids. Once this $l / d \sim 2$ has been reached, the discharge coefficient behaves as a tube orifice. It is seen in Figure 6-19 the discharge coefficient as a function of $l / d$ for irregular Jagged Extruded orifices. The discharge coefficient rises slightly until $l / d \sim 2$. 
It is important to note that since the discharge coefficient rises in the regime $l / d[0: 2]$ and that there is wall attachment. Although the attachment is not consistent, this requires the length of the orifice $l$ to be added to the head height in the discharge coefficient during data processing.

Future work for this study includes an irregular profile that is inconsistent as the orifice is extruded. It is important to create an orifice that would have a uniform area profile along the extrusion. The extrusion is recommended to have a twist with uniform profile area. This is to begin to compare to actual ruptures or cracks that may occur.

Another study is to add roughness to the extruded orifice to trigger turbulence such as bumps or ridges in the profile along the extrusion. These tests could confirm that after $l / d \sim 2$ that all orifices/tubes of any profile shape behave the same as a tube orifice after $l / d \sim 2$. Also, it is important to investigate the action above the orifice plate. It is uncertain how the entrance region is behaving. As stated before, a clear test tank section would make this entrance region visible to investigate the entrance behavior. 


\section{References}

1. Franzini, Joeseph B and Finnemore, E. John. Fluid Mechanics with Engineering Applications. Boston : McGraw Hill, 1997.

2. USBR Corporation. Chapter 2- Basic Concepts Related to Flowing Water and Measurement.

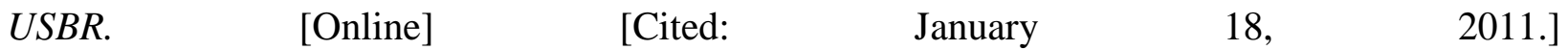
http://www.usbr.gov/pmts/hydraulics_lab/pubs/wmm/chap02_08.html.

3. King, Horace W., Wisler, Chester O. and Woodburn, James G. Hydraulics. London : John Wiley \& Sons, Inc., 1948.

4. Discharge Coefficents for Incompressible Non-Caviating Flow Through Long Orifices. Lichtarowicz, Duggins, Markland. 1965, Mechanical Engineering Science, pp. 210-218.

5. Discharge Characteristics of Sharp-Crested Circular Side Orifices in Open Channels. A, Hussain, Z, Ahmad and G.L., Asawa. 2010, Flow Measurement and Instrumentation 21, pp. 418-424.

6. Rouse, Hunter. Elementary Mechanics of Fluids. New York : Dover Publications, Inc., 1978.

7. Experimental Study of the Pressure Drop after Fractal-Shaped Orifices in a Turbulent Flow Pipe. A. Abou El-Azm Aly, A. Chong, F. Nicolleau, and S. Beck. s.l. : World Academy of Science, Engineering and Technology, 2008, World Academy of Science, Engineering and Technology .

8. wikimedia. Borda-Carnot Equation. [Online] 2011. [Cited: May 5, 2011.] http://reference.findtarget.com/search/Borda\%E2\%80\%93Carnot\%20equation/. 
9. Equivalent Diameter. The Engineering Toolbox. [Online] [Cited: November 22, 2011.] http://www.engineeringtoolbox.com/equivalent-diameter-d_205.html.

10. Orifice Specifications. Wyatt Engineering. [Online] [Cited: November 22, 2011.] http://www.wyattflow.com/products/orifice/optb_03.htm.

11. Evans, Harry B. Frontinus Biography. Bookrags. [Online] 2005-2006. [Cited: January 18, 2011.] http://www.bookrags.com/biography/frontius-dlb/.

12. Schoder, Ernest. W. and Dawson, Francis M. Hydraulics. New York and London : McGraw-Hill Book Company, Inc., 1934.

13. engineeringtoolbox. equivalent diameter. engineeringtoolbox.com. [Online] [Cited: October 4, 2011.] http://www.engineeringtoolbox.com/equivalent-diameter-d_205.html.

14. The Measurement and Effects of Edge Sharpness on the Flow Coefficients of Standard Orifices. Crockett, K.A. and Upp, E.L. 1, New York, NY : The American Society of Mechanical Engineers, 1973, Vol. 95. 


\section{Appendix-A Hydraulic Diameter vs. Area}
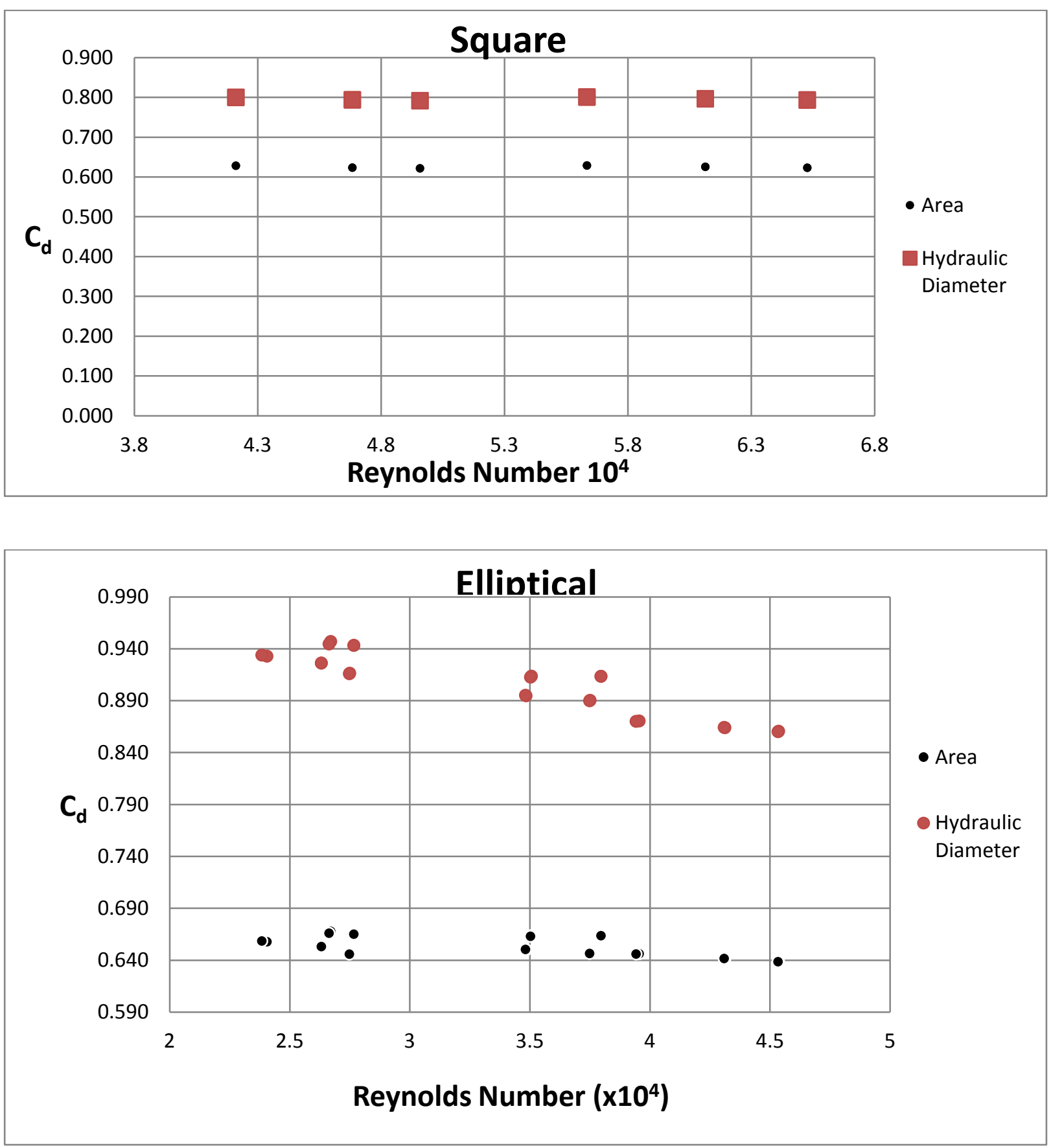


\section{Appendix- B Scale Documentation}

\section{DEFENDER ${ }^{\mathrm{TM}} 3000$}

The best selling modular scale for basic industrial needs

Defender 3000 Series Bench Scales are easy to use, reliable and affordable scales that are ideal for general weighing and simple counting applications in production, packaging, and shipping and receiving areas

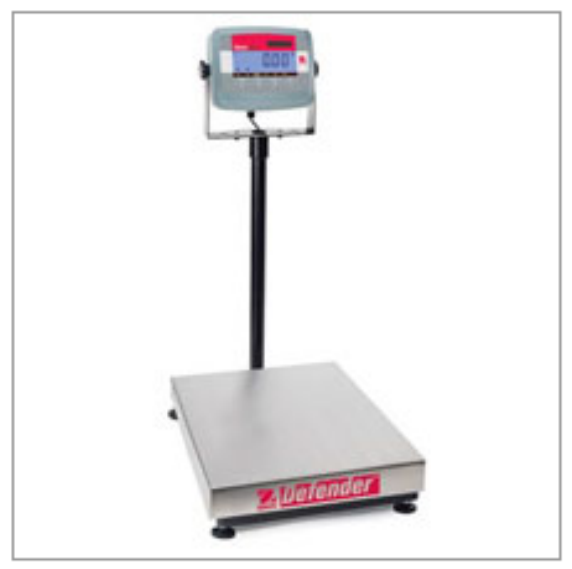

Additional Models:

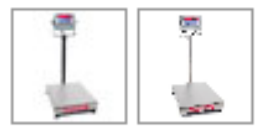

- Sturdy tubular platform design with high quality 304 stainless steel top plate

- Approved models

- Internal rechargeable battery

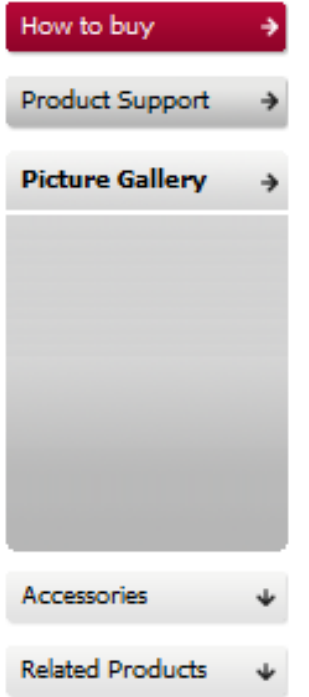

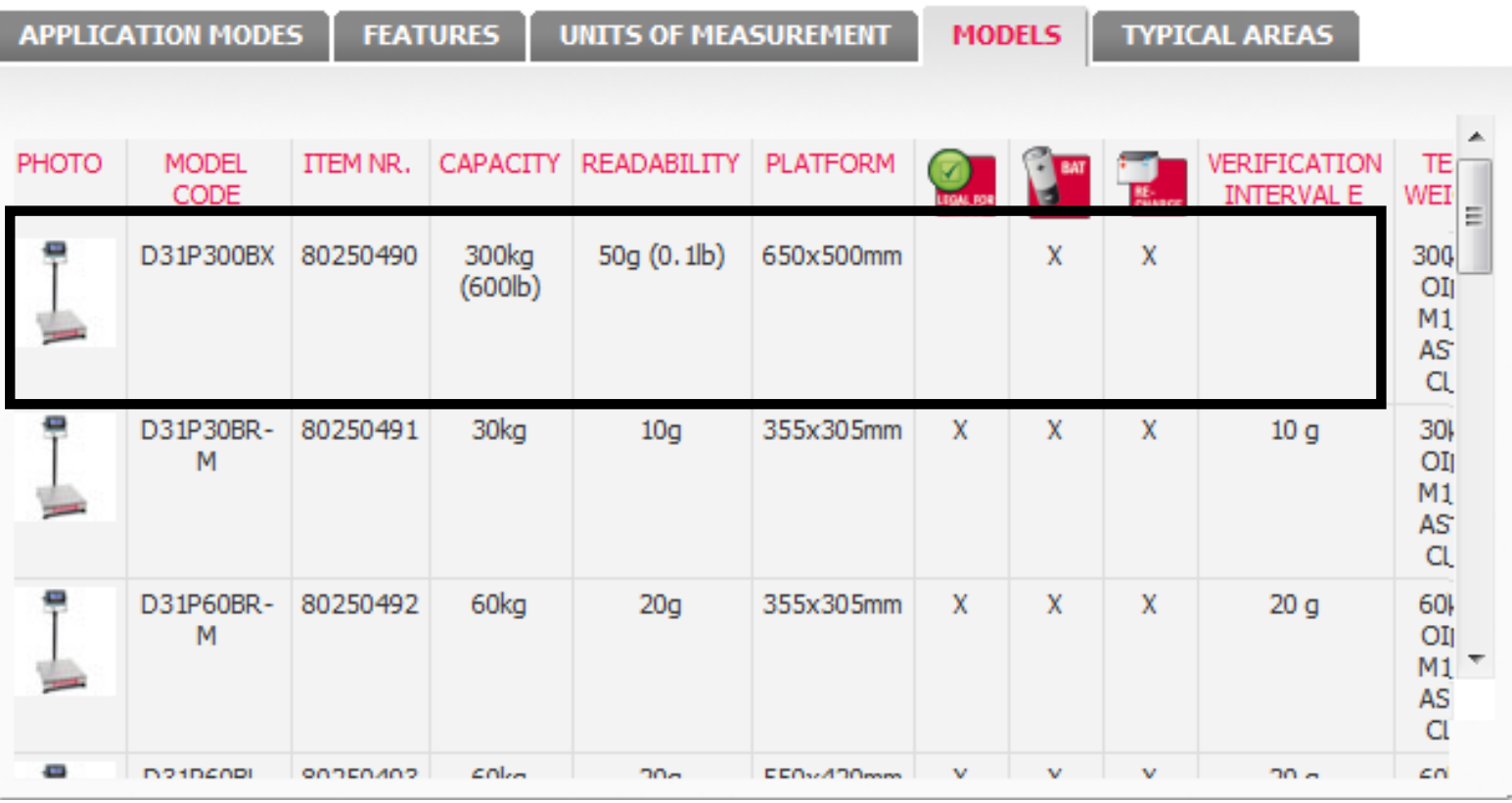




\section{Appendix-C Pump Curve Documentation}

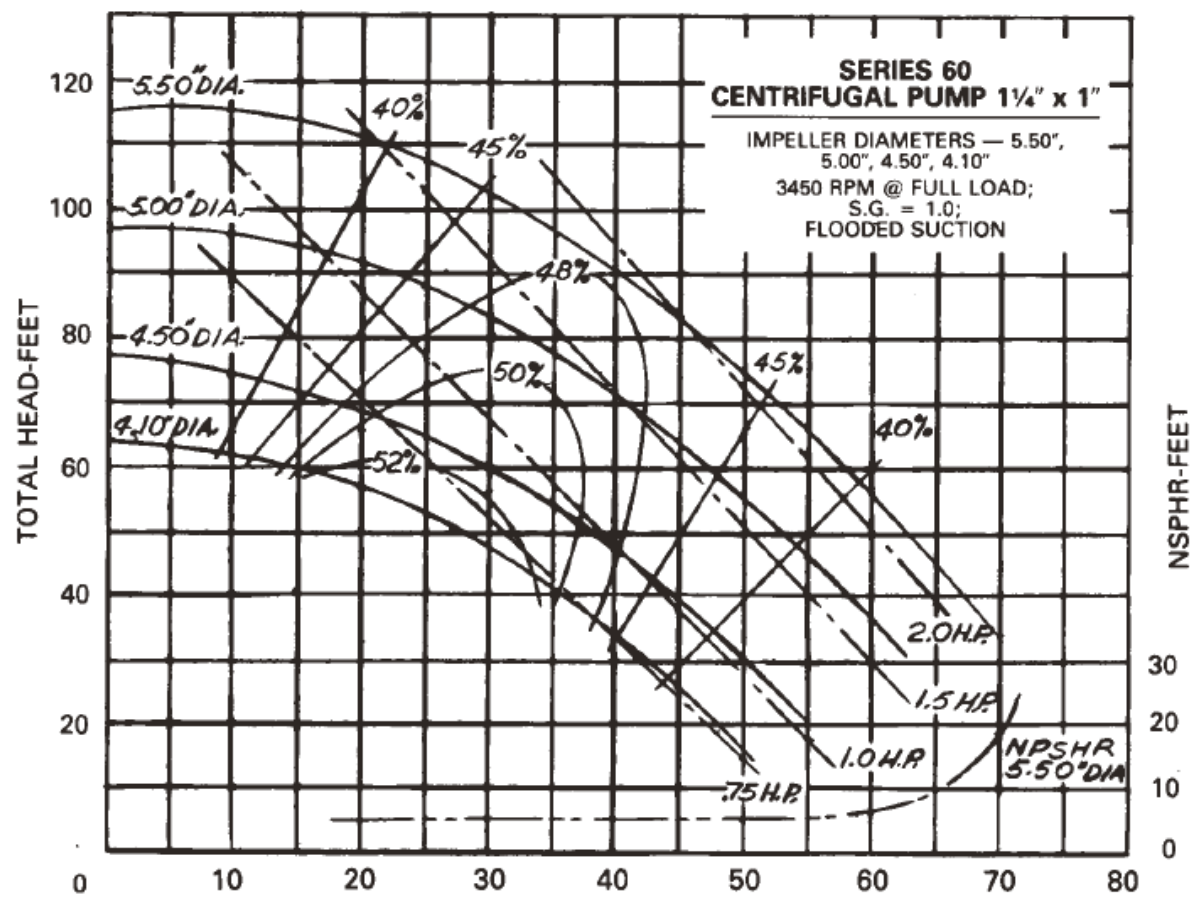

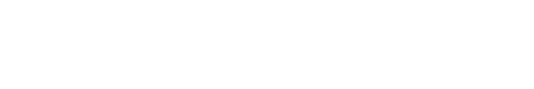

